University of San Diego

Digital USD

2016-1

\title{
Who Leads Nonprofit Organizations and What Does it Matter? A Mixed Methods Study of the Impact of Different Sector Experience on Nonprofit Leadership
}

\author{
Darrent Robert Tune \\ University of San Diego
}

Follow this and additional works at: https://digital.sandiego.edu/dissertations

Part of the Business Administration, Management, and Operations Commons

\section{Digital USD Citation}

Tune, Darrent Robert, "Who Leads Nonprofit Organizations and What Does it Matter? A Mixed Methods Study of the Impact of Different Sector Experience on Nonprofit Leadership" (2016). Dissertations. 31. https://digital.sandiego.edu/dissertations/31 
WHO LEADS NONPROFIT ORGANIZATIONS AND WHAT DOES IT MATTER? A MIXED METHODS STUDY OF THE IMPACT OF DIFFERENT SECTOR EXPERIENCE ON NONPROFIT LEADERSHIP

\author{
by
}

\author{
Darren Robert Tune \\ A dissertation submitted in partial fulfillment \\ Of the requirements for the degree of \\ Doctor of Philosophy \\ University of San Diego
}

January 2016

Dissertation Committee

Robert Donmoyer, Ph.D.

Fred J. Galloway, Ed.D.

Laura Deitrick, Ph.D. 
This page left intentionally blank. 


\begin{abstract}
The nonprofit sector serves an important economic and community-building role in California and the rest of the United States. However, the nonprofit sector may be facing a leadership deficit due to inadequate succession planning and training of future leaders. Given that nonprofit organizations are often pressured to become more business-like and that many nonprofit organizations may need to adhere to regulations imposed upon them by government funders, nonprofit organizations may be able to find qualified leaders from the for-profit and public sectors.
\end{abstract}

The purpose of this explanatory sequential mixed methods study was to build on prior research on the sector experience of nonprofit leaders and address what impact experience in each of the three primary sectors—nonprofit, for-profit, and governmental—has on one's ability to lead a nonprofit organization. More specifically, the study examined what proportion of leaders had experience in each of the three sectors, the leaders' perceptions regarding the impact that experience in each sector had upon their ability to lead nonprofit organizations, and whether the leaders' years of experience in each sector was associated with measures of the financial performance of the organizations they lead. The findings were obtained from distributing internet surveys to 188 nonprofit leaders and conducting eight follow-up interviews with respondents from the initial sample. Measures of financial performance were obtained from 990 returns obtained from public sources.

The findings supported prior studies that suggested there is substantial variation in the sector experience of nonprofit leaders. The findings also suggested that the leaders valued prior nonprofit experience as being more helpful than experience in the private and/or public sectors in developing their ability to lead nonprofit organizations. The study did not find that leaders' 
years of experience in each sector was associated with any of the variability in measures of financial performance in the organizations they lead. 


\section{DEDICATION}

I dedicate this to my wife Rita, who has encouraged and supported me throughout my dissertation and PhD program, and to Nicole, our daughter. 


\section{ACKNOWLEDGEMENTS}

Earning my doctorate has been a long and difficult process, which I could not have completed without encouragement and support. First, I would like to acknowledge my wife and daughter. Thank you, Rita, for supporting me in my decision to begin this journey and for encouraging me along the path. I could not have completed this program without your encouragement, love, and support. To Nicole, thank you for helping me to see life through the eyes of a child again. I look forward to spending more time exploring the world, real and imagined, with you now that my dissertation is complete. I would also like to thank my parents and grandparents who taught me perseverance.

Second, I would like to recognize Dr. Robert Donmoyer, my advisor and dissertation chair who has supported throughout this process, from the initial conception of the idea to completion of the dissertation. Thank you for your advice and patience through many iterations of this work and others.

I would also like to recognize my dissertation committee. Thank you Dr. Fred Galloway your assistance in formulating the ideas and methods for the quantitative phase of the dissertation and for your enthusiasm. Thank you Dr. Laura Deitrick for sharing your expertise and experience performing research on the nonprofit sector in California.

I am appreciative of the support and guidance provided me by the rest of the staff and faculty at the School of Leadership and Educational Sciences at the University of San Diego. I would also like to thank colleagues in the $\mathrm{PhD}$ program who have provided me with friendship, mentoring, and support. 


\section{TABLE OF CONTENTS}

ACKNOWLEDGEMENTS _....................................................................................... vii

TABLE OF CONTENTS ...................................................................................................... viii

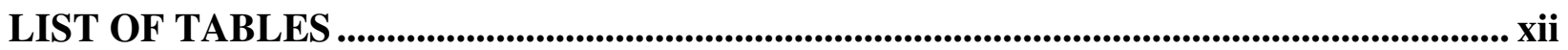

CHAPTER ONE: INTRODUCTION .....................................................................................1

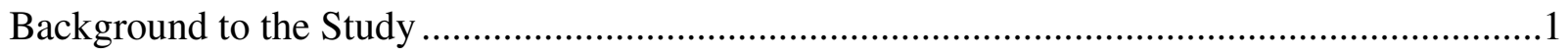

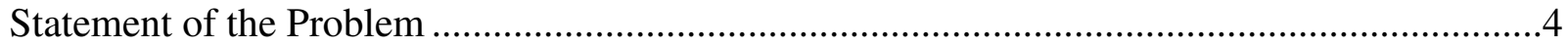

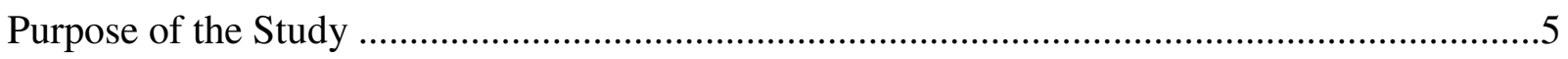

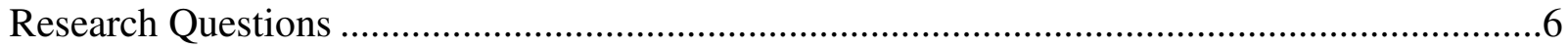

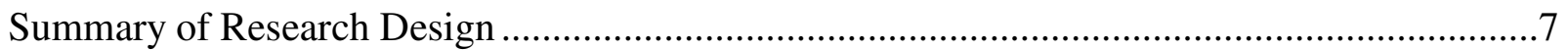

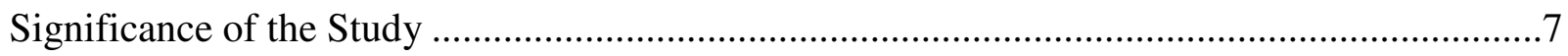

CHAPTER TWO: REVIEW OF THE LITERATURE ................................................................9

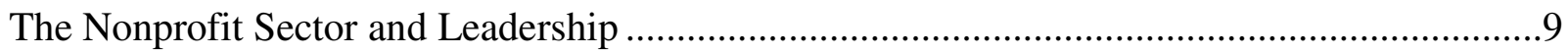

The Function of the Nonprofit Sector ......................................................................................10

Leadership and Sector Choice ………………............................................................12

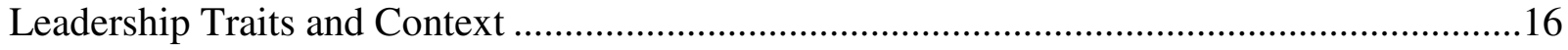

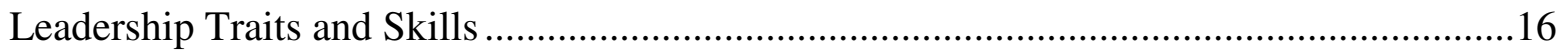

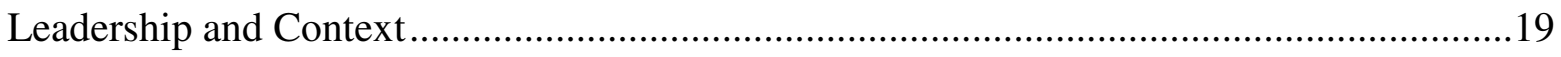

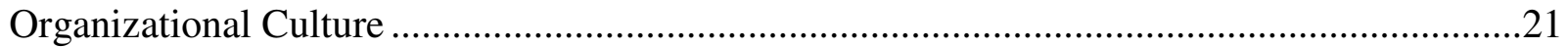

Evaluating Leadership Effectiveness in Nonprofits.............................................................24

Evaluating the Effectiveness of Nonprofit Organizations and Their Leaders........................25

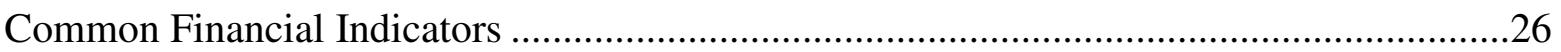

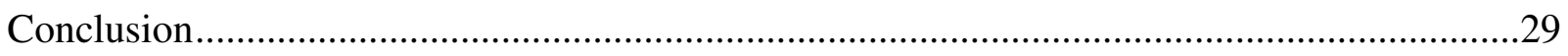


Selection of the Participants for the Quantitative Phase ........................................................31

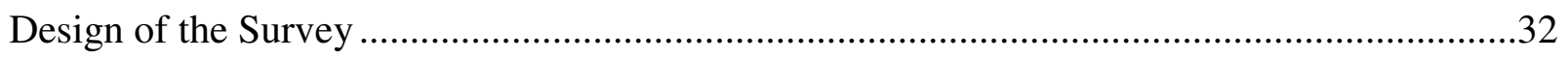

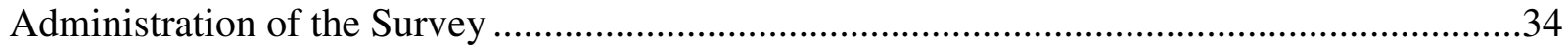

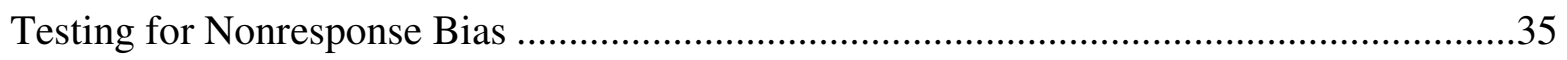

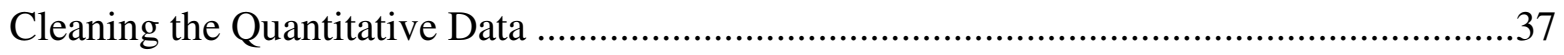

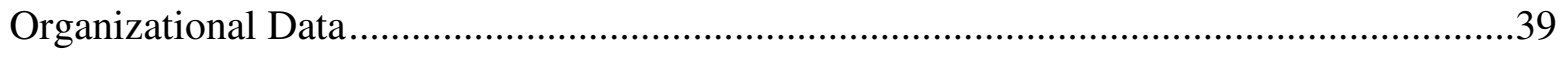

Analyzing the Quantitative Results ...............................................................................41

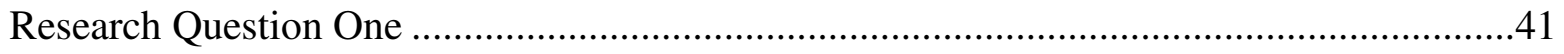

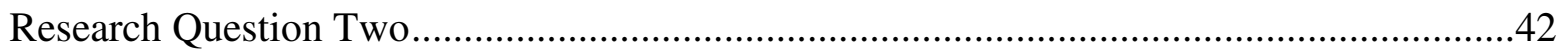

Research Question Three...........................................................................................4 42

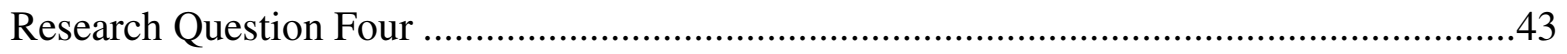

Selection of the Participants for the Qualitative Phase ...................................................47

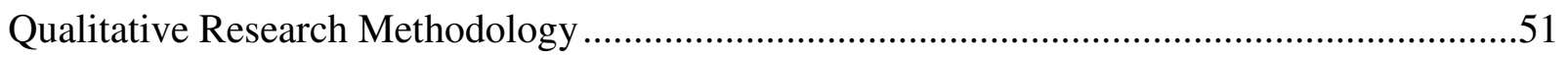

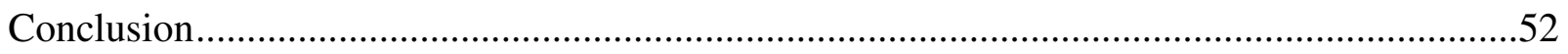

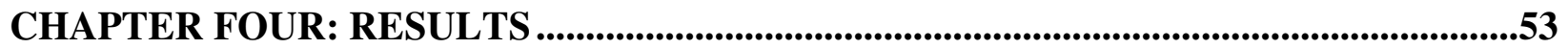

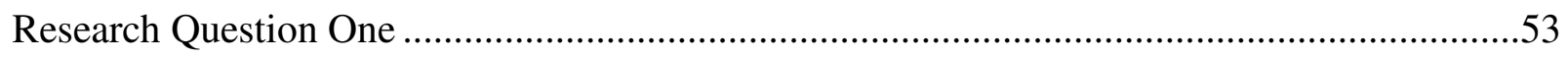

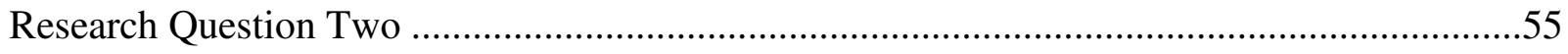

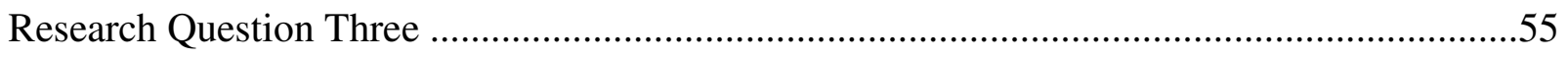

The Perceived Effect that Nonprofit Experience has Upon the Act of Leading Nonprofit

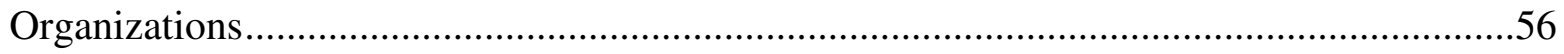

Positive Effects of Prior Nonprofit Sector Experience ................................................60

Limited Positive Effects of Prior Nonprofit Sector Experience ...................................61 
The Perceived Effect that Private Sector Experience has Upon the Act of Leading Nonprofit

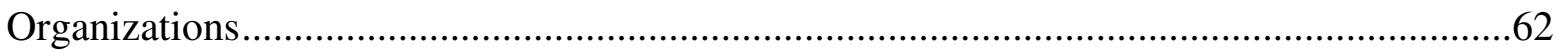

Positive Effects of Private Sector Experience ........................................................66

Limited Positive Effects of Private Sector Experience.................................................66

The Perceived Effect that Public Sector Experience has Upon the Act of Leading Nonprofit

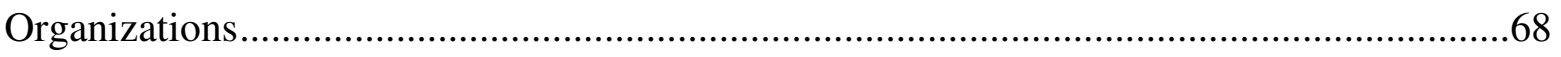

Positive Effects of Public Sector Experience............................................................ 72

Limited Positive Effects of Prior Nonprofit Sector Experience ....................................73

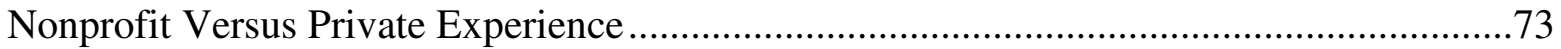

Nonprofit Versus Public Experience ................................................................... 74

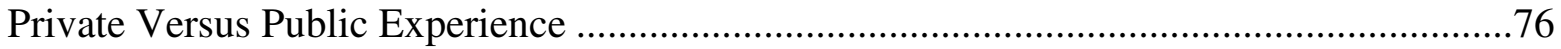

Qualitative Discussion on the Results of Different Sector Experience ..............................77

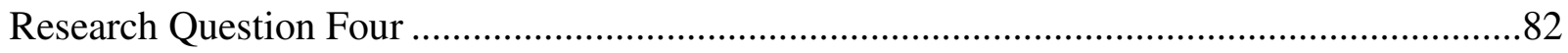

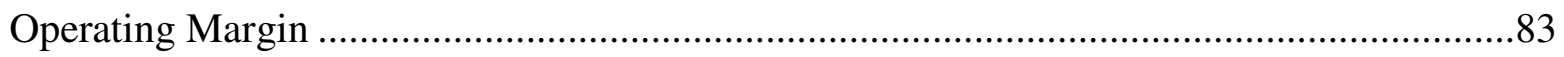

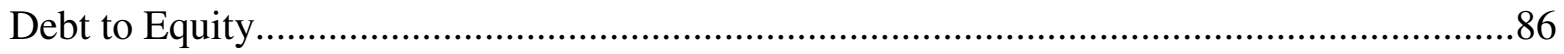

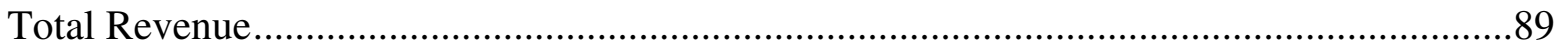

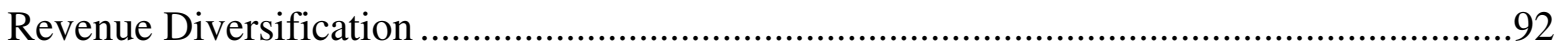

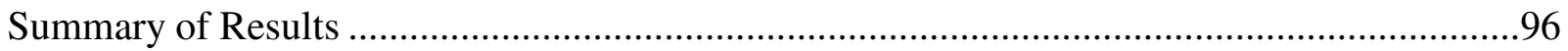

CHAPTER FIVE: DISCUSSION.............................................................................................98

Problem Statement/Purpose ............................................................................... 98

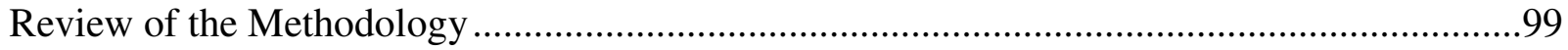

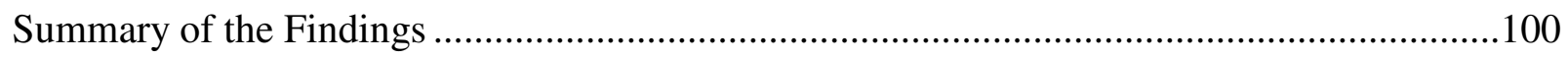

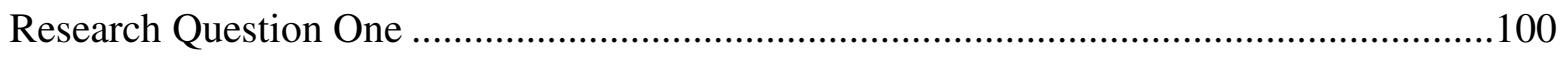

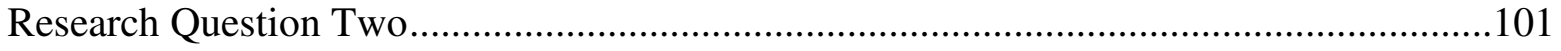




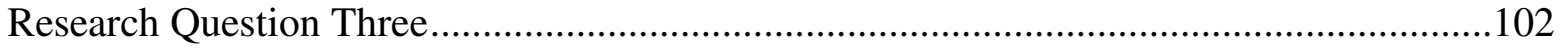

Nonprofit Versus Private Sector Experience ..............................................................103

Nonprofit Versus Public Sector Experience ........................................................... 104

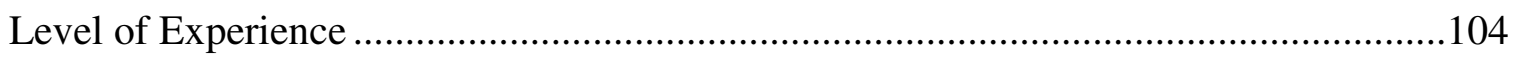

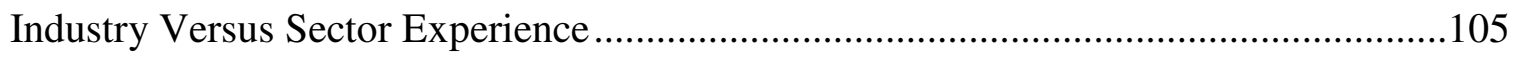

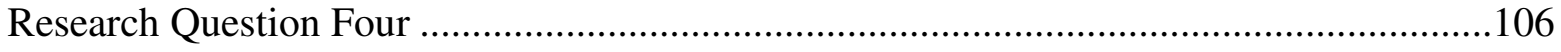

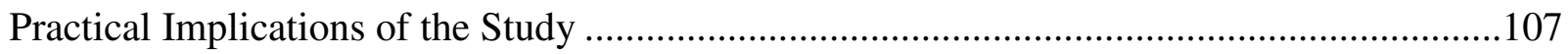

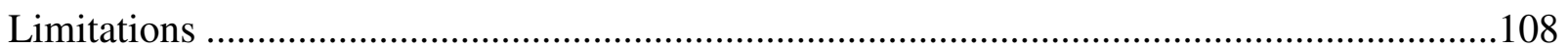

Directions for Future Research.................................................................................. 110

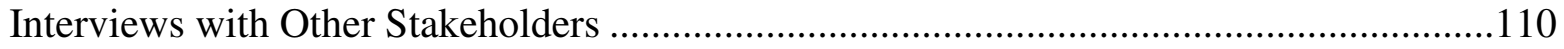

Evaluating Types of Prior Sector Experience ..............................................................111

Other Quantitative Measures of Leadership Effectiveness ..........................................112

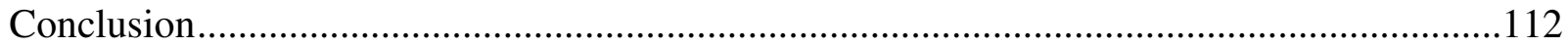

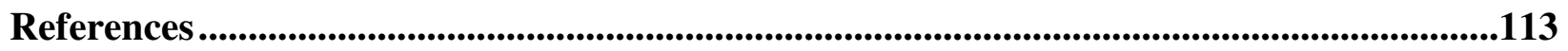

Appendix A - Recruitment Letter ....................................................................................120

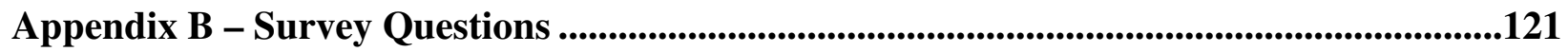

Appendix C - Research Participant Consent Form ......................................................................125

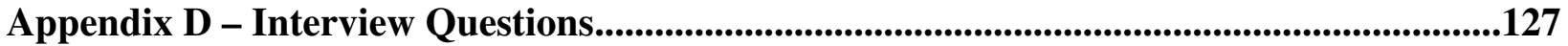




\section{LIST OF TABLES}

Table 1: Sample Demographics of Nonprofit Leaders in California Compared to a National

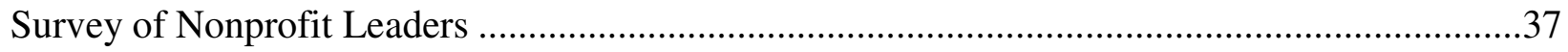

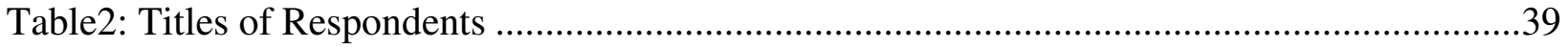

Table 3: Survey Response Rates by NTEE Subcode .............................................................40

Table 4: Comparison of Sample and Population Means and Medians Across Four Categories ...41

Table 5: Measurement of Independent Variables ...............................................................46

Table 6: Organizational Data and Personal Experience for Participants in Qualitative Phase......48

Table 7: Number and Percent of Respondents who had Experience in Each Sector Prior to

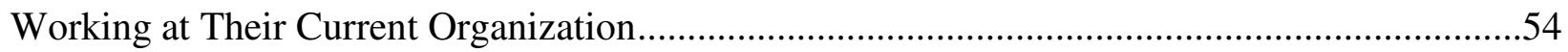

Table 8: Number of Respondents with Experience in Each Sector and the Average Number of

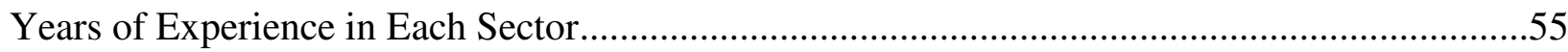

Table 9: Distribution of the Impact That Nonprofit Experience has on the Ability to Lead

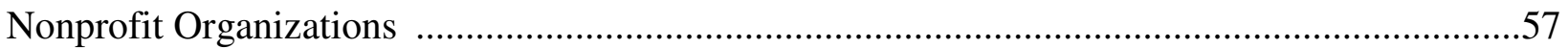

Table 10: Nonprofit Sector Experience and Responses to the Effect that Nonprofit Sector

Experience has on the Ability to Lead Nonprofit Organizations for Seven Qualitative

Respondents

Table 11: Impact that private sector experience has on the ability to lead nonprofit organizations

Table 12: Private Sector Experience and Responses to the Effect that Private Sector Experience

has on the Ability to Lead Nonprofit Organizations for Eight Qualitative Respondents

Table 13: Impact that Public Sector Experience has on the Ability to Lead Nonprofit

Organizations

Table 14: Public Sector Experience and Responses to the Effect that Public Sector Experience has on the Ability to Lead Nonprofit Organizations for Seven Qualitative Respondents 71 
Table 15: Perceived Impacts of Prior Sector Experience by Leaders who have Prior Nonprofit and Private Sector Experience

Table 16 Perceived Impacts of Prior Sector Experience by Leaders who have Nonprofit and

Public Sector Experience .75

Table 17: Perceived Impacts of Prior Sector Experience by Leaders who have Private and Public

Sector Experience .77

Table 18: The Eight Qualitative Participants' Perceptions Regarding Impact of Sector

Experience on Leading a Nonprofit Organization ..... .78

Table 19: Stepwise Multiple Regression Model for 2013 Operating Margin .84

Table 20: Stepwise Multiple Regression for Change in Operating Margin from 2011 to 2013 ....85

Table 21: Stepwise Multiple Regression Model for 2013 Debt to Equity..... .87

Table 22: Stepwise Multiple Regression for Change in Operating Margin from 2011 to 2013 ....88

Table 23: Stepwise Multiple Regression Model for 2013 Total Revenue .90

Table 24: Stepwise Multiple Regression for Change in Total Revenue from 2011 to 2013 .91

Table 25: Stepwise Multiple Regression Model for 2013 Revenue Diversification .93

Table 26: Stepwise Multiple Regression for Change in Revenue Diversification from 2011 to 2013. 


\section{Chapter One}

\section{Background to the Study}

There are approximately two million nonprofit organizations in the United States (Salamon, 2012). Public benefit nonprofits, such as universities, social service agencies, and hospitals, employed around 13.5 million people in 2007 , which represented approximately $10 \%$ of the nation's workforce. From 2001 to 2011, reported revenue for public charities grew from $\$ 876$ billion to $\$ 1.59$ trillion, twice the growth of the country's Gross Domestic Product during the same period (Pettijohn, 2013). Thus, the sector constitutes a large and growing segment of the United States economy. Demographic factors, such as an aging population and an increase in the number of people interested in volunteerism, suggest that the size of the nonprofit sector will only increase in the future.

The nonprofit sector constitutes about $15 \%$ of California's economy and, with nearly one million employees, employs about 6\% of the State's workforce (CalNonprofits, 2014). From 2008 to 2014, employment in California nonprofits increased 13\% and wages increased $22 \%$ compared to a decrease of $4 \%$ in employment and an increase of $6 \%$ in wages for other industries in California. Approximately 74\% of Californians polled believed that nonprofits play an important role in strengthening communities. Based upon the preceding data, which was compiled by CalNonprofits, the nonprofit sector plays an important economic and communitybuilding role for California.

One study predicts that nonprofit organizations will need to hire 80,000 new leaders per year by 2016 (Tierney, 2006). Even if this projection reflects some degree of exaggeration (Johnson, 2009), there is cause for concern regarding where future nonprofit leaders will come from. The sector, itself, may not be able to provide the needed number of leaders for the future, 
in part because some who currently work in the sector may not stay in the sector. For example, in a survey of identified "next generation leaders" of nonprofit organizations, the majority of respondents felt a career in the sector may not meet their financial needs (Cornelius, Corvington, \& Ruesga, 2008). Moreover, they believed management did not provide them with support to assist them in advancing in the sector, and they indicated that there were inadequate opportunities for advancement within their organizations. This sentiment is reinforced by surveys of executive directors and board members that indicated the majority of nonprofits did not have adequate succession plans in place and/or did not believe there were suitable internal candidates to replace existing leaders (Froelich, McKee, \& Rathge, 2011; Nonprofit HR Solutions, 2013).

While research suggests a leadership deficit exists within the nonprofit sector, approximately $21 \%$ of people ages 50 to 70 who were not necessarily affiliated with the sector have indicated they were very interested in accepting paid positions with organizations that serve the community (Met Life and Civic Ventures, 2005). These figures suggest that nonprofit organizations may be able to find qualified leaders outside of the sector. Furthermore, changing times may make what was once considered a liability into an asset. For example, if nonprofit organizations need to adopt characteristics of government agencies in order to comply with government contracts (Scott \& Meyer, 1991, Word \& Park, 2009) and/or follow strategies used in the private sector in order to manage economic risk (Henrikson, Smith, \& Zimmer, 2012 Hwang \& Powell, 2009, James, 2004), nonprofits may be more likely to hire leaders who have experience in the private or public sectors.

Although there may be some advantages to hiring leaders from other sectors to lead nonprofit organizations, other factors unique to the nonprofit sector may pose leadership 
challenges. For example, for the most part, mission statements of nonprofit organizations focus more on meeting the needs of people than the mission statements of for-profit organizations do (Frumkin \& Andre-Clark, 2000). Furthermore, although leaders in the private sector are ultimately evaluated by financial results, the goals for nonprofits can be vague and are heavily influenced by myriad stakeholders; consequently, the criteria to measure a leader's success are often ambiguous and certainly quite different than the measures of success used in the private sector (Weisbrod, 1998). Nanus and Dobbs, for instance, posit that a leader in a nonprofit organization is one who "marshals the people, capital, and intellectual resources of the organization to move it in the right direction" $(1999$, p. 6). On the surface, this may seem like a definition that could apply to leaders in the private sector, as well. However, running a nonprofit organization according to market-based principles may lead to lower quality services and a reduction in social capital (Dees, \& Anderson, 2004). Thus, hiring leaders from the private sector in order for a nonprofit organization to become more business-like may be a somewhat questionable practice.

To summarize, studies suggest there are not enough leaders with nonprofit experience to fulfill the nonprofit sector's leadership needs. Because nonprofit organizations are increasingly pressured to become more business-like and many nonprofits must follow regulations imposed by government entities in order to receive funding, the nonprofit sector may be able to find qualified leaders from the private and public sectors. In order to evaluate the merits of this proposition, studies are needed to address the impact that experience in different sectors has on the ability to lead nonprofit organizations. 


\section{Statement of the Problem}

As has already been noted, the nonprofit sector constitutes a large proportion of the economy in the U.S. It also plays an important part in community building (Katz \& Kahn, 1978). Thus, a lack of leaders in the sector could have negative implications for society. Nonprofit organizations may decide to hire leaders with private sector experience if they are unable to find a leader with prior sector experience and/or if they are interested in adopting business practices from the private sector. They may also be interested in hiring leaders with public sector experience in order to increase conformity with government funding requirements. However, such hiring practices may have implications for some of the roles that nonprofits fulfill in society.

Research on the impact of sector experience on those who end up leading nonprofit organizations is rather limited. Based upon the accounts of 60 leaders of voluntary organizations in England, Harrow and Mole (2005) developed three typologies of nonprofit leaders, based primarily upon sector commitment and managerial experience. The study also, however, categorized approximately $40 \%$ of respondents as "Nonaligned." These individuals represented a wide range of experience and entered the nonprofit sector primarily due to an absence of opportunity in or disillusionment with the private sector.

Based upon a survey of 200 leaders of San Francisco Bay Area nonprofit organizations, Suarez (2009) suggested that prior sector experience, paid and voluntary, does improve the marketability of candidates for executive positions. Approximately $18 \%$ of the respondents in the Suarez study were hired from outside the nonprofit sector. Bearing in mind the categories chosen by the researchers in the two studies may have been constructed differently, there does appear to be a significant difference between the studies regarding the proportion of respondents 
whose experience was shaped in other sectors. Moreover, neither of the studies presented comparative data on leadership tenure of leaders whose experience was shaped in the different sectors, which could be helpful when evaluating the efficacy of hiring leaders with experience in other sectors to lead nonprofit organizations. As a result, additional research is needed that examines prior sector experience of nonprofit executives.

There is also very little research that examines the effect of prior sector experience upon an individual's ability to lead a nonprofit organization. One study of MBA and MPA students at several universities suggested individuals with experience in the private and government sectors had lower confidence regarding their abilities to manage in the nonprofit sector than they did in their abilities to manage organizations in other sectors (Tschirhart, Reed, Freeman \& Anker, 2008). An additional study of twelve nonprofit leaders with substantial corporate experience (Silverman \& Taliento, 2006) found that crossing sectors was more difficult than the leaders expected due to differences in organizational culture, performance measurement, and revenue generation. Although the study suggested that leaders must be able and willing to adapt when crossing to the nonprofit sector, it did not examine how effectively the respondents were at leading nonprofit organizations. Therefore, additional research is needed on the sector experience of leaders of nonprofit organizations and what affect prior sector experience has upon the ability of people to lead nonprofit organizations.

\section{Purpose of the Study}

The current leadership deficit in the nonprofit sector could have negative implications upon society because of the sector's contribution to the economy and community building. Although hiring leaders with private and public sector experience may mitigate this leadership deficit, research on the sector experience of nonprofit executives and the impact of sector 
experience upon the act of nonprofit leadership is limited. The study expands on the research on sector experience of nonprofit executives and begins to address what, if any, impact sector experience of leaders has upon the ability to lead nonprofit organizations.

\section{Research Questions}

In order to expand the research on career experience of nonprofit leaders and the relative impacts of prior sector experience on nonprofit leader effectiveness, the following research questions were developed:

1. In California, what percent of chief executive officers (CEOs) and executive directors (EDs) of 501 (c)(3) public charities who filed IRS form 990 had each of the following types of experience prior to working at their current organization: only nonprofit, only government, only corporate, nonprofit and government, nonprofit and corporate, government and corporate, and experience in all three sectors?

2. How many years of experience did different types of participants have in the different sectors?

3. How do CEOs and EDs of California nonprofit organizations perceive the impact of different types of sector experience on their ability to lead nonprofit organizations? Do people who have had experience in a particular sector value experience in that sector differently than those who have never worked in that sector?

4. How much of the variation in measures of financial performance among California nonprofit organizations is associated with the prior sector experience of their CEOs and EDs? 


\section{Summary of Research Design}

In order to answer the research questions I utilized an explanatory sequential mixed methods design (Creswell \& Plano-Clark, 2011), which include both quantitative and qualitative phases. I began by conducting a survey of paid executive directors of 501(c)(3) public charities in California that submitted 990s in 2012. The surveys examined the prior sector experience of the respondents, their years of tenure, and their perceptions regarding the effects of prior sector experience upon the act of leadership within nonprofit organizations. Next, I analyzed financial outcomes of those organizations whose CEOs or EDs had been in their positions for at least four years to determine how much variation in measures of financial outcomes was associated with the prior sector experience of the leaders. Based upon the quantitative analysis generated by the first two phases of research, I interviewed eight executives to gain a deeper understanding of the interrelationship between sector experience and the ability to lead nonprofit organizations. A much more detailed discussion of these methods can be found in Chapter 3.

\section{Significance of the Study}

The study has implications for those who study the nonprofit sector and for nonprofit organizations. First, the study expands upon the relatively small amount of existing literature on the sector experience of nonprofit executives. Second, the study served as an important first step in understanding the relationship between one's prior sector experience and their ability to lead nonprofit organizations.

The results of the study suggest that experience in all three sectors-nonprofit, private,

and public — have a positive impact on one's ability to lead a nonprofit organization. However, respondents rated prior nonprofit sector experience has having a stronger positive impact than private or public sector experience upon one's ability to lead nonprofit organizations. The 
qualitative portion of the study suggested that industry-specific experience may also positively impact one's ability to lead a nonprofit organization. Although the impact that prior sector experience has on one's ability to lead may also be impacted by the amount and breadth of experience in each sector, the qualitative responses suggest that prior experience leading nonprofit organizations may provide leaders with unique sector-specific experiences they may not encounter in the private and public sectors.

Because experience in all three sectors had a positive impact upon one's ability to lead a nonprofit organization, leaders who do not have prior nonprofit experience may be able to effectively lead nonprofit organizations. However, leadership should often be exercised differently in the nonprofit sector than the other two sectors. Moreover, some of the tasks that leaders fulfill in the nonprofit sector may be different than the tasks they fulfill in the other sectors. As a result, nonprofit organizations may be able to hire leaders who have prior sector experience based upon the understanding that it may take these leaders some time to adapt their leadership style to the organization.

The most striking finding is that participants found nonprofit experience to have a stronger positive impact than experience in the private and public sectors. As I will show in the literature review, the nonprofit sector does not do a very good job at developing future leaders. Thus, nonprofit organizations and the sector in general need to improve the incentives and opportunities for emerging leaders within the sector so that the nonprofit sector itself can produce more qualified candidates for leadership positions. 


\section{Chapter Two}

\section{Review of the Literature}

The purpose of this chapter is to examine the literature on the careers of nonprofit leaders. The subtext of this review is two-fold: (a) to demonstrate that there is currently a gap in the literature when it comes to studies that examine the effectiveness of leaders who cross to the nonprofit sector and (b) to discuss a methodology for measuring at least one aspect of leadership effectiveness in the process of determining the impact—or lack of impact—of different sector experiences.

First, I will examine literature related to the nature of the nonprofit sector and its relationship to leadership. Second, I will discuss studies that analyze the effects of traits, skills and skill development, as well as context, on leadership in order to determine what the leadership literature suggests about leadership transfer, or, to be more specific, whether leadership success in one sector is likely to predict success in a different sector. Next, I will review literature on organizational culture, institutional theory, and studies of organizational values to determine if differences between the cultures of organizations in different sectors are likely to impact leaders' effectiveness. Finally, I will briefly review general literature on evaluating the effectiveness of nonprofit organizations before discussing, in considerable detail, common financial measures, which might be used to measure leader impact as part of an assessment of the impact of different types of sector experience on nonprofit leadership.

\section{The Nonprofit Sector and Leadership}

In this section I will review literature related to the nonprofit sector and leadership. First, I will discuss the function of the nonprofit sector to gain a general idea of whether or not nonprofit organizations should be led differently than for-profit and government organizations.

Next, I will review prior studies and theories that discuss differences between leaders in the three 
sectors and the sector experience of nonprofit leaders in particular. The purpose of this section is to determine what implications the relative function of the nonprofit sector may have upon the act of leadership in the sector and to review prior literature on leadership in the nonprofit sector.

\section{The Function of the Nonprofit Sector}

Nonprofit organizations are differentiated from for-profit firms in that they are excluded from distributing income to stakeholders (Hansmann, 1980); however, nonprofits may accumulate earnings as endowments, reserves, or funds to either distribute as grants to other organizations or support programs that serve the common good. Nonprofits were developed due to the failure of the private sector and government to provide an adequate supply of public goods (Weisbrod, 1975). In many instances, private firms choose not to provide goods or services to individuals who do not have the means to pay the market price; this decision illustrates a principle known as market failure. Oftentimes, the public sector will subsidize those consumables. However, government is subject to the will of the voters. As a result, goods and services which are not deemed necessary by a certain proportion of the electorate may not be supplied in a quantity sufficient enough to meet the needs of certain groups.

When stakeholders are not satisfied with the goods and services supplied by the private and public sectors, they may form a nonprofit organization or contribute to an existing nonprofit organization to provide for the services they deem necessary. Donors will not trust private firms to deliver subsidized goods for fear that the firm may not provide the contracted amount or quality of goods, a principle known as contract failure (Hansmann, 1980). Nonprofits are more trusted to dole out the goods in accordance with the agreement because they may not be enticed to distribute the revenue to owners and because key decision-makers of nonprofit organizations are believed to be less selfish than those in for-profit organizations (Steinberg, 2006). 
As noted, nonprofit organizations may engage in activities not directly related to their missions but that are designed to generate profits to support their nonprofit missions. When nonprofit organizations pursue profitable activities not related to mission and seek out new efficiencies in order to reduce reliance on external sources of funding such as donors and the government, this sort of activity may reduce nonprofit organizations' contributions to the public good (Eikenberry, 2009). Bearing in mind that for-profit organizations primary goal is often the generation of profits, rather than contribution to the public good, the relative nature of the sectors may have implications for leading nonprofit organizations.

Based upon its relative function, the building of social capital, King (2004) argues, is an important component of leading nonprofit organizations. Accordingly, Eikenberry (2009) asserts that nonprofit organizations should be governed and managed in a way that maximizes diversity and the social needs of donors in order to increase social capital. Nanus and Dobbs (1999) posit that a leader in a nonprofit organization is one who "marshals the people, capital, and intellectual resources of the organization to move it in the right direction" (p. 6).

Another important measure of nonprofit leadership is how well the leader maintains and channels managers, staff, volunteers, and other assets in order to meet the social good. A leader sets the vision but needs the support of others in order to attain it. Gathering support is accomplished by "finding the right message" that will "ignite their [i.e., stakehoders'] passion" (p. 150-151). Thus, it is likely some differences between effective leadership styles may exist between the nonprofit sector and other sectors. In the next section, I will review literature that examines potential differences between leaders in the three sectors and the sector experience of nonprofit leaders specifically. 


\section{Leadership and Sector Choice}

Young (1983) postulates that potential entrepreneurs generally fall into one of 10 entrepreneurial categories based upon their principle sources of satisfaction. Although other factors such as skills and other life experiences will have some effect upon career choice, people with different motivations will tend to sort themselves into different sectors based upon the nature of the service, the amount of institutional control of the industry, ease of entry, and the social status that comes with the industry. For instance, individuals who prefer autonomy and/or income may be likely to choose the private sector; those who are interested in pursuing a cause may be likely to choose the nonprofit sector; and those who prefer power may pursue a career in the public sector. Although this typology and its consequences were not directly tested, other studies tend to support the notion that potential leaders may select the sector they will be employed in based upon their personal values and perceptions of where they will be most effective.

Saas, Liao-Troth, and Wonder (2011), for example, examined differing motivations between leaders of for-profit and nonprofit healthcare organizations. Their findings suggested that leaders of nonprofit organizations are more likely to place an emphasis on the work they are performing rather than the amount they are paid. Moreover, individuals who lead for-profit healthcare organizations are more likely to be satisfied when they feel they are paid more than they earn, whereas those who lead nonprofit organizations are more likely to feel satisfied when they feel they are contributing more than they are earning. This study does show that, at least in one context, the motivations of leaders in the nonprofit and private sectors differ; however, it is not known whether or not the results are generalizable beyond healthcare organizations. 
Based upon the accounts of 60 leaders of voluntary organizations in England, Harrow and Mole (2005) developed a typology of three types of nonprofit leaders: Paid Philanthropists, Careerists, and Nonaligned. Paid Philanthropists were identified as altruists, for whom salary is secondary to the work itself. Careerists were those who had made a conscious decision to enter the sector. They had developed their skill primarily within the nonprofit sector. Lastly, the Nonaligned, who made up two-fifths of the 60 respondents in the England, et al. study, had a wide range of managerial experience. Although the latter respondents were presently committed to their positions, they had sometimes arrived at nonprofit organizations due to an absence of current opportunities in or disillusionment with the private sector. These categories support the belief that leaders in different sectors may have different values. It is also lends support to the notion that leaders who cross to the nonprofit sector have different motivations than those who have spent the majority of their careers in the sector.

A study of 200 San Francisco Bay Area nonprofits developed an additional typology of nonprofit leaders based upon career progression (Suarez, 2009). Nonprofit Lifers became involved in the sector early on, often in order to address a particular social problem, and gained management experience throughout their careers. Substantive Experts had experience and training in a particular profession that fits the nonprofit sector; however, they are not particularly tied to the nonprofit sector and may have gained management experience in the private or public sectors. Social Entrepreneurs are dedicated to the nonprofit sector but have experience and training in management, which may result in a greater focus upon finances. The Professional Administrator also has education and experience in management but does not feel tied to a particular sector. These individuals generally gained nonprofit experience from serving on the 
Board of Directors or as a volunteer in nonprofit organizations, which suggests that experience in the sector may improve the marketability of candidates for executive positions.

Approximately $18 \%$ of the respondents in the Suarez study were hired from outside the nonprofit sector. Interestingly, in that study, those leaders who crossed sectors had substantial exposure to the nonprofit sector as members of boards of directors and volunteers prior to assuming their leadership roles in nonprofit organizations. This notion seems to contradict, at least to some extent, the notion presented by England, et al. that leaders who cross sectors may not be as committed to the sector as "Nonprofit Lifers."

A study involving MBA and MPA students at different universities found that graduates who had previous nonprofit experience were more likely to choose nonprofit employment after graduation while previous public or private employment had no bearing upon future employment (Tschirhart, Reed, Freeman \& Anker, 2008). In addition, the study found that individuals with nonprofit experience had lower confidence in their ability to work in the business sector and that people with experience in the business sector also had lower confidence regarding their abilities in nonprofit management. Although the study suggests that students had more confidence in their abilities to work in the sector they had experience in, it does not provide direct evidence regarding what the implications of the study's results may be for leaders who do choose to cross sectors.

A survey of 12 nonprofit leaders with substantial corporate experience conducted by McKenzie and Company suggested that crossing sectors was more difficult than the leaders thought for several reasons (Silverman \& Taliento, 2006). First, in nonprofit organizations, people often do not defer to the leader's decisions, unless the leader has earned people's respect. Second, nonprofit leaders need to do more consensus building than in the business world 
oriented toward maximizing profits because of the different goals that stakeholders have. Third, it is more difficult to measure performance in the nonprofit sector than in the private sector. Fourth, environmental outreach is done differently in order to convince outsiders to contribute to the organizations. Lastly, resources are more constrained in nonprofit than for-profit organizations because increased demand does not result in more revenue, but more of a need for additional revenue. In short, the study indicates it is likely that leaders from the private sector do need to adapt when leading nonprofit organizations.

The studies reviewed in this section suggest that the majority of leaders of nonprofit organizations have substantial nonprofit experience and that leaders with substantial experience in other sectors constitute a minority of the leaders of nonprofits. Research also suggests that leaders in the different sectors may have different motivations, although the results of research are mixed on whether or not the motivations of leaders who cross from the private and public sector to the nonprofit sector are different than the motivations of those who have been in the sector the majority of their career. Moreover, graduate students surveyed in a study indicated they had more confidence to lead in the sectors they were employed in prior to entering graduate school than in other sectors. This finding may have merit because, based upon interviews with twelve executives who crossed from the private to nonprofit sectors, the challenges of leading nonprofit organizations are, in fact, different than the challenges associated with leading forprofit organizations.

While these studies are promising, there is little evidence to suggest whether or not leaders whose primary experience was shaped in the private and public sectors may be more or less effective at leading nonprofit organizations than those whose primary experience was in the 
nonprofit sector. Here, as in other areas of nonprofit leadership, there has been little focus on organizational outcomes and leader effectiveness.

In subsequent sections, I will examine studies and theories about leadership and organizational culture to see if existing literature in these areas provides insight about the likely transferability of leadership skills from one sector to another. The focus, here, of course, is transfer from the private and public sectors to the nonprofit sector.

\section{Leadership Traits and Context}

If leadership is transferable and not extensively moderated by context, proven leaders from all sectors will generally be successful in the nonprofit sector. In this section, I will review different leadership theories in order to examine what the leadership literature suggests about whether or not leadership skills are transferable. The focus, in short, is on how much context is likely to matter when leaders travel from one sector to another.

First, I will review theories related to leadership traits. Second, I will review research that examines the importance of context upon leadership. Lastly, I will discuss research on institutional theory and organizational culture to see whether or not this particular body of literature suggests that leadership skills can be easily transferred from one context to another.

\section{Leadership Traits and Skills}

According to Zaccaro, Kemp, and Bader (2004), leader traits can be defined as "relatively stable and coherent integrations of personal characteristics that foster a consistent pattern of leadership performance across a variety of group and organizational situations" (p. 104). If such patterns exist, it is likely that an effective leader from the private or public sector would be an effective leader in the nonprofit sector. 
There are many promising studies on the impact of leader traits such as personality, motivation, dominance, intelligence, and technical expertise (Mumford, Zaccaro, Harding, Jacobs, \& Fleishman, 2000; Zaccaro, Kemp, \& Bader, 2004). However, univariate research on trait theories has produced inconsistent results across studies (Stogdill, 1974; Zaccoro, et al., 2004). Findings, in fact, often suggested that individuals who exercised effective leadership in one group were not necessarily able to provide effective leadership in other groups (Stogdill, 1974). Moreover, many of the studies focused more on leadership emergence than leadership effectiveness.

Unfortunately research on models which examine the effects of multiple traits is limited (Iddekinge, Ferris, \& Heffner, 2009). The bottom line, consequently, is this: research on leader traits does not provide compelling evidence to suggest that effective leaders from the private and public sectors will be effective leaders in the nonprofit sector. Additional research suggests leadership skills acquired over the course of one's career may be transferable, although transferability may be moderated by other factors. Mumford, et al. (2000), for example, propose that leadership is indirectly influenced by traits but directly influenced by skills and environmental factors. The authors posit effective organizational leadership may be the result of three primary skills:

Complex creative problems-solving skills associated with identifying problems, understanding the problem, and generating potential solutions; social judgment skills associated with the refinement of potential solutions and the creation of implementation frameworks within a complex organizational setting; and social skills associated with motivating and directing others during solution implementation. (p. 26) 
The skills necessary to solve the problems leaders face are acquired based upon relevant, well-timed experiences throughout the leader's career (Mumford, Marks, Connelly, Zaccaro, \& Reiter-Palmon, 2000). In their study, Mumford, et al. categorized Army officers into groups of junior officers, mid-level officers, and senior officers. Responses were based on constructed response measures, which were rated by subject experts. The study found that scores on the leader achievement measure and unstructured military problems differed significantly among the groups, with senior officers outperforming mid-level officers and mid-level officers outperforming junior officers. Senior officers significantly outperformed other officers on critical incident scores; however, there was not a significant difference between the scores of junior and mid-level officers. Although the study does suggest that leadership skills are developed over the course of one's career, it is important to note this particular study is limited to one particular context, the US Army.

Lord and Hall (2005) argue that leaders progress through stages: novice, intermediate, and expert. Novice leaders tend to focus on the development of leadership skills. As such, they may observe successful leaders and mimic their behaviors in order to be accepted as a leader. However, novices may be inadequately prepared to respond to negative social cues and adapt their behavior accordingly. Through past leadership successes and failures, intermediate level leaders begin to adapt their behavior to different situations. However, their skills may be framed by a particular context to include a particular culture and specialized skills. As they become experts, leaders develop an understanding of the principles that underlie particular situations. Thus, novice and intermediate leaders from the private sector may have difficulty in the nonprofit sector if the leadership situations are dissimilar. Expert leaders may also encounter 
some difficultly, although they may be able to adapt if the principles that underlie the situations are similar.

As I noted in a previous section, it is likely that leadership may be done differently in the nonprofit sector than in other sectors as the result of the sector's unique function. Moreover, leaders from the private sector surveyed in one study indicated they did have to adapt in order to lead nonprofit organizations (Silverman \& Taliento, 2006). Although research on leadership traits does not provide sufficient evidence that leadership traits or even skills are transferable across sectors, other theories suggest that, with sufficient experience, leaders may be able to gain leadership skills that are at least somewhat applicable to different situations. Because the different sectors may present different contexts, I will now discuss studies that examine the moderating effect that context plays in the exercise of leadership.

\section{Leadership and Context}

Podsakoff, MacKenzie, \& Bommer (1996) suggest that "leaders need to have a better understanding of those contextual variables that influence subordinate attitudes, role perceptions, and performance, and how to influence these contextual variables" (p. 295). In that case, if leadership contexts within each of the three sectors are different, than some difficulties may arise when leaders cross sectors. In this section, I will discuss several of the primary theories related to contextual influences on leadership.

House and Mitchell's (1974) Path-Goal theory of leadership contrasted situations in which directive leadership versus supportive leadership are warranted. House and Mitchell found that directive leadership is seen as a hindrance when tasks are clear and is preferred when tasks are not clear. Supportive leadership that engages followers as active participants tends to be helpful when tasks are dissatisfying, frustrating, or stressful. In short, the effectiveness of 
participative leadership was moderated by the task at hand. To the extent that tasks in sectors differ, Path-Goal theory would seem to suggest that transferring experience from one sector to another may be difficult.

Burns (1976) and Bass (1985) determined that leadership behaviors can either be classified as transactional or transformational. Transactional leadership focuses largely upon the self-interest of followers and emphasizes providing rewards and sanctions to promote the behaviors desired among subordinates. By contrast, transformational leadership focuses on encouraging followers to look beyond their own self-interest to the interests of the group and a shared purpose. If, as studies I will discuss in the next section suggest, employees of nonprofit organizations are more likely to be intrinsically motivated than employees in other sectors, transformational leadership may be more effective than transactional leadership in nonprofit organizations.

Contingency theory proposes that group performance can be affected by the interaction of a leader's characteristics and the situation (Fiedler, 1967). According to the model, leaders who are relationship-oriented perform better in situations of moderate control whereas leaders who are more task-oriented perform better in situations of low and high control. Situational control is ranked based upon the dichotomized effects of group atmosphere, task structure, and leader position into eight octants. Meta-analytic studies have found strong support for several tenets of the contingency theory of leadership (Strube \& Garcia, 1981, Peters, Hartke, \& Pohlmann, 1995); however, further research is merited in order to refine the model and its practical implications (Schriesheim, Tepper, \& Tetrault, 1994). According to a study conducted by Chemers, Hayes, Rhodewalt, and Wysocki (1985), for instance, incongruity between a leader's relational orientation and level of situational control could result in exhibited symptoms of stress. Thus, if 
levels of situational control differ between sectors, leaders whose relationship orientation is effective in the private and public sector may be more or less effective in the nonprofit sector.

According to the before-mentioned theories and studies of leadership, leadership effectiveness may be impacted by contextual and situational factors. One of the most important contexts related to leadership effectiveness may be organizational culture. As I will discuss in the next section, differences in organizational culture between organizations in the three sectors may have a significant impact upon the effectiveness of leaders who cross from the private or public sectors to the nonprofit sector.

\section{Organizational Culture}

As previously mentioned, context may impact leader effectiveness. One important context may be the culture of an organization. According to Schein (2004), organizational culture is:

a pattern of shared basic assumptions that was learned by a group as it solved its problems of external adaptation and internal integration, that has worked well enough to be considered valid and, therefore, to be taught to new members as the correct way to perceive, think, and feel in relation to those problems. (p. 17)

There are three levels of culture (Schein, 2004). On the surface are artifacts, which are ambiguous and can easily be misunderstood if one is not familiar with the other levels of culture. Next are the espoused beliefs and values that a group claims to hold. The espoused beliefs help to predict what members of the group will say about a particular situation. Some parts of culture are unique to the individual and some are unique to the group (Jaskyte \& Dressler, 2004).

Navigating an organization's culture may be difficult because of discrepancies between "theories of action" and "theories-in-use" (Argyris \& Schon, 1974). A theory of action is how 
people say they will behave in a particular situation. A theory-in-use, which is the deepest level of an organization's culture, is the means by which an individual or group of individuals actually behave in a situation. A group's theory of action may differ from its actual theory-in-use, which could make it difficult for an outsider to understand an organization's culture. However, if the culture of nonprofit organizations are more similar to other nonprofit organizations than they are to the culture of organizations in other sectors, then leaders with experience in the nonprofit sector may have a better understanding of the cultures of other nonprofit organizations than leaders who do not have nonprofit eperience. Thus, it is important to discuss what theory and research suggest about the differences in cultures between organizations from different sectors. According to institutional theory, organizations with similar functions may share some aspects of culture and organizational structure (Dimagio \& Powell, 1991). For the most part, mission statements of nonprofit organizations focus more on meeting the needs of people than those of for-profit organizations (Frumkin \& Andre-Clark, 2000). As a result, the function of nonprofit organizations are more likely to resemble other nonprofit organizations than organizations in other sectors, it is likely their cultures and structures will also be more similar to each other than private and public organizations. Factors specific to an industry are also said to "channel the experiences of those working in an industry in certain directions and not others" (Trice \& Beyer, 1993, p. 58). As a professional field develops, existing organizations in and new entrants to the industry are subject to isomorphism, which leads organizations to resemble each other in some ways. Thus, organizations in the same field are also likely to share aspects of organizational culture.

Jeavons (2005) argued that, based upon the notion of trust explicit in contract and market failure, the culture of nonprofits should follow an ethical framework based upon integrity, 
openness, accountability, service, and charity. According to Teegarden, Hinden, and Sturm (2011), the organizational culture of most nonprofits is influenced by some of the following values: fairness in interpersonal relations; a shared understanding regarding provision of services; trust; diversity and tolerance; innovativeness, which may create tension with the need for uniformity; broad participation; volunteerism; focus on client success; and altruism. Additionally, many community-based nonprofits may value a "hero mentality" where individuals are expected to work long hours for low pay in order to provide maximum impact to clients, complex relationships with government funders due to the need of funding contrasted with the need for flexibility, community participation, and "a focus on racial justice (p. 25)." Although the studies did not directly address differences in cultures between nonprofit organizations and other organizations, other studies have found differences in values among employees of the different sectors, which could impact organizational culture.

According to De Cooman, De Gieter, Pepermans, \& Jegers (2009), nonprofit employees show a greater tendency toward altruism, value career advancement less, and exhibit higher integrated and identified regulation and lower external regulation than employees in the private sector. These findings are supported by surveys showing that nonprofit and public employees have a greater desire to help others than employees in the private sector (Tschirhart, et al., 2008). Nonprofit employees also had less of a desire for high pay than employees in the public sector, whose employees also had less desire for high pay than those in the private sector. Several studies have also shown that nonprofit employees were more likely to volunteer than public employees, who were more likely to volunteer than for-profit employees (Houston, 2006, Lee, 2012, \& Piatek, 2014). Among 1,220 nonprofit and public employees surveyed, Lee and Wilkins (2011) found that nonprofit employees were more likely to value increased 
responsibility, family-friendly policies, and volunteerism, whereas public employees were more likely to seek advancement, retirement plans, and the ability to serve the public interest. Thus, it is probable that a significant difference in values exists between members of the nonprofit and private sectors.

Research suggests that leadership skills acquired throughout one's career may be moderated by contextual factors such as the culture of an organization. Research and theory suggest that due to the function and mission statements of nonprofit organizations, the culture of nonprofit organizations will differ from those of private and public organizations. Additional research asserts that employees in the nonprofit sector have different values than those in the private and public sectors, which could impact the an organization's theories-in-use, the deepest level of organizational culture. Although research suggests that nonprofit organizations may share many similar aspects of culture, no studies have been conducted to date that examine the impact that sector experience has upon the ability to lead nonprofit organizations. Because there are not previous studies to build from, I will examine the literature on different methods to evaluate organizational effectiveness of nonprofit organizations in order to determine how I will compare leadership effectiveness of leaders whose experience was in the three different sectors.

\section{Evaluating Leadership Effectiveness in Nonprofits}

Although studies suggest that the majority of leaders of nonprofit organizations have considerable nonprofit sector experience and that leadership in nonprofit organizations may be exercised differently than in other sectors, research has not yet been conducted that evaluated the relative effectiveness of leaders who cross from the private and public sectors. In order to conduct such a study, some method must be established in order to evaluate leadership effectiveness. In this section, I will discuss some methods of evaluating nonprofits in order to 
show that financial measures are one method recommended by researchers to evaluate the effectiveness and sustainability of nonprofit organizations. Next, I will discuss several common financial measures used to evaluate organizational effectiveness in order to justify their use in my study.

\section{Evaluating the Effectiveness of Nonprofit Organizations and Their Leaders}

Sowa, Selden, and Sandfort (2004) propose that the effectiveness of nonprofit organizations can be judged predominantly at the management and program levels. Management effectiveness is primarily judged based upon capacity and outcomes. Capacity can be measured by surveying management and other insiders regarding the existence of and use of certain practices such as strategic planning, information technology, and audits. Management outcomes can be measured based upon financial results and employee satisfaction. Programs can be evaluated based upon the specific services provided and the outcomes of the services.

There are at least two reasons why using financial indicators are appropriate for assessing organizational effectiveness. First, financial data are readily available. Because all nonprofit organizations with revenue over $\$ 1$ million or assets over $\$ 2.5$ million are required to file the full 990 form with the IRS, an outsider can evaluate the financial status of an organization from publicly available resources. Second, according to Tuckman and Chang (1992), strong financial results are positively associated with an organization's sustainability. Other studies show that many nonprofit organizations may not hold enough reserves to withstand a significant economic shock (Blackwood and Pollak, 2009, Nonprofit Finance Fund, 2013). In addition, Herman and Renz (1997) found that paid staff members, board members, and funders of 64 charities surveyed all agreed that revenue is a valid measure for evaluating organizational effectiveness. In the 
following section, I will discuss several of the popular methods used to evaluate financial performance, in order to justify their use in my study.

\section{Common Financial Indicators}

Financial ratios, which examine the relationships of different financial data in a manner that controls for differences in size and time, are another common method for comparing the financial condition of an organization to the financial condition of other similar organizations because they can control for differences in size of the organization (Chabotar, 1989). The meaningfulness of ratios is increased if they are analyzed over a period of time in order to control for yearly fluctuations. There are several financial ratios recommended by researchers to assess the financial sustainability of nonprofit organizations. The most common methods include revenue diversity, liquidity ratios such as the current ratio, total assets versus total liabilities, operating margin, and administrative cost ratios.

Revenue diversity is an important financial measure because it provides an indication of the ongoing resources available to pay for the nonprofit to fulfill its mission (Chabotar, 1989). Multiple types of revenue are seen as desirable because the charity may utilize additional sources of funding if one source of revenue declines significantly (Tuckman \& Chang, 1991, Trussel, Greenlee, and Brady, 2002). Thus, it is preferable that an organization receives its revenue from a diverse set of funding sources, so one indicator of an organization's fiscal health is the diversity of the revenue sources it relies upon.

Liquidity ratios, which compare assets that can be turned into cash to debts that are due in the near future, are important for nonprofit organizations because they provide a measure of the organization's ability to pay for its expenses. The current ratio, current assets divided by current liabilities, is one common measure of liquidity although there are more conservative measures 
such as the quick ratio and the available funds ratio, both of which subtract less liquid assets such as inventory and long-term investments from assets (Chabotar, 1989). Total debt divided by total equity is another method for evaluating financial condition, in part because a stronger ratio makes it easier to obtain financing (Tuckman \& Chang, 1991, Trussel, Greenlee, and Brady, 2002).

An organization's operating margin, which is calculated by subtracting expenses from revenue and dividing the number by revenues is another effective financial measure (Tuckman \& Chang, 1991). For example, if an organization has revenue of $\$ 100$ and expenses of $\$ 50$, the ratio would be calculated as follows: $(\$ 100-\$ 50) / \$ 100=0.5$. A nonprofit organization with a higher operating margin may be less vulnerable because it has more of an ability to withstand a decrease in revenue without reducing expenses. On the contrary, on organization with a negative operating margin will have to fund some of its operations from existing equity, which is not sustainable long term because the organization will eventually run out of resources to draw on.

In an analysis of 990's for all organizations who filed 990's from 1991 to 2003 —a total of 2,075,294 observations-Carroll and Stater (2008) analyzed the degree that revenue diversification, financial flexibility, organizational efficiency, growth potential, and amount of donated revenue affected revenue volatility. Revenue diversification was analyzed by measuring the portion of an agency's revenue was derived from each of three sources-donative income, earned income, and investment income. The Hirschman-Herfindahl Index was used, which determines the amount to which revenue is balanced among the three categories. According to the study, organizations with greater revenue diversity did have less revenue volatility, which means their revenue streams are more stable over time. The study also found that organizational size as measured by total expenses, retained earnings, and the organization's fund balance were 
also negatively correlated with revenue volatility. The percent of revenue derived from donations was positively associated with revenue volatility. The industry the nonprofit operates in and whether the organization was located in an urban area also affected revenue volatility. Some scholars believe that organizations with a higher proportion of administrative costs are less vulnerable because they can reduce these costs if they encounter financial distress (Tuckman \& Chang, 1991, Trussel, Greenlee, and Brady, 2002). On the contrary, Bowman (2006) suggests that higher overhead may decrease giving because fewer donated donors reach their intended purpose. However, Carroll and Stater (2008), in a more robust study, did not find that administrative efficiency had any affect upon revenue stability. Conversely, interviews of leaders from 152 international nonprofit organizations, whose combined revenues totaled about $\$ 20$ billion, suggested that executives believe that lower overhead is an important indication of success (Mitchell, 2013). Although many stakeholders may prefer lower overhead, other studies suggest lower overhead reduces an organization's ability to withstand an economic shock, while other research posits overhead ratios have little effect upon revenue stability. Due to the controversy in the literature regarding administrative efficiency, I will not analyze this ratio in my study.

According to the literature, some of the most common and valid financial measures, which have been adopted from traditional financial analysis, include total revenue, revenue diversification, current ratios, debt to equity, and operating margin. For this study, I will examine all of the preceding measures with the exception of the current ratio, which I will not be able to examine because the IRS form 990 does not show current assets. A more detailed discussion of how I will utilize the ratios can be found in the methodology section. 


\section{Conclusion}

More nonprofit organizations may hire leaders who do not have previous experience in the sector. This may be helpful for nonprofit organizations who seek to adopt business models in order to satisfy the expectations of funders and increase their competitiveness or gain more access to public resources. However, others caution these models may lead nonprofit organizations away from the purposes for which they exist.

It is probable that some personal traits and skills are positively related to effective leadership; however, leaders who are effective in one situation may not be effective in another. Organizational culture may be one factor that influences effective leadership. Research shows that mission statements of organizations in the nonprofit sector differ significantly from those of organizations in the private and public sectors and members of the nonprofit sector have different values than those in the private and public sectors. Thus, it is likely that organizational cultures of nonprofit organizations are different than those of private and public organizations, which could impact the effectiveness of leaders who cross from the private or public sectors to the nonprofit sectors.

Although the research may indirectly suggest that differences among the sectors may impact the effectiveness of leaders who cross from the private or public to the nonprofit sector, no studies have yet been conducted that examine this phenomena. In order to evaluate the effectiveness of leaders who cross sectors, some objective criteria should be evaluated. One way to measure organizational effectiveness is through financial results because financial resources enable the organization to fulfill and/or expand its mission. Because leaders of nonprofit organizations spend a substantial amount of their time obtaining funding and managing 
organizational resources (Gronbjerg, 1993), financial results of organizations may serve as a measure to evaluate the effectiveness of nonprofit leaders. 


\section{Chapter Three}

\section{Methodology}

The purpose of this explanatory sequential mixed-methods study was to expand the research on sector experience of nonprofit executives and begin to address the question of what, if any, impact sector experience of leaders has upon the ability to lead nonprofit organizations. The following questions guided the study: (1) In California, what percent of chief executive officers (CEOs) and executive directors (EDs) of 501 (c)(3) public charities who filed IRS form 990s had each of the following types of experience prior to working at their current organization: only nonprofit, only government, only corporate, nonprofit and government, nonprofit and corporate, government and corporate, or experience in all three sectors? (2) For those leaders of California nonprofit organizations who did have experience in each sector, what was the average number of years that leaders had worked in each sector? (3) What impact do leaders of California nonprofit organizations perceive their experience in each of the three sectors had on their ability to lead nonprofit organizations; do those people who had experience in a particular sector value experience in that sector differently than those who had not had experience in that particular sector? (4) How much of the variation in measures of financial performance among California nonprofit organizations is associated with the prior sector experience of their leaders?

\section{Selection of the Participants for the Quantitative Phase}

In order to investigate the topic of sector experience of nonprofit executives in California, I distributed a survey to a random sample of CEO's and ED's of California nonprofit organizations who filed circa 2012 IRS form 990s. In order to increase the likelihood that the sample was representative of all types of nonprofit organizations, I used a stratified sampling 
technique (Fowler, 2014). Between September 2013 and March 2014 the Caster Center at the University of San Diego compiled a list of all 23,200 IRS form 990s for California public charities available in December, 2013, and, then, Center personnel hand-keyed additional data that were not provided by the IRS. I utilized the before-mentioned database to compile my sample. First, I sorted nonprofit organizations listed in the database into groupings according to the NTEE subcodes and then I sorted the 990s in each group by total assets. In order to build a sample of $10 \%$ of charities who filed 990s, I selected every 10th nonprofit from the sequential list for inclusion in the study.

I have chosen executives of nonprofit organizations in California for several reasons. First, there were approximately 123,000 registered public charities in California in 2012, the most recent year for which 990 data were available for researchers to analyze; this number represented nearly $13 \%$ of the public charities in the United States (CalNonprofits, 2014, Urban Institute, 2014). I also chose participants in California for convenience. The Caster Center at the University of San Diego agreed to provide me 990 financial data for all nonprofit organizations that filed 990s in 2012; I used these data to draw my sample. The data also included the financial information I had planned to use to answer research question number four. Geographic proximity also allowed me greater access to nonprofit executives for the qualitative interviews I conducted in phase two of the research design.

\section{Design of the Survey}

Due to the lack of prior research on sector experience of nonprofit leaders and the absence of an existing instrument, I designed a survey that sought to answer research questions 
one through three. The survey contained questions designed to obtain demographic data about the leaders and other questions that assisted in answering the research questions.

The survey (see Appendix B) contained five questions (1 through 5) that sought the following demographic data about the leader responding to the survey: age, gender, ethnicity, level of education, and education major. Survey questions $6,7,8$, and 9 respectively sought to determine how long leaders had been in their position at the time of the survey, their title, how long they had worked for their organization, and whether or not the position was paid or voluntary. I explored research question one using three questions (Questions 10, 14, and 18) that identified which sector(s) the participants had experience in. To answer research question two, I asked the respondents how many years of experience they had in each sector (Questions 11, 15, and 19). Research question three was examined using questions that sought respondents' opinions on how nonprofit (Questions 12 and 13), private (Questions 16 and 17), and public (Questions 20 and 21) impacts the ability to lead a nonprofit organization.

Prior to administering the survey to those in the selected sample, I administered the survey in person to three individuals who were senior leaders at a nonprofit organization. Consistent with cognitive interviewing piloting procedures (Fowler, 2014), I asked the volunteers to indicate verbally what they thought each question was asking as they completed the survey. I also asked the volunteers if there were any questions they felt were difficult to understand and if they felt the answer choices were adequate. I also recorded the amount of time it took to answer each question as an additional check for difficulty (Baker, Crawford, \& Swinehart, 2004). Following the interviews, I adjusted the wording of three of the questions. 


\section{Administration of the Survey}

The survey was administered to a sample of 1,092 executives of nonprofit organizations via email, which represented 5\% of the public charities that filed 990s in 2012. After I compiled the list of nonprofit organizations, I engaged in a web-based search for the email address of the highest-ranking executives of the nonprofit organizations in the sample. Although my goal was to submit the survey to Chief Executive Officers and Executive Directors of the organizations, many of the organizations did not have CEOs or EDs. In those circumstances, I used personal judgment in determining which person appeared to be the highest-ranking leader of the organization. In order to make the determination, I reviewed the personnel listed in Part VII Section A of the organization's 990 information return and the organization's website. In most cases, I selected the highest paid individual. However, if the organization listed the leadership team on the organization's website, I also reviewed this information in order to determine which executive the organization listed as the primary executive and selected that individual.

Of the 2,203 organizations selected from a population of 22,039, I excluded 892 organizations because they either had no paid staff or reported very low salaries and no paid key employees. I also excluded 27 organizations because they were supporting organizations for other nonprofit organizations, whose executives were paid by another organization. I was unable to find contact information for another 79 organizations on Guidestar or on the internet. In these instances, I selected the next organization on the stratified list I used for the sample. After subtracting the 889 organizations that did not appear to have paid key employees and the 27 supporting organizations, the sample size was 1,287 organizations. I was able to obtain direct email addresses for 689 executives and general email addresses for 71 nonprofit organizations via the internet. I attempted to obtain email addresses for the remainder of the sample via 
telephone. Out of 527 executives whom I attempted to contact via telephone I was able to obtain 332 email addresses either directly from the executive or from another organization member.

Between December 4, 2014 and January 6, 2015, I submitted the surveys via email to the executives I had identified. The email contained the recruitment letter in Appendix A and provided a link to the survey with the questions listed in Appendix B. Consistent with the process recommended by Dillman, Smyth, and Christian (2008), I sent two follow-up emails after the initial survey link was sent to remind individuals who had not responded to the survey. I received 191 responses; however, one of those responses was by someone whom I confirmed was not the highest ranking paid staff member. I dropped this response from my results.

\section{Testing for Nonresponse Bias}

It is possible that those individuals who responded to the survey differ from those who did not respond to the survey (Fowler, 2014). Thus, those who respond to the survey may not be truly representative of all executive directors in California. As a result, I checked to see if the

percent of responses was consistent across NTEE subcodes and across organizations of different sizes. With the exception of Mutual Benefit and Membership organizations and Unknown, Unclassified organizations, which I did not receive any responses for, the response rates for all other types of organizations fell within one standard deviation of the average response rate of $14.64 \%$.

I also broke the group of eligible organizations into four quartiles based upon total revenue in the 990 data I used. The mean number of responses per quartile was 47.5 and the standard deviation was 9.15. The total responses in the first quartile fell below one standard deviation of the mean, so I attempted to contact 20 respondents via telephone. Of those whom I 
reached out to, one individual said he did not have enough time to complete the survey because, as the primary employee, he did everything. Two others stated they felt their organizations were too unique to be included in the study. Another stated that providing any information regarding the organization would be in violation of the organization's bylaws. Only one person whom I reached out to completed the survey. I left the survey open for one additional week to allow those whom I had reached out to additional time to complete. By the time I had closed the survey the response rate increased from 190 to 191.

I also compared demographic data of the respondents against demographic data in a recent national survey of nonprofit executives (Table 1). Responses for gender and education were similar. However, the response rates for White/Latino was higher than the national sample and the response rates for Black/African American was lower than the national sample. The response rate of $6.2 \%$ for leaders under 40 was lower in my sample than the response rate of $15.6 \%$ in the national survey. 


\section{Table 1}

Sample Demographics of Nonprofit Leaders in California Compared to a National Survey of Nonprofit Leaders

\begin{tabular}{lcc}
\hline & Sample Percent & National Survey Percent \\
\hline Gender $(N=182)$ & 36.3 & 29.0 \\
Male & 63.7 & 71.0 \\
Female & & \\
Race $(N=180)$ & 92.2 & 88.1 \\
White (Latino) & 1.7 & 5.2 \\
Black or African-American & 3.3 & 3.1 \\
Asian/Pacific Islander & 0.6 & 0.5 \\
Native American & 2.2 & 2.1 \\
Multi-racial & 0.0 & 1.0 \\
Other & & \\
Age $(N=178)$ & 6.2 & 15.6 \\
Under 40 & 24.2 & 25.1 \\
40-49 & 41.0 & 36.8 \\
50-59 & 28.7 & 22.5 \\
60+ & & \\
Education $(N=182)$ & 9.3 & 5.9 \\
Less than college degree & 34.6 & 33.7 \\
Bachelor's & 42.9 & 47.5 \\
Master's & 13.2 & 12.9 \\
Doctoral & 188 & 3,067 \\
Sample Size & & \\
\hline Source: Cornelus, Marta & Rick Moyers, & \\
\hline
\end{tabular}

Source: Cornelius, Marla, Rick Moyers, and Jeanne Bell, Daring to Lead 2011: A National Study of Nonprofit Executive Leadership (San Francisco, CA: CompassPoint Nonprofit Services and the Meyer Foundation, 2011).

\section{Cleaning the Quantitative Data}

While reviewing the data, I dropped two additional respondents because they indicated they were volunteers, rather than paid staff members. I then reviewed the titles of the respondents to confirm the title was consistent with what I would expect. I reviewed the organizations' websites for those titles that I questioned to see whether they corresponded to the 
highest paid individual in the organization. Those titles included Associate Vice President, Clinical Director, Development Director, Director of Children and Family Services, Executive Director of Education and Programs, Program Director, Training Director, and Vice President. Upon review of the websites, I did confirm the Director of Children and Family Services was not the highest paid staff member, so I dropped the respondent from the study. As a result, I counted only 188 out of 191 respondents.

After I reviewed titles, I reviewed participants' responses to my primary research questions. When I looked at the results in the years of experience area, I noticed that one respondent commented that he wasn't sure whether or not "private" and "nonprofit" meant the same thing. As a result, I added together the total years of experience in each sector and subtracted the total from the person's age to see if the difference was less than 16 , the current legal age for people to begin working. For 38 respondents, the listed age minus years of experience in all categories came out to lower than 16 years. I sent emails to all 38 of these respondents with a further clarification that "private" was the same as "for-profit" and asked for them to notate if they had experience in multiple sectors at the same time. Thirty-one of the respondents replied and 15 of them confirmed there were errors in their survey responses. Several of these individuals indicated there was confusion regarding what was meant by either "private" or "public" sectors. Another five individuals indicated they had included prior unpaid volunteer work in their nonprofit experience, which I deducted. Five people responded that they worked concurrently in two sectors at some point in their careers. In this case, I did not adjust the years of experience because it could skew the results for these respondents compared to other respondents who worked in both sectors whom I did not review and because my research 
question did not address years of full-time experience. The remaining individuals noted that the answers were correct because they did begin work as teenagers and have never ceased working.

Table 2 lists the titles of research participants and the number of respondents associated with each title. I did make some changes to titles in order to consolidate the data. For instance, I consolidated all titles that included CEO or Chief Executive Officer into the Chief Executive category. With the exception of interim Executive Directors, I also consolidated all titles that included Executive Director into one category.

\section{Table 2}

Titles of Respondents

\begin{tabular}{lc}
\hline \multicolumn{1}{c}{ Title } & Responses \\
\hline Administrator & 1 \\
Consulting/Interim Executive Director & 3 \\
Chief Executive Officer & 45 \\
Declined to State & 5 \\
Director (Other) & 13 \\
Executive Director & 102 \\
General Manager & 2 \\
Head of School & 1 \\
President & 11 \\
Principal & 2 \\
Vice President & 3 \\
Total & 188 \\
\hline
\end{tabular}

\section{Organizational Data}

The sample included leaders from 188 nonprofit organizations. To determine if the sample was representative of the population, I first analyzed the response rate by type of nonprofit organization. I did not receive any responses from organizations listed as Mutual Benefit/Membership or Unknown/Unclassified organizations. As shown in Table 3, 
Environment and Animals, Health, Public and Societal Benefit, and Human Services had response rates above the mean and Arts, Culture, and Humanities, Education, and International and Foreign Affairs had response rates below the mean.

\section{Table 3}

Survey Response Rates by NTEE Subcode

\begin{tabular}{lccc}
\hline \multirow{2}{*}{ NTEE code } & \multicolumn{2}{c}{ Number } & \\
\cline { 2 - 3 } & Eligible & Surveyed & Percent \\
\hline Arts, Culture, Humanities & 169 & 21 & 12.43 \\
Education & 247 & 30 & 12.15 \\
Environment and Animals & 82 & 16 & 19.51 \\
Health & 200 & 34 & 17.00 \\
Human Services & 427 & 64 & 14.99 \\
International, Foreign Affairs & 31 & 3 & 9.68 \\
Public, Societal Benefit & 126 & 20 & 15.87 \\
Mutual, Membership Benefit & 0 & 0 & N/A \\
Unknown, Unclassified & 2 & 0 & N/A \\
Total & 1,284 & 188 & 14.64 \\
\hline
\end{tabular}

As presented in Table 4, I also compared the average size and age of organizations in the sample to the average age and size of organizations in the population. The results of my analysis seemed to disconfirm my earlier analysis that showed that organizations with revenue in the bottom quartile had a lower response rate than organizations in the other three quartiles. Because revenue for the upper quartile of organizations had a range from $\$ 2,747,914$ to $\$ 1,253,533,385$, it was apparent that larger organizations would have a greater impact upon the mean than smaller organizations. As a result, I concluded that comparing the median of the sample with the median of the population would be a reasonable way to compare the sample to the population. The financial results for the sample were higher than the median for the entire population, which was consistent with my observations in the research that many smaller nonprofit organizations did 
not have paid staff and that, in some cases, leaders of smaller nonprofit organizations chose not to complete the surveys because they felt their organizations were too unique to be meaningful in the sample.

\section{Table 4}

Comparison of Sample and Population Means and Medians Across Four Categories

\begin{tabular}{lcccc}
\hline & Revenues & Expenses & Assets & Organization Age \\
\hline Population Mean & $\$ 8,333,685$ & $\$ 7,919,889$ & $\$ 12,778,667$ & 27.7 \\
Sample Mean & $\$ 3,577,088$ & $\$ 3,410,847$ & $\$ 5,846,257$ & 30.4 \\
Population Median & $\$ 424,238$ & $\$ 413,644$ & $\$ 480,745$ & 22.0 \\
Sample Median & $\$ 965,032$ & $\$ 889,639$ & $\$ 705,673$ & 27.5 \\
\hline
\end{tabular}

\section{Analyzing the Quantitative Results}

The purpose of this section is to discuss the quantitative methodologies I employed in order to answer the four research questions. Procedures used to analyze the survey data to answer each question are discussed in turn.

\section{Research Question One}

In California, what percent of paid chief executive officers and executive directors of 501 (c)(3) public charities who filed IRS form 990s had each of the following types of experience prior to working at their current organization: only nonprofit, only government, only corporate, nonprofit and government, nonprofit and corporate, government and corporate, and experience in all three sectors? — was answered through close-ended survey questions 10, 14, and 18 (See Appendix B). The results were presented by reporting the number and percent of respondents who had each type of experience. 


\section{Research Question Two}

For those leaders of California nonprofit organizations who did have experience in each sector, what was the average number of years that leaders had in each sector?-was answered through survey questions 11, 15, and 19 (See Appendix B.). In order to answer the research question, I separated the results by respondents who had experience in each sector. I then calculated the average number and standard deviation of years of experience for respondents who had experience in each sector.

\section{Research Question Three}

Research question three had two parts: (a) What impact do leaders of California nonprofit organizations perceive their experience in each of the three sectors or experience in multiple sectors had on their ability to lead nonprofit organizations? (b) Do those people who had experience in a particular sector value experience in that sector differently than those who do not have experience in that particular sector?

The answers to the questions were represented by a five-point Likert scale with the following answers: 1. Strong Negative Impact, 2. Some Negative Impact, 3. Neither Negative nor Positive impact, 4. Some Positive impact, and 5. Strong Positive Impact. In order to answer the first part of question three, I calculated the total and average number of respondents who provided each Likert scale rating regarding the effects of Nonprofit, Public, and Private sector experience separately. I also separated the results for those respondents who fit into each category of experience and those who did not fit into each category of experience and performed independent t-tests to determine if, at the $95 \%$ confidence interval, the differences in means are significant. Lastly, I used paired sample t-tests to see whether respondents who had experience 
in multiple sectors perceived their experience had a more positive or negative impact in one sector than in another sector.

After I reviewed the data for research question three, I recognized that respondents rated nonprofit experience higher than private sector experience, which was rated higher than public sector experience. This led me to perform paired sample t-tests, at the $95 \%$ confidence level, to determine if people who had experience in two sectors or more rated their experience in the sectors differently. Thus, I compared the differences in means regarding the perceived utility of sector experience between the nonprofit and private sectors, the nonprofit and public sectors, and the private and public sectors.

\section{Research Question Four}

\section{How much of the variation in measures of financial performance among California} nonprofit organizations' is associated with the prior sector experience of leaders?-was examined utilizing data obtained from the surveys and 990s of the organizations associated with those respondents who have led their organizations for four or more years. I utilized 990's for my analysis because other studies have found their data to be reliable (Gronjberg and Paarlberg, 2002, Froelich \& Knoepfle, 1996, \& Froelich, Knoeplfle, \& Pollak, 2000). I used financial data for 2013 for the four primary models because, at the time of the study, more recent 990 returns were not publicly available for many of the organizations in the sample. I also included financial data for the fiscal year ending 2011 in the other four models. Bearing in mind that 2011 was four years before I conducted the study I included only organizations whose leaders had four years or more of tenure as part of the multiple regression analysis. 
I used multiple regression analysis to determine to what extent financial organizational measures such as debt to equity, operating margin, total revenue, and revenue diversification are associated with the sector experience of the organization's leader. I have chosen these calculations because the literature has shown these to be effective measures to analyze the financial performance of nonprofit organizations (Chabotar, 1989, Tuckman \& Chang, 1991, Trussel, Greenlee, \& Brady, 2002, Carroll \& Stater, 2008). Data for all of the following calculations came from organization 990s for fiscal years ending in 2013. I determined the debt to equity ratio by dividing line 21 (Total liabilities) by line 22 (Net assets or fund balances) for "End of Year" column of Section I. I calculated the operating margin by dividing line 19 (Revenue less expenses) by line 12 (Total revenue) for the "Current Year" column of Section I. I calculated revenue diversification using the Hirschman-Hefindahl Index, which determines the amount to which revenue is balanced among the three categories-donative income, earned income, and investment income. Donative income came from line 8 (Contributions and grants), Program service revenue came from line 9 (Program service revenue) and line 11 (Other revenue), and Investment income will came from line 10 (Investment income) of Section I. I built four separate models, which utilized each of the preceding financial measures as a dependent variable.

In specifying the four regression models used in my study, an array of individual and organizational demographics were used as independent variables. Individual demographic variable included respondent's age, male, White, some college, master's degree, doctoral degree, years in current position, prior years at current organization, prior years in nonprofit sector, years private sector experience, and years public sector experience. Bearing in mind that managerial capabilities are affected by one's innate abilities and past experiences (Beck \& Wiersema, 2013), 
I included basic demographic such as age, education, gender, and race, which may have impacted the respondents past experiences. I also included years at the organization because, along with age, leaders' organizational tenure has been linked to leadership philosophy (KorackKakabadse, Korac-Kakabadse, \& Meyers, 1998). As shown in Table 5, I used a 1 for the dummy variable for white, male, and the education variables of some college, master's degree, and doctoral degree. I did not include variables for other races because the number of respondents for races other than white was too low to be representative of the population. Thus, the absence of a 1 for dummy variables would represent either female for male/female, nonwhite for white/nonwhite, and bachelor's degree for education.

Organizational demographics included organization age in years and the industry within which the organization was situated (e.g., arts, education, environment and animals, health, human services, international and foreign affairs, and public, societal benefit. I included industry as a series of independent variables because prior studies have shown that financial data may differ among organizations in different industries due to industry-specific environmental factors (Carroll \& Stater, 2009, Trussel, Greenlee, \& Brady, 2002). I also included organization age as an independent variable because I anticipated that organizations would accumulate assets and revenue sources over time, which would affect the financial metrics analyzed in the study. As shown in Table 5, I used separate dummy variables equal to 1 to represent the arts industry, education industry, environment and animals industry, health industry, human services industry, and international and foreign affairs industry. In order to avoid perfect collinearity of dummy variables, the absence of a 1 in another industry category represented that the organization was in the public, societal benefit industry. 


\section{Table 5}

Measurement of Independent Variables

\begin{tabular}{lcc}
\hline \multicolumn{1}{c}{ Variable } & Number & Unit of Measurement \\
\hline Organization's age & Cardinal & Years \\
Respondents Age & Cardinal & Years \\
Male & Nominal & "1" for yes, "0" for no \\
Female & Nominal & Indicated by "0" for Male \\
White & Nominal & "1" for yes, "0" for no \\
NonWhite & Nominal & Indicated by "0" for White \\
Some College & Nominal & "1" for yes, "0" for no \\
Masters Degree & Nominal & "1" for yes, "0" for no \\
Doctoral Degree & Nominal & "1" for yes, "0" for no \\
Bachelors Degree & Nominal & "0" in other education \\
Years in current position & Cardinal & Years \\
Prior years at organization & Cardinal & Years \\
Prior years of nonprofit experience & Cardinal & Years \\
Years experience in private sector & Cardinal & Years \\
Years experience in public sector & Cardinal & Years \\
Arts, Culture, Humanities & Nominal & "1" for yes, "0" for no \\
Education & Nominal & "1" for yes, "0" for no \\
Environment and Animals & Nominal & "1" for yes, "0" for no \\
Health & Nominal & "1" for yes, "0" for no \\
Human Services & Nominal & "1" for yes, "0" for no \\
International, Foreign Affairs & Nominal & "1" for yes, "0" for no \\
Public, Societal Benefit & Nominal & "0" in all other industry \\
\hline
\end{tabular}

Because it is meaningful to analyze the change in financial measures for an organization over time (Chabotar, 1989, Carroll \& Stater, 2008), I also built four models that measured the change in the dependent variables from 2011 to 2013 . For these models, I subtracted the debt to equity, operating margin, total revenue, and revenue diversification for 2011 from the corresponding ratio from 2013 and divided by the ratio from 2011. The change metric I calculated for each ratio served as the dependent variable for each of the four models. With the exception of the financial measures of interest for 2011, which I did not include because they 
were part of the dependent variables, I included all other independent variables from the other four models I discussed.

\section{Selection of the Participants for the Qualitative Phase}

As part of the survey I submitted in the first, quantitative phase, I included a question that asked respondents "Are you interested in being contacted for a 30 to 60 minute follow-up interview to further discuss the effects of sector experience on leading nonprofit organizations?" Of the respondents who completed the survey, 96 indicated they were interested in being contacted for a follow-up interview. In order to examine participant's perceptions of the comparative effectiveness of experience in each of the three sectors, preference was given to respondents who had experience in multiple sectors. Ultimately, I conducted eight interviews. As shown in table 6, there was considerable diversity in terms of type of organization, size of the organization as measured by annual revenue, and the number of years of experience the respondents had in their current positions. 


\section{Table 6}

Organizational Data and Personal Experience for Participants in Qualitative Phase

\begin{tabular}{|c|c|c|c|c|c|}
\hline $\begin{array}{c}\text { Respondent } \\
\#\end{array}$ & $\begin{array}{l}\text { Organization's } \\
\text { NTEE Code }\end{array}$ & $\begin{array}{l}\text { Organization's } \\
\text { Annual Revenue } \\
\text { (rounded) }\end{array}$ & $\begin{array}{l}\text { Years in } \\
\text { Current } \\
\text { Position }\end{array}$ & $\begin{array}{c}\text { Years at } \\
\text { Current } \\
\text { Organization }\end{array}$ & $\begin{array}{c}\text { Prior } \\
\text { Sector } \\
\text { Experience }\end{array}$ \\
\hline 1 & Educational & $2,600,000$ & 20 & 20 & Private \\
\hline 2 & Educational & $3,100,000$ & 9 & 9 & $\begin{array}{l}\text { Nonprofit, } \\
\text { Private, } \\
\text { Public }\end{array}$ \\
\hline 3 & $\begin{array}{l}\text { Health--General \& } \\
\text { Rehabilitative }\end{array}$ & $35,700,000$ & 2 & 3 & $\begin{array}{l}\text { Nonprofit, } \\
\text { Public }\end{array}$ \\
\hline 4 & $\begin{array}{c}\text { Health--General \& } \\
\text { Rehabilitative }\end{array}$ & $7,700,000$ & 18 & 18 & $\begin{array}{l}\text { Nonprofit, } \\
\text { Private, } \\
\text { Public }\end{array}$ \\
\hline 5 & $\begin{array}{c}\text { Mental Health, } \\
\text { Crisis Intervention }\end{array}$ & $2,700,000$ & 10 & 10 & $\begin{array}{c}\text { Nonprofit, } \\
\text { Private, } \\
\text { Public }\end{array}$ \\
\hline 6 & Human Services & $3,800,000$ & 2 & 10 & $\begin{array}{l}\text { Nonprofit, } \\
\text { Private, } \\
\text { Public }\end{array}$ \\
\hline 7 & $\begin{array}{l}\text { Science and } \\
\text { Technology } \\
\text { Research }\end{array}$ & 300000 & 7 & 7 & $\begin{array}{c}\text { Nonprofit, } \\
\text { Private, } \\
\text { Public }\end{array}$ \\
\hline 8 & $\begin{array}{l}\text { Social Science } \\
\text { Research }\end{array}$ & 600,000 & $<1$ & 4 & $\begin{array}{c}\text { Nonprofit, } \\
\text { Private, } \\
\text { Public }\end{array}$ \\
\hline
\end{tabular}

Participant one was President of organization that provided books to in-need students, which she founded 20 years ago. Prior to that she earned a degree in Finance and worked in real estate development for 13 years, which she says was "all about people."

Participant two had been CEO of a charter school for nine years at the time of the interview. She had a PhD in Education and held education-related jobs in all three sectors. She spent three years in the private sector, first as a teacher at a private school and then as a 
curriculum writer. She then spent 10 years working at a University Foundation before becoming a teacher in the public school system, which led to additional leadership positions within schools and at the district level.

Participant three was President and CEO of an organization that provided services to individuals and families affected by disabilities. In a little over three years in her position her organization grew from revenue of $\$ 13$ million to $\$ 90$ million per year. After she earned her Bachelor's degree in Psychology, she worked for two years in the public sector and one year in the nonprofit sector in her home country before she spent 10 years as a nanny in Europe. She then worked for a short period of time at a for-profit organization that served people with disabilities. Prior to her current position, she worked at several organizations affiliated with her current organization. During that time she led a couple of organizations through significant challenges.

Participant four had been the President and CEO of an organization that advocates for community health clinics for 18 years. While she was earning her bachelor's degree and her juris doctorate she spent two summer internships at private law firms serving corporate interests and less than a year as an assistant to president of community college. After she earned her juris doctorate, she began her career in the nonprofit sector at organizations that focused on healthcare access for the Latino and other multicultural communities.

Participant five was executive director for an organization that provides services to the developmentally disabled. She started her career as a teacher but quickly realized it was not for her. She then went to work at a grocery store chain and was promoted into management quickly. After working with people with disabilities at the grocery store she decided to become a job 
coach at a nonprofit, where she was eventually promoted to director of employment. She then became a research specialist for the State, working with ED's and boards to build new services. From there, she was recruited by a Board member whom she had worked with to lead the organization she led at the time of the interview.

Participant six had been executive director of her organization for two years and had been at the organization for eight years prior to that. Early in her career she led a trade association-which she considered to be private sector experience because the mission was to make money for its members. Her public sector experience included time as a cook in the reserves and two years evaluating grants for a State agency.

Participant seven was chief executive officer of an organization that provides programs related to technology to people with disabilities. She began her career at 17 , when she started her own landscaping business that put her through school. After college, she became international director of human resources for a multinational company. She also worked at an internet startup and then as VP of Development for a nonprofit radio station. She then worked for political campaigns before she came back to the nonprofit sector.

Participant eight was executive director of an organization that seeks to increase intercultural understanding through the arts. Prior to his current position, he worked for his organization for four years, two years for a private sector information technology company, and five years working at a school. He came back to his current organization when they were in crisis. 


\section{Qualitative Research Methodology}

Interviews were conducted using the interview questions in Appendix D. Respondents number two and seven were interviewed in person using a portable recording device; however, during the interview for participant seven, the recording device stopped recording toward the end of the interview. Once I noticed the recording device stopped working, I took detailed notes to capture the person's responses. Participant five was interviewed over the phone. Because of a malfunction of the recording device I typed her responses during the interview. I emailed my notes to her for review, but she did not respond. The remaining five participants were interviewed over the phone using a portable recording device. Prior to the interviews I obtained signed participant consent forms from the participants (Appendix C).

Subsequent to the interviews, I transcribed all interviews by hand. After all of the interviews were transcribed, I reviewed my notes and any demographic data available online and created a one paragraph summary of experience for each participant.

I created separate files for effects of nonprofit, private, and public experience and for the relationships among the three. I also reviewed each person's career history and input the appropriate contexts within the appropriate files to add context to the effects that experience in each sector had upon the act of leading nonprofit organizations. I included those sections of partcipants' responses that I felt clarified the answers they provided to the effects that prior sector experience had upon the act of leading nonprofit organizations along with those sections that compared the relative effects of experience in each sector. I also compiled analytic notes as I was reviewing the interviews so that I could keep a record of any pertinent ideas that came to me in the process of the analysis. After I completed the first draft of the results, I emailed the 
results to each of the qualitative respondents to allow them to correct any errors I made and include any information they felt I left out of the results section. Five respondents replied and two asked me to make minor changes, which I incorporated into the results.

\section{Conclusion}

Although a limited number of studies have examined the prior experience of nonprofit executives, no previous studies have examined the relationship between prior sector experience and nonprofit leadership. In this study, I compiled information on the prior sector experience of nonprofit leaders, analyzed their perceptions regarding the effects that prior sector experience had upon the act of leading nonprofit organizations, and analyzed what effect prior sector experience of leaders, when moderated by other factors, had upon the financial results of the organizations they lead. I also performed follow-up interviews with some of the original respondents to gather explanatory data on what effects prior sector experience had upon nonprofit leadership. Although this study has its limitations, which will be discussed in chapter

five, it expands upon the limited research on the prior sector experience of nonprofit leaders and provides an important first-step in determining what effects prior sector experience has upon the act of leading nonprofit organizations. The next chapter will present the number of respondents who had experience in each sector and their average years of experience along with the relative impact they perceived experience in each sector had upon the ability to lead nonprofit organizations. 


\section{Chapter 4}

\section{Results}

The purpose of this dissertation was to examine the prior sector experience of those who lead nonprofit organizations and determine what effect, if any, prior sector experience has upon the ability to lead nonprofit organizations, as well as whether prior sector experience accounts for variation in measures of an organization's financial effectiveness. In this chapter, I present the findings of the study. Results to each research question are presented quantitatively. Following the presentation of the quantitative data relevant to answering research questions two and three, qualitative responses are presented in order to expand upon the results.

\section{Research Question One}

Research question one-In California, what percent of paid chief executive officers and executive directors of 501 (c)(3) public charities who filed IRS form 990s had each of the following types of experience prior to working at their current organization: only nonprofit, only government, only corporate, nonprofit and government, nonprofit and corporate, government and corporate, and experience in all three sectors?-was answered through close-ended survey questions 10, 14, and 18 (See Appendix B). The results are summarized in Table 7. 


\section{Table 7}

Number and Percent of Respondents who had Experience in Each Sector Prior to Working at Their Current Organization

\begin{tabular}{lcc}
\hline \multicolumn{1}{c}{ Category } & Number & Percentage \\
\hline Nonprofit Only & 12 & 6.4 \\
Public Only & 7 & 3.7 \\
Private Only & 44 & 23.4 \\
Nonprofit and Public & 7 & 3.7 \\
Nonprofit and Private & 55 & 29.3 \\
Private and public & 20 & 10.6 \\
Experience in all Three Sectors & 41 & 21.8 \\
No Prior Experience & 2 & 1.1 \\
Total & 188 & 100.0 \\
\hline
\end{tabular}

Overall, $61.2 \%$ of respondents had experience in the nonprofit sector prior to working at their current organization, $85.1 \%$ had experience in the private sector, and $39.9 \%$ had experience in the public sector. The majority of respondents, $29 \%$, had experience in both the nonprofit and private sectors prior to working at their current organization, followed by about $23 \%$ who had experience in only the private sector and $22 \%$ who had experience in all three sectors. Although it is not reflected in the data below, 27 of the respondents who did not report nonprofit experience prior to working at their current organization did report they had been at their current organization for longer than they have been in their current position. However, I did not include these responses as having nonprofit experience because, based upon the responses to emails I sent seeking clarification, I noted that some respondents included volunteer experience in the number of years of experience they reported. 


\section{Research Question Two}

Research question two- For those leaders of California nonprofit organizations who did have experience in each sector, what was the average number of years that leaders had in each sector?-was answered through survey questions 11, 15, and 19 (See Appendix B.). As table 8 shows, the respondents did spend more time in the nonprofit and private sectors than the public sectors. It is important to note that some respondents continued to work in the private sector while serving in their current positions. Thus, the average number of years of private sector experience prior to their current positions may be lower than 13.8 years.

\section{Table 8}

Number of Respondents with Experience in Each Sector and the Average Number of Years of Experience in Each Sector

\begin{tabular}{lccc}
\hline & & \multicolumn{2}{c}{ Years } \\
\cline { 3 - 4 } \multicolumn{1}{c}{ Experience } & Number & Average & Standard Deviation \\
\hline Nonprofit & 115 & 13.3 & 9.3 \\
Private & 157 & 13.8 & 11.4 \\
Public & 73 & 8.7 & 8.5 \\
\hline
\end{tabular}

\section{Research Question Three}

Research question three had two parts: (a) What impact do leaders of California nonprofit organizations perceive their experience in each of the three sectors or experience in multiple sectors had on their ability to lead nonprofit organizations? (b) Do those people who had experience in a particular sector value experience in that sector differently than those who do not have experience in that particular sector? 
Results to both sections of the research question are presented in tables 8,10 , and 12, which show the number and percent of participants who characterized the impact of prior experience in different sectors as having a Strong Negative Impact, Some Negative Impact, Neither Negative nor Positive Impact, Some Positive impact, and Strong Positive Impact. Results are separated according to whether or not participants did or did not have experience in each sector. Subsequent to the presentation of the quantitative results, I present responses from qualitative participants about the effects that prior experience in each sector has on the ability to lead a nonprofit organization in tables 9, 11, and 13.

In order to determine if participants who had experience in multiple sectors rated the impact of their relationship in each sector differently, I compare the mean differences between the characterized impact of experience in each sector for leaders who had nonprofit and private, nonprofit and public, and private and public sector experience. I present the quantitative results in tables 14 through 16 followed by a discussion of the qualitative responses regarding the relative impact of experience in different sectors.

\section{The Perceived Effect that Nonprofit Experience has Upon the Act of Leading Nonprofit Organizations}

As Table 9 shows, leaders perceive that nonprofit experience does have a strong positive impact upon leading nonprofit organizations. Almost $76 \%$ of leaders who did have prior nonprofit experience and $93 \%$ of leaders who did not have prior nonprofit experience perceived that nonprofit experience has a strong positive impact upon leading nonprofit organizations. 


\section{Table 9}

Distribution of the Impact That Nonprofit Experience has on the Ability to Lead Nonprofit Organizations

\begin{tabular}{lcccccc}
\hline & \multicolumn{2}{c}{$\begin{array}{c}\text { Previous Nonprofit } \\
\text { Experience }\end{array}$} & & \multicolumn{2}{c}{$\begin{array}{c}\text { No Previous Nonprofit } \\
\text { Experience }\end{array}$} \\
\cline { 2 - 3 } \cline { 5 - 6 } & Number & Percentage & & Number & Percentage \\
\hline Strong Negative Impact (1) & 0 & 0.00 & & 0 & 0.00 \\
Some Negative Impact (2) & 1 & 0.90 & & 0 & 0.00 \\
Neither Positive nor Negative (3) & 3 & 2.70 & & 1 & 1.33 \\
Some Positive Impact (4) & 23 & 20.72 & & 4 & 5.33 \\
Strong Positive Impact (5) & 84 & 75.68 & & 70 & 93.33 \\
Average & 4.71 & & & 4.92 & \\
\hline
\end{tabular}

The average score for leaders who had nonprofit experience was 4.71 and for those who did not have prior nonprofit experience was 4.92. In order to determine whether or not the difference in means was significant, I performed independent sample t-tests. The null hypothesis is: when asked what effect prior nonprofit experience has upon the act of leading nonprofit organizations, responses from leaders who had nonprofit experience and those who did not have nonprofit experience prior to leading their current organizations do not differ. For the alternative hypothesis, responses would differ among the two categories of respondents.

In testing this hypothesis, I first rejected the null hypothesis regarding equal variance. Using the $F$ max test, $F=3.10$. The critical value of $F$ with 110 and 74 degrees and $\alpha=.05$ is 1.48. Because I did not assume the variances were equal, I used the Cochran and Cox/Satterthwaite procedures to test the null hypothesis of the sample means. The significance of the test of the means with equal variances not assumed is .002 . As a result, I rejected the null hypothesis at $\mathrm{p}=.05$, which suggested the differences in means probably did not occur by chance. Although leaders who did have prior nonprofit experience stated their nonprofit 
experience had a strong positive impact upon their ability to lead nonprofit organizations, leaders who did not have prior nonprofit experience believed that previous nonprofit experience would have an even greater impact upon the ability to lead nonprofit organizations.

Of the seven qualitative respondents who had prior nonprofit experience, six rated their experience as having a "strong positive" impact and one rated nonprofit experience as having "some positive" impact. Respondent one, who did not have prior nonprofit experience also rated nonprofit experience as having a "strong positive" impact upon the ability to lead a nonprofit organization.

The qualitative response provide additional insight regarding the effect that prior nonprofit sector experience has on the ability to lead nonprofit organizations. Respondents three and four felt their experience improved their ability to lead their current organizations because their roles were similar and the organizations they previously led were similar to their current roles and organizations. Respondent five's experience provided utility because it groomed her to lead a nonprofit organization. Respondents six and eight both provided examples of how working as staff members at nonprofit organizations helped them to understand how to work with and motivate those they currently lead. On the other hand, respondents two and seven both didn't feel their experience at other nonprofit organizations had as much utility because the experience was very different. Table 10 displays quotes that exemplify the respondents' views on the utility of prior nonprofit sector experience. 
Table 10

Nonprofit Sector Experience and Responses to the Effect that Nonprofit Sector Experience has on the Ability to Lead Nonprofit Organizations for Seven Qualitative Respondents

\begin{tabular}{|c|c|c|}
\hline Respondent \# & $\begin{array}{l}\text { Years of } \\
\text { Prior } \\
\text { Nonprofit } \\
\text { Sector } \\
\text { Experience }\end{array}$ & Response \\
\hline Two & 10 & $\begin{array}{l}\text { When I actually took over leading this organization } \\
10 \text { years ago I had not led a nonprofit. } \\
\text { I think developing the relationships in politics and } \\
\text { policy as it relates to my nonprofit, I think it was year } \\
\text { two and three that I was feeling really confident and } \\
\text { that had to do with navigating that world well... }\end{array}$ \\
\hline Three & 25 & $\begin{array}{l}\text { In the other organizations I had gone through } \\
\text { difficult things... I learnt an enormous amount about } \\
\text { change management, how you bring your staff through } \\
\text { that and when you're a nonprofit you have donors as } \\
\text { well as a lot of Federal and State funding and you have } \\
\text { to work with those entities as well so in all of my } \\
\text { previous jobs I had to do some of that. }\end{array}$ \\
\hline Four & 6 & $\begin{array}{l}\text { [At her prior nonprofit] It was an incredible } \\
\text { experience... I learned what it took to be a CEO and I } \\
\text { knew that while I was running that firm that I was } \\
\text { ready to be CEO of a nonprofit but I just had to find the } \\
\text { right one and this was the only right one for me. }\end{array}$ \\
\hline Five & 11 & $\begin{array}{l}\text { I learned about leading because I was allowed to... } \\
\text { [The CEO] allowed me into the budget process and I } \\
\text { learned about that part of the job. Invited to board } \\
\text { meetings to present monthly on our program. Had I not } \\
\text { had that experience I would have had a very different } \\
\text { perception of all of it. }\end{array}$ \\
\hline Six & 13 & $\begin{array}{l}\text { Having come through the ranks of [a] nonprofit has } \\
\text { made me a better leader for my staff because I } \\
\text { understand what they think and how they feel. I think } \\
\text { differently now, but I remember what it was like when I } \\
\text { was doing their job. }\end{array}$ \\
\hline Seven & 20 & $\begin{array}{l}\text { [Her current nonprofit organization] is a totally } \\
\text { different ball game. }\end{array}$ \\
\hline Eight & 5 & $\begin{array}{l}\text { In a nonprofit the mission is very critical and } \\
\text { leading with that mission... people have to come to } \\
\text { work and be passionate about it so I think there's a } \\
\text { technique there. }\end{array}$ \\
\hline
\end{tabular}


Positive effects of prior nonprofit sector experience. Respondent five felt she was allowed to grow as a leader at a prior nonprofit organization because her boss allowed her to become very involved in decision making, manage her own budget, and present to the Board of directors. She and her boss also had a healthy level of conflict, which she felt was beneficial. According to the respondent:

There's ugliness and bad things. You have to have a vision to get through it to the other side. I got through that similar type of activity with this company. Had I not worked in that environment, I wouldn't have the vision of where I see I want this company to grow.

It is clear from the interviews with respondents three and four that prior experience leading similar nonprofit organizations prepared them for the leadership tasks and challenges that they encountered in their current positions. Recalling her experience at the prior nonprofit organization, respondent four recounted:

By the time I left there, I was only 31 years old and I became the CEO... so I was really well equipped. With the sink or swim environment of public advocates, I swam big time, I loved it. And so I learned what it took to be a CEO, and I knew... while I was running that firm that I was ready to be CEO of a nonprofit, but I just had to find the right one, and this was the only right one for me.

Respondent number three believed her prior nonprofit experience had a strong positive impact for two primary reasons. First, her prior nonprofit experience was with organizations affiliated with the organization she led at the time of the interview. Second, she had to lead the prior nonprofit organizations through difficult times, which provided her with experience that 
helped her to navigate many of the challenges she faced in her current organization, an organization that had been experiencing profound change. In summary she noted:

You need to take people on the journey with you and I learnt that in all my other situations. Facing difficult challenges, when you are the leader when something happens you are the person that they want to hear from and being able to message difficult things in the most positive way and helping people move through it, I learned from all my other positions, which was essential in this role.

Respondents three, four, and five all mentioned instances in which their prior experience prepared them for the challenges they face at their current organizations.

Limited positive effects of prior nonprofit experience. Although respondent number two stated that prior nonprofit experience had a strong positive impact upon her ability to lead, she was primarily referring to her experience in her current organization when she answered the question because she had never been part of a nonprofit that ran the way her current organization is run. For instance, she noted, "In the nonprofit that I'm currently running, there is a lot more work to be done on the political front and the networking side than I had ever experienced prior to coming here." Although she considers herself to be a continuous learner, she said it took her about two to three years of experience in her current position before she was comfortable with fundraising and other political activities such as influencing public policy and leveraging resources within the community to achieve mission.

Respondent seven, on the other hand, had opinions on why she felt nonprofit experience may not always be a good thing. According to her, the current organization is "a totally different ball game" than the prior nonprofits she worked at. She also felt a nonprofit mentality was actually detrimental to the organization when she stepped in: 
It was being run as a, and I hate to use this word, but almost like social workers. It was

like I walked into a union even though it wasn't a union. And I hadn't experienced managing people that had such tenure.

For respondent seven, one of her biggest challenges was overcoming the culture that existed when she took over leadership of her organization.

Taken together, the responses suggest that prior experiences in roles or at organizations similar to their current roles and organizations have more utility than prior nonprofit experience in dissimilar roles or organizations.

\section{The Perceived Effect that Private Sector Experience has on the Act of Leading Nonprofit Organizations}

Table 11 reports findings related to the second part of Question 3. Specifically, table 10 shows that the majority of leaders felt like private sector experience does have a positive impact upon leading nonprofit organizations. Over $50 \%$ of leaders who had private experience felt it had a strong positive impact and almost $30 \%$ felt it had some positive impact upon leading nonprofit organizations. Thus, over $80 \%$ of leaders with private experience felt it was helpful.

The figures for those who had never had private sector experience were somewhat less positive about the utility of private sector experience for working in the nonprofit sector: A little over $50 \%$ of leaders who didn't have private sector experience felt it would have a positive impact but less than $10 \%$ felt it would have a strong positive impact upon the act of leading nonprofit organizations. Almost $40 \%$ felt it would not have a positive or negative impact and nearly $10 \%$ felt private sector experience would have some negative impact upon leadership of 
nonprofit organizations. I performed independent sample t-tests to determine whether the differences between the two groups were significant at $\mathrm{p}=.05$.

\section{Table 11}

Impact that Private Sector Experience has on the Ability to Lead Nonprofit Organizations

\begin{tabular}{lcccccc}
\hline & \multicolumn{2}{c}{$\begin{array}{c}\text { Private Sector } \\
\text { Experience }\end{array}$} & & \multicolumn{2}{c}{$\begin{array}{c}\text { No Private Sector } \\
\text { Experience }\end{array}$} \\
\cline { 2 - 3 } \cline { 5 - 6 } & Number & Percentage & & Number & Percentage \\
\hline Strong Negative Impact (1) & 0 & 0.00 & & 0 & 0.00 \\
Some Negative Impact (2) & 1 & 0.63 & & 2 & 9.52 \\
Neither Positive nor Negative & $(3)$ & 27 & 16.98 & & 8 & 38.10 \\
Some Positive Impact (4) & 47 & 29.56 & & 9 & 42.86 \\
Strong Positive Impact (5) & 84 & 52.83 & & 2 & 9.52 \\
Total Responses & 159 & 100.00 & & 21 & 100.00 \\
Average & 4.35 & & & 3.52 & \\
\hline
\end{tabular}

For the experience that private sector experience has upon the act of leading nonprofit organizations the null hypothesis is that, when asked what effect private sector experience has upon the act of leading nonprofit organizations, responses from leaders who had private sector experience and those who did not have private sector experience did not differ. For the alternative hypothesis, responses would differ among the two categories of respondents.

Using the F Max test for homogeneity of variance, I did not reject the null hypothesis regarding equality of variance and assumed the variances were equal. The basic test statistic for variance among the means was $t=4.52$. Using 180 degrees of freedom $(161+21-2)$ the critical value at $\alpha=.05$ was 1.98 . Thus, I rejected the null hypothesis regarding equality of means, which suggested the differences between the means probably did not occur by chance. Leaders who did have prior private sector experience believed that prior private sector 
experience would have a more positive impact upon the ability to lead nonprofit organizations than leaders who did not have prior private sector experience believed private sector experience would have.

During the qualitative portion of the study, seven of the respondents reported having private sector experience. Two reported a "strong positive impact," three reported "some positive impact," and two reported "neither a positive nor negative impact" for the effect that private sector experience has on leading nonprofit organizations. It is important to note that the results for the participants in the qualitative phase had reported lower impact ratings for private sector experience than the average for all quantitative respondents. Respondent three also had private sector experience, although she reported not having private sector experience in the quantitative portion of the survey. The results of the quantitative section were not adjusted to reflect this.

The qualitative responses provide additional insight regarding the effect that prior private sector experience has upon the ability to lead nonprofit organizations. Four of the respondentsone, three, five, and seven provided instances of specific skills they learned in the private sector that helped them to run their current organizations. The other four respondents, two, four, six, and eight were not as positive about the utility of their private sector experiences because their experience was limited or they did not feel the management styles they saw exhibited in the private sector would be helpful at a nonprofit organization. Table 12 presents the total years of private sector experience for respondents and displays the quotes that exemplify the respondent's views on the effects of private sector experience. The effects of private sector experience will be discussed in greater detail in the following section. 


\section{Table 12}

Private Sector Experience and Responses to the Effect that Private Sector Experience has on the Ability to Lead Nonprofit Organizations for Eight Qualitative Respondents

\begin{tabular}{|c|c|c|}
\hline Respondent \# & $\begin{array}{l}\text { Years of } \\
\text { Private } \\
\text { Sector } \\
\text { Experience }\end{array}$ & Response \\
\hline One & 13 & $\begin{array}{l}\text { My experience both academically and being in the } \\
\text { business world for } 13 \text { years prior to starting the } \\
\text { nonprofit both provided a very important foundation for } \\
\text { me then to lead [my current] organization. }\end{array}$ \\
\hline Two & 3 & $\begin{array}{l}\text { In the private sector, the focus was more on parent } \\
\text { relationships. From watching leaders I worked with, I } \\
\text { learned more what I didn't want to do than what I } \\
\text { should do. }\end{array}$ \\
\hline Three & $\begin{array}{l}\text { No } \\
\text { response }\end{array}$ & $\begin{array}{l}\text { [I worked at] a for-profit but it really ran like a } \\
\text { nonprofit so I don't think I learned anything differently. }\end{array}$ \\
\hline Four & $<1$ & $\begin{array}{l}\text { Being in a corporate firm environment was } \\
\text { challenging for me... I think it was a good experience } \\
\text { in learning that you have to buck up and do what you } \\
\text { have to do }\end{array}$ \\
\hline Five & 10 & $\begin{array}{l}\text { Working at a for-profit there's a lot more black and } \\
\text { white because it's all based on money... Now I see that } \\
\text { having had that experience and really having the focus } \\
\text { on customer service--I worked on selling food, I feel } \\
\text { it's been a very beneficial trait. }\end{array}$ \\
\hline Six & 2 & $\begin{array}{l}\text { My experience in the private sector reinforced for } \\
\text { me where I should be, that I should be in the nonprofit } \\
\text { sector and I definitely learned things from the private } \\
\text { sector but I think that those things are accessible. I } \\
\text { don't think that you have to bring in somebody from } \\
\text { the private sector. }\end{array}$ \\
\hline Seven & 7 & $\begin{array}{l}\text { The issue with nonprofits is that they don't think } \\
\text { that they're a business and they are. They are held } \\
\text { accountable to donors, to their sponsors, their } \\
\text { employees, their mission, and everybody thinks, "I'm } \\
\text { just going to file a } 501 \text { (c) } 3 \text { " but no, do your research. } \\
\text { Nine times out of } 10 \text { somebody else is already doing it } \\
\text { and doing it better than you could }\end{array}$ \\
\hline Eight & 2 & $\begin{array}{l}\text { Even though the [leadership] was } 50 \text { feet down I } \\
\text { never really felt it... So it never really impacted me as } \\
\text { much as these smaller organizations I worked with } \\
\text { where I had this one connection with the leader. }\end{array}$ \\
\hline
\end{tabular}


Positive effects of private sector experience. Respondents one, five, and seven felt their private sector experience had a positive impact because they felt nonprofit leaders need to have business skills. Respondent one specifically felt her academic business training and experience in the private sector taught her an understanding of finance, management, and HR law, which helped her to effectively lead her nonprofit organization because, "a nonprofit leader has to have the business skillset to be successful."

Respondent one also mentioned ways in which her private sector experience in real estate development taught her how to build community. In her opinion, real estate development "is about getting people together." She added, "Negotiating, creating teams, all of those skills become very fundamentally important as you develop a team that then becomes an organization." Respondent three, on the other hand, did not reply that she had private sector experience in the quantitative survey because she had worked at a for-profit therapy business that was run similar to a nonprofit organization. However, it did positively impact her ability to lead her current organization because it gave her an understanding of the challenges her staff face. Thus, the responses suggest that private sector experience provides leaders with specific business skills that help them to effectively lead and, for some, leadership experiences that may mimic those they may be confronted with in the nonprofit sector.

Limited positive effects of private sector experience. Some respondents did not perceive the utility of their private sector was as positive of the preceding respondents either because their experience was limited and/or because they believed nonprofit and private organizations should be managed differently. 
Respondent eight, who spent two years at a technology company, did not feel he learned much from his private sector experience. Although he learned how to communicate with people he felt he had no rapport with leadership because it was closed off from employees at his level. In his words:

Even though the office was 50 feet down I never really felt it... So it never really impacted me as much as these smaller organizations I worked with where I had this one connection with the leader. If I had seen the people up there maybe I would have understood the structures but I felt there was this ivory tower that you could never touch.

Respondent four's private sector experience was also limited in that it consisted of only two years of summer internships at a law firm.

Technically, respondent six did not actually have private sector experience. The experience that she considered to be private sector experience actually consisted of time she spent working at a nonprofit trade association that served the interests of business. Respondent six felt the positive things one can learn from the private sector can also be learned from training sessions and that many of the skills learned in the private sector are not transferrable:

The private sector is used to flexibility in certain areas but the model is different. It doesn't work the same way. While I think it's valuable for a nonprofit professional to learn things from the private sector, I think taking private sector leaders and putting them in charge of nonprofits is often not effective... It's not a business for a reason, the market doesn't support our work. You can't walk in to Starbucks and say, 'I'm only going to pay for the beans' but that's what our funders do. 
Respondent two also felt her private sector experience wasn't as helpful as experience in other sectors because the focus was different and she did not spend as much time in the private sector as she spent in the other sectors. She said that she learned more about how she didn't want to lead than how she did want to lead from the leadership styles she observed in the private sector.

In summary, respondents one, five, and seven felt that business specific skills they learned in the private sector helped them in their roles as nonprofit leaders and respondent three feels she learned similar skills she may have learned in the nonprofit sector, which helped her in her role as a nonprofit leader. Respondents two and six felt that the positive impact of private sector experience was limited because the business models between the nonprofit and private sectors are different. Respondent eight's private sector experience was not as helpful because his exposure to leadership was limited. Lastly, respondent four saw her private sector experience more as something that had to be endured to get her where she wanted to be.

\section{The Perceived Effect that Public Sector Experience has on the Act of Leading Nonprofit Organizations}

As table 13 shows, the majority of leaders believed that private sector experience had a positive impact upon leading nonprofit organizations. Over $50 \%$ of leaders who had private experience felt it had a strong positive impact and almost $30 \%$ felt it had some positive impact upon leading nonprofit organizations. Thus, over $80 \%$ of leaders with private experience felt it was helpful. The figures were not quite as high for leaders who had not had private sector experience: A little over $50 \%$ of these leaders felt private sector experience would have a positive impact and a little less than $10 \%$ felt it would have a strong positive impact upon the act of leading nonprofit organizations. Almost $40 \%$ felt it would not have a positive or negative 
impact and nearly $10 \%$ felt private sector experience, actually, would have some negative impact upon leadership of nonprofit organizations. I performed independent t-tests to determine whether the means among the two groups was significant at the $95 \%$ confidence level.

\section{Table 13}

Impact that Public Sector Experience has on the Ability to Lead Nonprofit Organizations

\begin{tabular}{lrrrrr}
\hline & \multicolumn{2}{c}{$\begin{array}{c}\text { Public Sector } \\
\text { Experience }\end{array}$} & & \multicolumn{2}{c}{$\begin{array}{c}\text { No Public Sector } \\
\text { Experience }\end{array}$} \\
\cline { 2 - 3 } \cline { 5 - 6 } & Number & Percent & & No $\begin{array}{c}\text { No Prior } \\
\text { Experience }\end{array}$ \\
\cline { 2 - 3 } Strong Negative Impact (1) & 0 & $0.00 \%$ & & 2 & $2.13 \%$ \\
Some Negative Impact (2) & 1 & $1.39 \%$ & & 5 & $5.32 \%$ \\
Neither Positive nor Negative (3) & 10 & $13.89 \%$ & & 37 & $39.36 \%$ \\
Some Positive Impact (4) & 27 & $37.50 \%$ & & 45 & $47.87 \%$ \\
Strong Positive Impact (5) & 34 & $47.22 \%$ & & 5 & $5.32 \%$ \\
Total Responses & 72 & $100.00 \%$ & & 94 & $100.00 \%$ \\
Average & 4.32 & & 3.49 & \\
\hline
\end{tabular}

For the question about the impact that public sector experience has upon the act of leading nonprofit organizations, the null hypothesis is that, when asked what effect public sector experience has upon the act of leading nonprofit organizations, responses from leaders who had public sector experience and those who did not have public sector experience will not differ. The alternative hypothesis is that response rates do differ among the two categories of respondents.

Using the F Max test for homogeneity of variance, I did not reject the null hypothesis regarding equality of variance and assumed the variances were equal. The basic test statistic for variance among the means was $t=6.79$. Using 164 degrees of freedom the critical value at $\alpha=$ 
.05 was 1.98 . Thus, I rejected the null hypothesis regarding equality of means, which suggested the differences between the means probably did not occur by chance. Leaders who did have prior public sector experience believed that public sector experience had a more positive impact upon the ability to lead nonprofit organizations than leaders who did not have public sector experience believed public sector experience would have.

During the qualitative portion of the study, seven of the respondents reported having public sector experience. Two reported a "strong positive impact," four reported "some positive impact," and one reported "neither a positive nor negative impact" for the effect that public sector experience has on leading nonprofit organizations. The majority of the respondents provided positive examples of ways in which their public sector experience improved their ability to lead nonprofit organizations. Table 14 displays quotes that exemplify the respondent's views on the effects of public sector experience. 


\section{Table 14}

Public Sector Experience and Responses to the Effect that Public Sector Experience has on the Ability to Lead Nonprofit Organizations for Seven Qualitative Respondents

\begin{tabular}{|c|c|c|}
\hline Respondent \# & $\begin{array}{l}\text { Years of } \\
\text { Prior } \\
\text { Public } \\
\text { Sector } \\
\text { Experience }\end{array}$ & Response \\
\hline Two & 10 & $\begin{array}{l}\text { There were key moments and critical turning points } \\
\text { where I recognized what made a good leader. A good } \\
\text { leader keeps children central in decision making. Far } \\
\text { fewer leaders do this than I expected. }\end{array}$ \\
\hline Three & 2 & $\begin{array}{l}\text { Because it's a government entity and I didn't learn } \\
\text { anything about decision making. No lessons about } \\
\text { what you should or shouldn't do. It was just a learning } \\
\text { experience. I learned about managing relationships but } \\
\text { it was very early in my career, and I wasn't able to } \\
\text { really watch people manage a department, so I didn't } \\
\text { learn anything in particular. }\end{array}$ \\
\hline Four & $<1$ & $\begin{array}{l}\text { It was much more like the nonprofit sector than say } \\
\text { the corporate law firm. It felt much more like that. I } \\
\text { think that's why it was a good experience. }\end{array}$ \\
\hline Five & 10 & $\begin{array}{l}\text { It has everything to do with record keeping and } \\
\text { patience to deal with bureaucracy and rubbish. It takes } \\
\text { a lot of patience to deal with public sector. } \\
\text { Bureaucracy. Documentation and organization of } \\
\text { information. }\end{array}$ \\
\hline Six & 2 & $\begin{array}{l}\text { My experience as a contractor for [the State] was } \\
\text { very helpful, it gave me a lot of insight into how } \\
\text { government funding works, how government } \\
\text { programming and policy works... And, as a grant } \\
\text { reviewer I learned how to write better proposals. }\end{array}$ \\
\hline Seven & 7 & $\begin{array}{l}\text { In nonprofits, if you are not up to speed on the laws } \\
\text { and how to navigate the red tape, and how to advocate, } \\
\text { and to walk the line, because as a nonprofit unless this } \\
\text { is why you are a nonprofit, you really cannot endorse } \\
\text { one particular thing over another. }\end{array}$ \\
\hline
\end{tabular}


(table continued from previous page)

\begin{tabular}{cl}
\hline Eight & $\begin{array}{l}\text { The biggest thing I learned was that you have to } \\
\text { have that confidence within to lead. Especially in the } \\
\text { graduate setting, with students... In the public sector I } \\
\text { had more practice to be a leader, how to speak in } \\
\text { public, how to give speeches, rhetoric whatever it is } \\
\text { and that impacted me more. }\end{array}$ \\
\hline
\end{tabular}

Positive effects of public sector experience. For respondent four, the public sector provided a positive experience because it felt more like the nonprofit environment than the private sector did. Other respondents expressed that working in the public sector provided valuable experience because they either learned communication and leadership skills or because it helped them to understand the contracting environment.

Respondent two spent 10 years working at a University Foundation before becoming a teacher in the public school system. As a teacher, she found herself in positions of informal authority early in her career. Eventually, she took a position at the district; the position involved training principals and vice-principals. In this role, she was able to witness principals as learners and leaders, which gave her a unique vantage point on the activity of leadership. She stated:

It was both exciting and depressing because the way that leaders said they handled situations was sometimes very different than what I saw when I observed them actually leading at their schools. Instead of accepting responsibility many of them would blame someone who wasn't in the room.

She learned that leaders sometimes have to make tough decisions that could have a negative personal impact and now helps others to develop their leadership capabilities. 
In addition to teaching her how to navigate government bureaucracy, respondent five worked with leaders of nonprofit organizations to establish new Federal grants. This particular experience was beneficial because, from her experiences with executive directors, she learned what worked and what didn't work for nonprofit organizations.

Limited positive effects of private sector experience. Respondent three spent about two years working for the government of New Zealand as an administrative specialist to the social work department. Because the experience was very early in her career she felt she wasn't really provided the opportunity to manage or to observe effective management. Based upon her response, it appears one of the primary lessons she learned from her experience was that she did not want to be a social worker. Thus, she did not seem to feel her public sector experience was positive.

In summary, the public sector did provide many of the respondents with experiences that enhanced their ability to lead nonprofit organizations. Positive examples included opportunities to develop leadership skills and to understand the environment related to government contracting. On the other hand, one respondent who spent a limited amount of time in the public sector did not feel she learned much about leadership.

\section{Nonprofit Versus Private Experience}

In order to determine if individuals rated the impact of their experience in the nonprofit and private sector differently, I compared the responses for the effects that leaders' perceived their prior nonprofit experience had upon their ability to lead nonprofit organizations versus the effects that leaders' perceived their prior private sector experience had upon their ability to lead nonprofit organizations. The null hypothesis is that there is no perceived difference in the means 
between the effects of nonprofit and private sector experience. The alternative hypothesis is that there is a difference in the means between the effects of nonprofit and private sector experience.

Table 15 shows the means and standard deviations for the perception data about the impact that prior experience in the nonprofit/private sectors had upon the respondents' ability to lead a nonprofit organization. For the pair samples $t$-test, the mean was .558 , the standard deviation was .975 , and the standard error of the mean was .100 . The value of $t$ is 5.575 and the critical value at $\alpha=.05$ with $94 d f$ is 2.0 . Thus, I rejected the null hypothesis and concluded that leaders perceived the positive impact of nonprofit sector experience as being higher than the perceived impact of private sector experience on the ability to lead a nonprofit organization.

\section{Table 15}

Perceived Impacts of Prior Sector Experience by Leaders who have Prior Nonprofit and Private Sector Experience

\begin{tabular}{lccc}
\hline \multicolumn{1}{c}{$\mathrm{N}=95$} & Mean & $\begin{array}{c}\text { Std. Deviation } \\
\text { The Mean }\end{array}$ & $\begin{array}{c}\text { Std. Error of } \\
\text { the Mat impact did your prior experience in the }\end{array}$ \\
$\begin{array}{l}\text { Whonprofit sector have upon your ability to lead a } \\
\text { nonprofit organization? }\end{array}$ & 4.71 & 0.56 & 0.06 \\
$\begin{array}{l}\text { What impact did your prior experience in the } \\
\text { private sector have upon your ability to lead a } \\
\text { nonprofit organization? }\end{array}$ & 4.15 & 0.81 & 0.08 \\
\hline
\end{tabular}

\section{Nonprofit Versus Public Experience}

In order to determine if individuals rated the impact of their experience in the nonprofit and public sector differently, I compared the responses for the effects that leaders' perceived their prior nonprofit experience had upon their ability to lead nonprofit organizations versus the 
effects that leaders' perceived their public sector experience had upon their ability to lead nonprofit organizations. The null hypothesis is that there is no difference in the means between the effects of nonprofit and public sector experience. The alternative hypothesis is that there is a difference in the means between the effects of nonprofit and public sector experience.

Table 16 shows the means and standard deviations for the impact that prior experience in the nonprofit/public sectors had upon the respondents' ability to lead a nonprofit organization. For the pair samples $t$-test, the mean was .553 , the standard deviation was .951 , and the standard error of the mean was .139. The value of $t$ is 3.987 and the critical value at $\alpha=.05$ with $46 d f$ is 2.021. Thus, I rejected the null hypothesis. Thus, I rejected the null hypothesis and concluded that leaders perceived the positive impact of nonprofit sector experience as being higher than the perceived impact of public sector experience on the ability to lead a nonprofit organization.

\section{Table 16}

Perceived Impacts of Prior Sector Experience by Leaders who have Nonprofit and Public Sector Experience

\begin{tabular}{lccc}
\hline \multicolumn{1}{c}{$\mathrm{N}=47$} & Mean & Std. Deviation & $\begin{array}{c}\text { Std. Error of } \\
\text { the Mean }\end{array}$ \\
\hline $\begin{array}{l}\text { What impact did your prior experience in the } \\
\text { nonprofit sector have upon your ability to lead a } \\
\text { nonprofit organization? }\end{array}$ & 4.70 & 0.69 & 0.10 \\
$\begin{array}{l}\text { What impact did your prior experience in the } \\
\text { public sector have upon your ability to lead a } \\
\text { nonprofit organization? }\end{array}$ & 4.15 & 0.98 & 0.14 \\
\hline
\end{tabular}




\section{Private Versus Public Experience}

In order to determine if individuals rated the impact of their experience in the private and public sectors as having different impacts, I compared the responses for the effects that leaders' perceived their prior private sector experience had upon their ability to lead nonprofit organizations versus the effects that leaders' perceived their prior public sector experience had upon their ability to lead nonprofit organizations. The null hypothesis is that there is no difference in the means between the effects of private and public sector experience. The alternative hypothesis is that there is a difference in the means between the effects of private and public sector experience.

Table 17 shows the means and standard deviations for the impact that prior experience in the private/public sectors had upon the respondents' ability to lead a nonprofit organization. For the pair samples $t$-test, the mean was -.017, the standard deviation was .930 , and the standard error of the mean was .120 . The value of $t$ is -.139 and the critical value at $\alpha=.05$ with $59 d f$ is 2.021. Thus, I failed to reject the null hypothesis. The probability that the differences between the means of the effects of prior private and public sector experience was due to chance is greater than $5 \%$. 


\section{Table 17}

Perceived Impacts of Prior Sector Experience by Leaders who have Private and Public Sector Experience

\begin{tabular}{lccc}
\hline \multicolumn{1}{c}{$\mathrm{N}=60$} & Mean & Std. Deviation & $\begin{array}{c}\text { Std. Error of } \\
\text { the Mean }\end{array}$ \\
\hline $\begin{array}{l}\text { What impact did your prior experience in the } \\
\text { private sector have upon your ability to lead a } \\
\text { nonprofit organization? }\end{array}$ & 4.28 & 0.78 & 0.10 \\
$\begin{array}{l}\text { What impact did your prior experience in the } \\
\text { public sector have upon your ability to lead a } \\
\text { nonprofit organization? }\end{array}$ & 4.30 & 0.77 & 0.10 \\
\hline
\end{tabular}

Qualitative Discussion on the Results of Different Sector Experience

In order to provide context to the responses from the qualitative participants, I have presented their results to the question, "What impact does sector experience have upon leading a nonprofit organization?" in table 18 below. 


\section{Table 18}

The Eight Qualitative Participants' Perceptions Regarding Impact of Sector Experience on Leading a Nonprofit Organization

\begin{tabular}{|c|c|c|c|}
\hline \multirow[t]{2}{*}{$\begin{array}{l}\text { Respondent } \\
\#\end{array}$} & \multicolumn{3}{|c|}{$\begin{array}{c}\text { Impact of Sector Experience Upon Leading a } \\
\text { Nonprofit Organization }\end{array}$} \\
\hline & Nonprofit & $\begin{array}{l}\text { Private } \\
\end{array}$ & Public \\
\hline 1 & N/A & Strong Positive & N/A \\
\hline 2 & Strong Positive & Some Positive & $\begin{array}{l}\text { Strong Positive } \\
\text { Neither }\end{array}$ \\
\hline 3 & Strong Positive & N/A & $\begin{array}{l}\text { Positive nor } \\
\text { Negative }\end{array}$ \\
\hline 4 & Strong Positive & Some Positive & Some Positive \\
\hline 5 & Strong Positive & Some Positive & Some Positive \\
\hline 6 & Strong Positive & $\begin{array}{l}\text { Neither } \\
\text { Positive nor } \\
\text { Negative }\end{array}$ & Some Positive \\
\hline 7 & Some Positive & $\begin{array}{l}\text { Strong Positive } \\
\text { Neither }\end{array}$ & Strong Positive \\
\hline 8 & Strong Positive & $\begin{array}{l}\text { Positive nor } \\
\text { Negative }\end{array}$ & Some Positive \\
\hline
\end{tabular}

Respondent one, who did not have previous paid experience in the nonprofit sector, did have extensive experience as a volunteer and as a board member with nonprofit organizations prior to founding her organization. In her opinion, basic business skills are important to leading a nonprofit organization; however, she argued that there are fundamental differences between nonprofit and private organizations. For instance, nonprofit leaders must be able to cultivate passion for the mission in other stakeholders, and nonprofits should see other organizations more as partners than competitors. The following statement demonstrates how she thought about the contributions that nonprofit and private sector experience contributes to the act of leading: 
The basic business skills to me are a prerequisite. Having then the nonprofit experience in different roles prior to starting a nonprofit was really helpful. If I had to trade one for the other, I had to have every one of those business expertise from my entire career [sic]. The rest of them I can build on. It is hard to distinguish. In order of priorities you have to have the business skills, but you are not going to be able to launch an idea or engage people without the other skills, without those other leadership skills. Where do those come from? I'm not sure if they're not in our DNA, as well.

So, Respondent one felt leadership is exercised differently in the nonprofit and private/business sectors, and believed that experience in the private sector helped develop business skills. By contrast, she felt the specific people skills necessary to effectively lead nonprofit organizations were largely innate.

For respondent number two, prior nonprofit and public sector experience were more helpful than experience in the private sector because she had less experience in the private sector. She couldn't think of a strong mentor or supporter in the private sector whose style resonated with her beliefs. In the public sector she was exposed to leaders she respected, which provided her more opportunities to shape her personal beliefs and philosophy.

Respondent number three felt her nonprofit experience was more beneficial than her public sector experience because she was exposed to more challenges in the nonprofit sector. She stated:

It was the number of challenges that I faced very early on in my career and continually through it. So every position I had was an accelerated learning experience and that was about where I started and the things that I moved into. I like challenging situations. I 
like going into something that needs sorting out and making it work. Every one of those (nonprofit) positions that I've had has been an accelerated learning experience... It would have been much harder to step into this role if I hadn't had all of those experiences along the way.

She felt the breadth of challenging experiences she gained in the nonprofit sector was more helpful to her than the fact that the experience was in the nonprofit sector specifically.

Respondent number four was also provided with specific instances early in her nonprofit career that provided her with the opportunity to grow as a leader. Speaking of her nonprofit experience, she said:

I had the sink or swim opportunity to be flexible and to create things and advance my own ideas like every five years. Create the coalition out of nothing. That to me is what the nonprofit sector did for my career. And I don't say you can't do it. If I was at a corporate law firm I don't know how you do something like that but in the nonprofit sector I had that freedom, that flexibility. That ability to reinvent, grow, and so that is what I think makes the nonprofit experience so important for leadership. That's what it comes down to me.

Respondent four felt like the growth opportunities she experienced early in her nonprofit career may not have been available in a corporate setting.

Respondent five felt that nonprofit leadership experience is more helpful than experience in the other sectors because of the relative value of the consumer: 
For me, that (nonprofit) experience taught me about putting our consumers first.

Whether our records are clean or we have enough money or not our focus and our goal is to treat our clients. They're our focus. They're the center of our universe. I feel that working with them and supporting and creating an environment where they flourish. That trumps anything else. You can always get out of trouble financially, you can always do records. You can't undo damage to people with disabilities. Creating the environment where they are the center of the universe. That's why we come to work every day.

She felt her prior nonprofit, rather than private or public, developed her leadership philosophy.

Respondent six felt nonprofit experience was more helpful than experience in other sectors. However, she also felt her public sector experience had more of a direct application to the nonprofit sector than her private sector experience because she felt the private and nonprofit sector models are much different. While discussing the difference between the private and nonprofit business models she said, "It's completely different from the way government contracting in the nonprofit sector works, it's completely different from understanding the life cycle of fundraising and some of the other things that go on."

Respondent seven felt that private sector experience is very important to one's ability to lead a nonprofit organization. In her opinion, one should not spend their entire career in the nonprofit sector:

If you start off in nonprofit, it's not a good idea... There's also this mentality. Go along to get along kind of thing in the nonprofit world and that's BS... It's still competitive, and nonprofits have to be competitive. 
In the context of the interview, respondent seven's remarks seemed to be heavily influenced by her perception that the organization was not run well before she became the executive director. This assessment was based on the fact that the organization was having financial problems before she became the organization's leader.

Respondent eight felt the relative difference in leadership experiences was largely personal. First, he was not in direct contact with the leadership at the corporation he worked at. Second, he felt the small nonprofit environment was more conducive to his personality than a larger corporate style-structure:

I navigated more toward a private small setting where I felt like I could impact more qualitatively people and the programs that we do. I never see myself at an organization of more than 20 people and I like to be hands-on. It's more of my own personal experience that led into that. The place where I'm working now is the only place where I want to be the executive director.

Respondent eight's experience in different sectors seemed to confirm what type of organization he wanted to be a part of and lead.

\section{Research Question Four}

Research question four-How much of the variation in measures of financial performance among California nonprofit organizations' is associated with the prior sector experience of leaders? - was examined utilizing data obtained from the surveys and the 990 forms submitted to the IRS. Because I used financial data from 2011, four years before the study, I only included organizations associated with those respondents who had led their 
organizations for four or more years in the analysis. Regressions for the models include individual and organizational demographics as independent variables.

\section{Operating Margin}

The hypothesis for this section was as follows: a leader's prior years of experience in the nonprofit sector and his or her years of experience in the private and public sectors would have an impact on the leader's organization's operating margin. According to the regression model summarized in Table 19, the probabilities that the effects of years of experience in the nonprofit, private, and public sectors occurred by chance, respectively, were $66.4 \%, 21.2 \%$, and $62.5 \%$ respectively; in other words, none of the three years-of-experience variables proved to be statistically significant 


\section{Table 19}

Stepwise Multiple Regression Model for 2013 Operating Margin

\begin{tabular}{lrrr}
\hline \multicolumn{1}{c}{ Variable } & Coefficient & \multicolumn{1}{c}{$\mathrm{t}$} & $\mathrm{P}>\mathrm{t}$ \\
\hline Organization's age in years & $1,561.16$ & 2.03 & 0.046 \\
Respondents Age & 537.50 & 0.44 & 0.663 \\
Male & $29,868.16$ & 1.12 & 0.268 \\
White & $3,739.73$ & 0.08 & 0.934 \\
Some College & $-17,057.25$ & -0.35 & 0.728 \\
Masters & $-31,243.19$ & -0.98 & 0.328 \\
Doctoral & $-25,982.17$ & -0.58 & 0.564 \\
Years in current position & $-1,045.55$ & -0.48 & 0.633 \\
Prior years at organization & $-4,473.45$ & -1.28 & 0.204 \\
Prior years of nonprofit experience & -841.31 & -0.44 & 0.664 \\
Years experience in private sector & $-1,928.16$ & -1.26 & 0.212 \\
Years experience in public sector & $1,222.44$ & 0.49 & 0.625 \\
Arts, Culture, Humanities & $163,517.47$ & 2.65 & 0.010 \\
Education & $33,445.41$ & 0.61 & 0.543 \\
Environment and Animals & $18,975.87$ & 0.30 & 0.765 \\
Health & $21,466.82$ & 0.44 & 0.663 \\
Human Services & $27,990.98$ & 0.60 & 0.549 \\
International, Foreign Affairs & $11,927.28$ & 0.12 & 0.906 \\
Constant & $-44,004.54$ & -0.54 & 0.593 \\
\hline Note: F = 1.118; probability $>\mathrm{F}=649 ;$ Overall $\mathrm{R}^{2}=0.195$ & & \\
\hline
\end{tabular}

Although none of the three variables had a significant impact at the $95 \%$ confidence level, I ran an additional restricted model to see if the three variables together have a significant impact upon the organization's operating margin. The overall $\mathrm{R}^{2}$ model for the restricted model was .178. The value of $\mathrm{F}$ for the difference in the significance of the two models is 0.58 . The critical value of $F$ at $\alpha=.05$ and $(3,83)$ is 3.15 . Thus, the probability that the difference between the two models is due to chance is greater than 5\%. Adding the leaders' years of experience in each of the three sectors into the models did not have a significant impact upon the operating margin of the organizations. 
After analyzing the model that used operating margin as the dependent variable, I ran an additional model utilizing the change in the organizations' operating margins from 2011 to 2013 (See Table 20). The hypothesis was as follows: prior years of experience in the nonprofit sector and years of experience in the private and public sectors would have an impact on the change in the leader's organization's operating margin from 2011 to 2013. According to the regression model I ran in SPSS, the probabilities that the effects of years of experience in the nonprofit, private, and public sectors occurred by chance, respectively, were $66.4 \%, 21.2 \%$, and $62.5 \%$ respectively. As a result, years of experience did not have a significant impact upon operating margin at $\mathrm{p}=.05$.

\section{Table 20}

Stepwise Multiple Regression for Change in Operating Margin from 2011 to 2013

\begin{tabular}{lrrr}
\hline \multicolumn{1}{c}{ Variable } & Coefficient & \multicolumn{1}{c}{$\mathrm{t}$} & $\mathrm{P}>\mathrm{t}$ \\
\hline Organization's age in years & $3,498.12$ & 2.03 & 0.046 \\
Respondents Age & $1,204.39$ & 0.44 & 0.663 \\
Male & $66,928.56$ & 1.12 & 0.268 \\
White & $8,388.14$ & 0.08 & 0.934 \\
Some College & $-38,214.59$ & -0.35 & 0.728 \\
Masters & $-70,009.99$ & -0.98 & 0.328 \\
Doctoral & $-58,227.18$ & -0.58 & 0.563 \\
Years in current position & $-2,343.01$ & -0.48 & 0.633 \\
Prior years at organization & $-10,023.43$ & -1.28 & 0.204 \\
Prior years of nonprofit experience & $-1,884.68$ & -0.44 & 0.664 \\
Years experience in private sector & $-4,320.75$ & -1.26 & 0.212 \\
Years experience in public sector & $2,739.62$ & 0.49 & 0.625 \\
Arts, Culture, Humanities & $366,383.21$ & 2.65 & 0.010 \\
Education & $74,937.74$ & 0.61 & 0.543 \\
Environment and Animals & $42,527.33$ & 0.30 & 0.765 \\
Health & $48,096.01$ & 0.44 & 0.663 \\
Human Services & $62,721.96$ & 0.60 & 0.549 \\
International, Foreign Affairs & $26,727.72$ & 0.12 & 0.906 \\
Constant & $-98,609.05$ & -0.54 & 0.593 \\
\hline Note: F 1.118; probability $>$ F & & &
\end{tabular}

Note: $\mathrm{F}=1.118 ;$ probability $>\mathrm{F}=.649 ;$ Overall $\mathrm{R}^{2}=0.195$ 
Although none of the three variables had a significant impact at the $\mathrm{p}=.05$ level, I ran an additional restricted model to see if the three variables together have a significant impact upon the organization's operating margin. The overall $\mathrm{R}^{2}$ model for the restricted model was .178. The value of $\mathrm{F}$ for the difference in the significance of the two models is 0.58 . The critical value of $\mathrm{F}$ at $\alpha=.05$ and $(3,83)$ is 3.15 . Thus, the probability that the difference between the two models is due to chance is greater than 5\%. Adding the leaders' years of experience in each of the three sectors did not have a significant impact upon the change in operating margin from 2011 to 2013.

\section{Debt to Equity}

The hypothesis for this section was as follows: prior years of experience in the nonprofit sector and years of experience in the private and public sectors would have an impact on the organization's debt to equity ratio. According to the regression model summarized in Table 21, the probabilities that the effects of years of experience in the nonprofit, private, and public sectors occurred by chance, respectively, were $63.7 \%, 46.9 \%$, and $70.3 \%$ respectively. 
Table 21

Stepwise Multiple Regression Model for 2013 Debt to Equity

\begin{tabular}{lccc}
\hline \multicolumn{1}{c}{ Variable } & Coefficient & $\mathrm{t}$ & $\mathrm{P}>\mathrm{t}$ \\
\hline Organization's age in years & -0.04 & -0.81 & 0.421 \\
Respondents Age & 0.10 & 1.30 & 0.198 \\
Male & -1.41 & -0.80 & 0.426 \\
White & 3.68 & 1.25 & 0.214 \\
Some College & -1.30 & -0.41 & 0.683 \\
Masters & -1.42 & -0.69 & 0.495 \\
Doctoral & -0.30 & -0.10 & 0.922 \\
Years in current position & 0.12 & 0.80 & 0.429 \\
Prior years at organization & -0.04 & -0.17 & 0.866 \\
Prior years of nonprofit experience & -0.06 & -0.47 & 0.637 \\
Years experience in private sector & -0.08 & -0.73 & 0.469 \\
Years experience in public sector & -0.06 & -0.38 & 0.703 \\
Arts, Culture, Humanities & 0.22 & 0.06 & 0.956 \\
Education & -1.12 & -0.31 & 0.755 \\
Environment and Animals & -1.88 & -0.46 & 0.645 \\
Health & -3.84 & -1.21 & 0.232 \\
Human Services & -0.13 & -0.04 & 0.967 \\
International, Foreign Affairs & -4.03 & -0.63 & 0.534 \\
Constant & -4.74 & -0.86 & 0.392 \\
\hline Note: F = 0.620; probability $>$ F = .873; Overall $\mathrm{R}^{2}=0.124$ & \\
\hline
\end{tabular}

Although none of the three variables had a significant impact at the $95 \%$ confidence level, I ran an additional restricted model to see if the three variables together have a significant impact upon the organization's debt to equity ratio. The overall $\mathrm{R}^{2}$ model for the restricted model was .116. The value of $\mathrm{F}$ for the difference in the significance of the two models is 0.24. The critical value of $F$ at $\alpha=.05$ and $(3,79)$ is 3.15 . Thus, the probability that the difference between the two models is due to chance is greater than 5\%. Adding the leaders' years of experience in each of the three sectors into the models did not have a significant impact upon the debt to equity ratio of the organizations. 
After analyzing the model for operating margin I ran an additional model utilizing the change in the organizations' debt to equity ratio from 2011 to 2013 (See Table 22). The hypothesis was as follows: prior years of experience in the nonprofit sector and years of experience in the private and public sectors would have an impact on the change in the organization's debt to equity from 2011 to 2013 . According to the regression model I ran in SPSS, the probabilities that the effects of years of experience in the nonprofit, private, and public sectors occurred by chance, respectively, were $91.5 \%, 79.1 \%$, and $46.1 \%$ respectively. As a result, years of experience did not have a significant impact upon debt to equity at $p=.05$.

\section{Table 22}

Stepwise Multiple Regression for Change in Operating Margin from 2011 to 2013

\begin{tabular}{lccc}
\hline \multicolumn{1}{c}{ Variable } & Coefficient & $\mathrm{t}$ & $\mathrm{P}>\mathrm{t}$ \\
\hline Organization's age in years & -0.14 & -1.03 & 0.308 \\
Respondents Age & -0.05 & -0.22 & 0.826 \\
Male & -0.46 & -0.09 & 0.927 \\
White & 5.95 & 0.72 & 0.476 \\
Some College & -1.97 & -0.22 & 0.827 \\
Masters & 5.37 & 0.92 & 0.360 \\
Doctoral & 2.20 & 0.26 & 0.796 \\
Years in current position & 0.09 & 0.21 & 0.834 \\
Prior years at organization & 0.05 & 0.08 & 0.934 \\
Prior years of nonprofit experience & -0.04 & -0.11 & 0.915 \\
Years experience in private sector & -0.08 & -0.27 & 0.791 \\
Years experience in public sector & -0.34 & -0.74 & 0.461 \\
Arts, Culture, Humanities & 0.30 & 0.03 & 0.978 \\
Education & 1.12 & 0.11 & 0.912 \\
Environment and Animals & 5.59 & 0.49 & 0.628 \\
Health & 6.88 & 0.76 & 0.447 \\
Human Services & -3.57 & -0.42 & 0.674 \\
International, Foreign Affairs & -2.57 & -0.14 & 0.888 \\
Constant & 3.25 & 0.21 & 0.835 \\
\hline Note: F = 0.368; probability $>$ F $=.990 ;$ Overall $\mathrm{R}^{2}=0.077$ & & \\
\hline
\end{tabular}


Although none of the three variables had a significant impact at the $95 \%$ confidence level, I ran an additional restricted model to see if the three variables together have a significant impact upon the organization's operating margin. The overall $\mathrm{R}^{2}$ model for the restricted model was .07. The value of $F$ for the difference in the significance of the two models is 0.20 . The critical value of $F$ at $\alpha=.05$ and $(3,79)$ is 3.15 . Thus, the probability that the difference between the two models is due to chance is greater than 5\%. Adding the leaders' years of experience in each of the three sectors did not have a significant impact upon the change in debt to equity from 2011 to 2013.

\section{Total Revenue}

The hypothesis for this section was as follows: prior years of experience in the nonprofit sector and years of experience in the private and public sectors would have an impact on the organization's total revenue. According to the regression model summarized in Table 23, the probabilities that the effects of years of experience in the nonprofit, private, and public sectors occurred by chance, respectively, were $27.3 \%, 82.5 \%$, and $42.2 \%$ respectively. 
Table 23

Stepwise Multiple Regression Model for 2013 Total Revenue

\begin{tabular}{lrrc}
\hline \multicolumn{1}{c}{ Variable } & \multicolumn{1}{c}{ Coefficient } & \multicolumn{1}{c}{$\mathrm{t}$} & $\mathrm{P}>\mathrm{t}$ \\
\hline Organization's age in years & $126,832.99$ & 1.93 & 0.056 \\
Respondents Age & $42,626.88$ & 0.41 & 0.681 \\
Male & $518,769.94$ & 0.24 & 0.814 \\
White & $-902,697.80$ & -0.25 & 0.805 \\
Some College & $-907,893.53$ & -0.23 & 0.815 \\
Masters & $5,183,582.77$ & 2.01 & 0.048 \\
Doctoral & $696,539.11$ & 0.19 & 0.850 \\
Years in current position & $-229,412.73$ & -1.48 & 0.142 \\
Prior years at organization & $-413,753.04$ & -1.40 & 0.163 \\
Prior years of nonprofit experience & $-177,888.40$ & -1.10 & 0.273 \\
Years experience in private sector & $25,984.27$ & 0.22 & 0.825 \\
Years experience in public sector & $-167,242.81$ & -0.81 & 0.422 \\
Arts, Culture, Humanities & $-524,230.88$ & -0.10 & 0.918 \\
Education & $2,164,571.07$ & 0.48 & 0.634 \\
Environment and Animals & $766,530.51$ & 0.16 & 0.870 \\
Health & $751,697.48$ & 0.18 & 0.855 \\
Human Services & $3,123,156.86$ & 0.82 & 0.415 \\
International, Foreign Affairs & $2,520,919.36$ & 0.29 & 0.771 \\
Constant & $11,709.04$ & 0.00 & 0.999 \\
\hline Note: F = 0.689; probability $>\mathrm{F}=.814 ;$ & Overall $\mathrm{R}^{2}=0.116$ & \\
\hline
\end{tabular}

Although none of the three variables had a significant impact at the $95 \%$ confidence level, I ran an additional restricted model to see if the three variables together have a significant impact upon the organization's total revenue. The overall $\mathrm{R}^{2}$ model for the restricted model was .093. The value of $\mathrm{F}$ for the difference in the significance of the two models is 0.82 . The critical value of $\mathrm{F}$ at $\alpha=.05$ and $(3,95)$ is 3.15 . Thus, the probability that the difference between the two models is due to chance is greater than 5\%. Adding the leaders' years of experience in each of the three sectors into the models did not have a significant impact upon the total revenue of the organizations. 
After analyzing the model for total revenue I ran an additional model utilizing the change in the organizations' revenue from 2011 to 2013 (See Table 24). The hypothesis was as follows: prior years of experience in the nonprofit sector and years of experience in the private and public sectors would have an impact on the change in the organization's revenue from 2011 to 2013. According to the regression model I ran in SPSS, the probabilities that the effects of years of experience in the nonprofit, private, and public sectors occurred by chance, respectively, were $47.6 \%, 66.1 \%$, and $14.2 \%$ respectively. As a result, years of experience did not have a significant impact upon change in total revenue at $\mathrm{p}=.05$.

\section{Table 24}

Stepwise Multiple Regression for Change in Total Revenue from 2011 to 2013

\begin{tabular}{lccc}
\hline \multicolumn{1}{c}{ Variable } & Coefficient & $\mathrm{t}$ & $\mathrm{P}>\mathrm{t}$ \\
\hline Organization's age in years & -0.01 & -1.90 & 0.061 \\
Respondents Age & 0.00 & -0.09 & 0.929 \\
Male & 0.04 & 0.19 & 0.848 \\
White & -0.48 & -1.26 & 0.211 \\
Some College & -0.44 & -1.10 & 0.272 \\
Masters & -0.24 & -0.91 & 0.367 \\
Doctoral & -0.47 & -1.22 & 0.226 \\
Years in current position & -0.02 & -1.19 & 0.237 \\
Prior years at organization & -0.03 & -1.02 & 0.312 \\
Prior years of nonprofit experience & -0.01 & -0.72 & 0.476 \\
Years experience in private sector & -0.01 & -0.44 & 0.661 \\
Years experience in public sector & -0.03 & -1.48 & 0.142 \\
Arts, Culture, Humanities & -0.77 & -1.46 & 0.147 \\
Education & -0.08 & -0.18 & 0.859 \\
Environment and Animals & -0.66 & -1.37 & 0.174 \\
Health & 0.08 & 0.19 & 0.853 \\
Human Services & -0.21 & -0.52 & 0.605 \\
International, Foreign Affairs & -0.69 & -0.77 & 0.442 \\
Constant & 2.10 & 2.95 & 0.004 \\
\hline Note: F = 1.247; probability $>\mathrm{F}=.242 ;$ & Overall R ${ }^{2}=0.191$ & \\
\hline
\end{tabular}

Note: $\mathrm{F}=1.247$; probability $>\mathrm{F}=.242 ;$ Overall $\mathrm{R}^{2}=0.191$ 
Although none of the three variables had a significant impact at the $95 \%$ confidence level, I ran an additional restricted model to see if the three variables together have a significant impact upon the organization's operating margin. The overall $\mathrm{R}^{2}$ model for the restricted model was .169. The value of $\mathrm{F}$ for the difference in the significance of the two models is 0.86 . The critical value of $F$ at $\alpha=.05$ and $(3,95)$ is 3.15 . Thus, the probability that the difference between the two models is due to chance is greater than 5\%. Adding the leaders' years of experience in each of the three sectors did not have a significant impact upon the change in total revenue from 2011 to 2013.

\section{Revenue Diversification}

The hypothesis for this section was as follows: prior years of experience in the nonprofit sector and years of experience in the private and public sectors would have an impact on the organization's revenue diversification. According to the regression model summarized in Table 25 , the probabilities that the effects of years of experience in the nonprofit, private, and public sectors occurred by chance, respectively, were $80.1 \%, 26.7 \%$, and $41.2 \%$ respectively. 


\section{Table 25}

Stepwise Multiple Regression Model for 2013 Revenue Diversification

\begin{tabular}{lrrc}
\hline \multicolumn{1}{c}{ Variable } & Coefficient & \multicolumn{1}{c}{$\mathrm{t}$} & $\mathrm{P}>\mathrm{t}$ \\
\hline Organization's age in years & 0.00 & 1.87 & 0.065 \\
Respondents Age & 0.00 & 0.99 & 0.323 \\
Male & -0.01 & -0.11 & 0.916 \\
White & -0.04 & -0.39 & 0.700 \\
Some College & -0.04 & -0.39 & 0.697 \\
Masters & -0.08 & -1.14 & 0.258 \\
Doctoral & -0.13 & -1.27 & 0.206 \\
Years in current position & 0.00 & -0.33 & 0.743 \\
Prior years at organization & 0.00 & -0.02 & 0.982 \\
Prior years of nonprofit experience & 0.00 & 0.25 & 0.801 \\
Years experience in private sector & 0.00 & -1.12 & 0.267 \\
Years experience in public sector & 0.01 & 0.82 & 0.412 \\
Arts, Culture, Humanities & 0.26 & 1.84 & 0.069 \\
Education & -0.06 & -0.48 & 0.630 \\
Environment and Animals & 0.11 & 0.81 & 0.421 \\
Health & -0.03 & -0.29 & 0.776 \\
Human Services & -0.01 & -0.05 & 0.962 \\
International, Foreign Affairs & -0.33 & -1.36 & 0.177 \\
Constant & 0.17 & 0.89 & 0.378 \\
\hline Note: F = 1.139; probability $>\mathrm{F}=.671 ;$ Overall $\mathrm{R}^{2}=0.177$ & \\
\hline
\end{tabular}

Although none of the three variables had a significant impact at the $95 \%$ confidence level, I ran an additional restricted model to see if the three variables together have a significant impact upon the organization's revenue diversification. The overall $\mathrm{R}^{2}$ model for the restricted model was .155. The value of $\mathrm{F}$ for the difference in the significance of the two models is 0.85 . The critical value of $\mathrm{F}$ at $\alpha=.05$ and $(3,95)$ is 3.15 . Thus, the probability that the difference between the two models is due to chance is greater than 5\%. Adding the leaders' years of experience in each of the three sectors into the models did not have a significant impact upon the revenue diversification of the organizations. 
After analyzing the model for revenue diversification I ran an additional model utilizing the change in the organizations' revenue diversification from 2011 to 2013 (See Table 26). The hypothesis was as follows: prior years of experience in the nonprofit sector and years of experience in the private and public sectors would have an impact on the change in the organization's revenue diversification from 2011 to 2013. According to the regression model I ran in SPSS, the probabilities that the effects of years of experience in the nonprofit, private, and public sectors occurred by chance, respectively, were $41.8 \%, 93.6 \%$, and $70.4 \%$ respectively. As a result, years of experience did not have a significant impact upon change in revenue diversification at $\mathrm{p}=.05$.

\section{Table 26}

Stepwise Multiple Regression for Change in Revenue Diversification from 2011 to 2013

\begin{tabular}{lccc}
\hline \multicolumn{1}{c}{ Variable } & Coefficient & $\mathrm{t}$ & $\mathrm{P}>\mathrm{t}$ \\
\hline Organization's age in years & 0.02 & 0.18 & 0.859 \\
Respondents Age & -0.02 & -0.17 & 0.870 \\
Male & -2.25 & -0.76 & 0.449 \\
White & -2.68 & -0.55 & 0.586 \\
Some College & -13.39 & -2.57 & 0.012 \\
Masters & -2.59 & -0.75 & 0.458 \\
Doctoral & -5.07 & -1.03 & 0.308 \\
Years in current position & 0.23 & 1.10 & 0.273 \\
Prior years at organization & 0.35 & 0.88 & 0.383 \\
Prior years of nonprofit experience & 0.18 & 0.81 & 0.418 \\
Years experience in private sector & 0.01 & 0.08 & 0.936 \\
Years experience in public sector & 0.11 & 0.38 & 0.704 \\
Arts, Culture, Humanities & -14.51 & -2.12 & 0.036 \\
Education & 1.93 & 0.32 & 0.752 \\
Environment and Animals & 1.65 & 0.26 & 0.793 \\
Health & 1.53 & 0.28 & 0.782 \\
Human Services & 1.51 & 0.29 & 0.770 \\
International, Foreign Affairs & 1.93 & 0.17 & 0.868 \\
Constant & 0.90 & 0.10 & 0.922 \\
\hline Note: F 1 314; probability $>$ F & $803 ; 0 v e r a 11 \mathrm{R}^{2}$ & 0.199 & \\
\hline
\end{tabular}

Note: $\mathrm{F}=1.314$; probability $>\mathrm{F}=.803$; Overall $\mathrm{R}^{2}=0.199$ 
Although none of the three variables had a significant impact at the $95 \%$ confidence level, I ran an additional restricted model to see if the three variables together have a significant impact upon the organization's operating margin. The overall $\mathrm{R}^{2}$ model for the restricted model was .192. The value of $\mathrm{F}$ for the difference in the significance of the two models is 0.28 . The critical value of $F$ at $\alpha=.05$ and $(3,95)$ is 3.15 . Thus, the probability that the difference between the two models is due to chance is greater than 5\%. Adding the leaders' years of experience in each of the three sectors did not have a significant impact upon the change in revenue diversification from 2011 to 2013.

The model for the change in total revenue from 2011 to 2013 had the highest $\mathrm{F}$ value of 1.247. However, the critical value of $F$ at $\alpha=.05(18,95)$ is 1.84 . Thus, none of the models established a relationship between the independent variables and the dependent variables at $\mathrm{p}=$ .05. Moreover, only three of the independent variables showed a statistically significant relationship with the dependent variables in any of the models. Organization age in years and whether the organization was in the Arts, Culture, and Humanities industry both had a significant positive impact upon operating margin and the change in operating margin from 2011 to 2013. Organization's age in years also had a positive impact upon total revenue; however, with a $\mathrm{t}$ value of 1.93 , the variable did not quite meet the threshold to be statistically significant at $\mathrm{p}=$ .05. The only variables related to individual demographics that a statistically significant relationship with any of the dependent variables were related to education. Organizations whose leaders had a Masters degree had more revenue than other organizations in 2013 and organizations whose leader had Some College showed a decrease in revenue diversification from 2011 to 2013. Bearing in mind that the $\mathrm{F}$ values of none of the models were significant at $\mathrm{p}=$ 
.05 and that very few of the independent variables were statistically significant across models, it does not seem like any of the demographics related to the organizations or to the primary paid leaders of the organizations had a significant impact upon the financial results of the organizations in general.

\section{Summary of Results}

The study provided several findings related to the effects that leaders of California nonprofits perceived different sector experience had on their ability to lead nonprofit organizations. First, the findings suggest that there is no singular career path toward becoming a leader of a nonprofit organization. The majority of leaders did have experience in either the nonprofit or private sector; however, almost $40 \%$ did not have prior paid experience in the nonprofit sector before they came to the organizations they led at the time of the study.

Second, the participants in the study believed that prior nonprofit experience had a stronger positive impact than experience in the private or public sectors on the act of leading nonprofit organizations. This may be because leadership is exercised differently in the nonprofit sector than other sectors and because some of the functions that leaders fulfill in the nonprofit sector are different than those that leaders in other sectors fulfill. However, participants also revealed that experience in the private and public sectors provided helpful experience in learning how to run competitive organizations and manage grants, which provide an important source of revenue for many nonprofit organizations. Moreover, some of the qualitative respondents felt their prior experience in the private and public sectors may not have been as helpful as experience in the nonprofit sectors because they were not put in leadership positions in the private and public sectors. The study did not find any evidence that the leaders' prior years of 
experience in any of the three primary sectors had a significant impact upon the financial results of the organizations they led.

The qualitative results indicated that, while every sector offered some degree of meaningful experience, leaders can gain many of the skills necessary to exercise effective leadership on the job. Thus, hiring leaders who do not have prior nonprofit experience may be one effective solution in confronting the leadership deficit facing the nonprofit sector. Although the study offers some important conclusions, additional research is needed on how breadth and length of experience in different sectors impacts effective leadership and how prior sector experience impacts effective leadership using other measures of leadership effectiveness than the perceptions of the leaders themselves. 


\section{Chapter 5}

\section{Discussion}

The results of the study suggest two things. First, there is considerable variation in the amount of experience that leaders of nonprofit organizations who participated in the study have in each of the three sectors. Second, although leaders do, on average, perceive that experience in the nonprofit sector has a stronger positive impact than experience in the private and public sectors on the act of leading nonprofit organizations, this impact may be moderated by the extent and breadth of prior sector experience. The study, however, did not find any relationship between prior sector experience of a nonprofit organization's key paid leader and indicators of the financial health of the organization. In this final chapter I will present a summary of this study that includes brief reviews of the statement of the problem and purpose of the study sections, the study's methodology, and the study's findings. I also will discuss some practical implications and limitations of the study, followed by recommendations for additional research.

\section{Problem Statement/Purpose}

Some studies suggest the nonprofit sector may be facing a leadership deficit it is not prepared to confront (Tierney, 2006, Froelich, McKee, \& Ruthge, 2011, Nonprofit HR Solutions, 2013). Such a deficit could have negative implications for society due to the sector's impact upon the economy and its role in community building (Salamon, 2012, Pettijohn, 2013, CalNonprofits, 2014). While a large number of people ages 50 to 70 who did not have previous nonprofit experience may be interested in employment within the nonprofit sector (Met Life and Civic Ventures, 2005), studies that examine the sector experience of nonprofit leaders are limited (Harrow \& Mole, 2005, Suarez, 2009). Moreover, I was not able to find any studies that 
examined the impact of prior sector experience upon nonprofit leadership. This study was designed to document the sector experience of a relatively large sample $(n=188)$ of nonprofit leaders and to evaluate the impact that prior sector experience has on the ability to lead nonprofit organizations.

\section{Review of the Methodology}

The study employed a mixed-methods design to answer the research questions that are reiterated in the summary of the findings below. First, I electronically distributed a survey to paid leaders of $10 \%$ of nonprofit organizations in California; the survey asked about survey participants' sector experience, as well as their perceptions of the impact of sector experience upon nonprofit leadership.

After I compiled the quantitative responses, I calculated the number of respondents who had experience in each of the three sectors and the number that had different combinations of sector experience. I then calculated participants' average of years of experience in a particular sector for those who had worked in that sector. I also compared the perceptions of the relative impact of experience in different sectors by comparing the mean scores of the effects of prior sector experience using paired sample t-tests at the $95 \%$ confidence level.

After doing the procedures listed above, I performed multiple regression analysis. More specifically, I utilized years of experience in each sector along with other independent variables to determine if the leaders' years of experience in each sector helped explain the variation in measures of the financial health of the different organizations the different types of participants led. 
After compiling the quantitative results, I interviewed eight leaders of nonprofit organizations who had experience in multiple sectors to gain further insight into the impact that their prior sector experience had upon their ability to lead nonprofit organizations. I selected interviewees from those who indicated while responding to the survey that they would be willing to be interviewed. From this group, interviewees were selected based on whether their particular quantitative scores were aligned with the aggregated quantitative results.

\section{Summary of the Findings}

\section{Research Question One}

The first research question was: In California, what percent of chief executive officers (CEOs) and executive directors (EDs) of 501 (c)(3) public charities who filed IRS form 990s had each of the following types of experience prior to working at their current organization: only nonprofit, only government, only corporate, nonprofit and government, nonprofit and corporate, government and corporate, or experience in all three sectors?

The findings suggest that there is no singular career path toward becoming a leader of a nonprofit organization. What was particularly noteworthy was that $85 \%$ of respondents had some prior experience in the private sector, followed by $61 \%$ with prior experience in the nonprofit sector, and $40 \%$ with experience in the public sector. The fact that $61 \%$ of respondents had prior paid experience in the nonprofit sector means that $39 \%$ of respondents did not have prior paid experience in the nonprofit sector, which is similar to Harrow and Mole's (2005) findings, which indicated $40 \%$ of respondents, arrived in the nonprofit sector later in their careers. However, the number of respondents with prior nonprofit experience was substantially lower than a prior study of San Francisco Bay area executives (Suarez, 2009), which suggested 
that leaders from other sectors often have unpaid experience with nonprofit organizations. The finding from this study did indicate that many leaders who have not served as paid employees of nonprofit organizations have gained experience in the sector by serving as volunteers and/or Board members with nonprofit organizations. It is important to note that, however, that if I included prior experience at the respondents' current organization, which some respondents indicated was unpaid, the number of respondents who had prior nonprofit experience prior to assuming their current position increases from $61 \%$ to $76 \%$.

\section{Research Question Two}

The second research question was: For those leaders of California nonprofit organizations who did have experience in each sector, what was the average number of years that leaders had worked in each sector?

The average years of private sector experience for current nonprofit leaders who had private sector experience was slightly higher than average years of nonprofit sector experience for leaders who had nonprofit sector experience, 13.8 years versus 13.3 years. On the other hand, leaders who had public sector experience average 8.7 years of experience in the public sector. It's important to note that, the standard deviation for private sector experience was higher than the standard deviation for nonprofit experience-11.4 versus 9.3. These data indicate substantial variation in the years of private sector experience that respondents had prior to assuming their positions.

For the seven of the eight qualitative respondents who had private sector experience, one respondent's experience consisted of two summer internships and another had two years of experience which he said he was largely insulated from the organization's leadership. One of the 
seven qualitative respondents who had prior public sector experience spent less than one year in the public sector. While the quantitative results do show that a substantial number of respondents did have experience in multiple sectors, for some respondents, experience was limited in terms of the time they spent working in and the amount of management experience they had in different sectors.

\section{Research Question Three}

The third research question was: What impact do leaders of California nonprofit organizations perceive their experience in each of the three sectors had on their ability to lead nonprofit organizations; do those people who had experience in a particular sector value experience in that sector differently than those who had not had experience in that particular sector?

The majority of respondents who had experience in a particular sector felt their experience did have a positive impact upon their ability to lead a nonprofit organization. However, respondents felt experience in the nonprofit sector was more helpful than experience in the private and public sectors. On a five-point Likert scale, the effects that prior experience had on the ability to lead a nonprofit organization was rated at an average of 4.71 for respondents with prior nonprofit organization experience, 4.35 for prior private sector experience, and 4.32 for prior public sector experience. It is interesting to note that respondents who did not have prior nonprofit experience actually believed that prior nonprofit experience would be more helpful than leaders who did have prior nonprofit experience believed their experience was. Conversely, leaders who did have experience in the private and public sectors felt their experience was more helpful than leaders who did not have experience in the private and public 
sectors perceived that such experience would have been. The quantitative results of the study found that, while experience in all three sectors has a positive impact, experience in the nonprofit sector has a more positive impact than experience in the private and public sectors upon the act of leading nonprofit organizations. The qualitative results suggest that the impact of prior sector experience may also be affected by the amount and breadth of experience and whether or not that experience was in a similar industry.

Nonprofit versus private sector experience. When I compared the relative means of the perceived impacts of prior nonprofit experience and private sector experience for all respondents who had experience in both sectors, the mean for the impact of prior nonprofit experience was 4.71 and for the impact of prior private sector experience was 4.15. The difference in means was significant at the $95 \%$ confidence interval, which suggests that leaders do rate their prior nonprofit experience as being more helpful than prior private sector experience.

Although many leaders felt there are key business principles that can be learned in the private sector that have a positive impact upon the ability to lead nonprofit organizations, the findings from the qualitative portion of this study support prior research that suggest leadership should be exercised differently in the nonprofit and private sectors (King, 2004, Eikenberry, 2009). For instance, two of the qualitative interview respondents felt that leadership in nonprofit organizations is exercised more empathically than in private sector organizations. One respondent also pointed out that nonprofit organizations do not have the same "carrots and sticks" available to motivate employees that private organizations have. Another respondent noted that leadership cannot be exercised solely based upon empathy because nonprofit organizations are still a business that needs fiscal responsibility in order to survive. 
While leadership in nonprofit organizations is exercised differently than it is in private organizations, the responses supported prior studies that suggested leaders of nonprofit organizations do need to be cognizant of basic business principles in order to remain competitive (Hwang \& Powell, 2009). However, respondents believed that, whatever experience they lacked in a certain area crucial to leading a nonprofit organization, they were often able to overcome by attending training sessions and receiving effective mentoring from key Board members.

Nonprofit versus public sector experience. When I compared the relative means of the perceived impacts of prior nonprofit experience and public sector experience for all respondents who had experience in both sectors the mean for the impact of prior nonprofit experience was 4.70 and for the impact of public private sector experience was 4.15. The difference in means was significant at the $95 \%$ confidence interval, which suggests that leaders do rate their prior nonprofit experience as being more helpful than prior public sector experience. The qualitative responses suggested that respondents may have rated nonprofit sector experience higher than public sector experience because they were not exposed to the same challenges nor did they have the same opportunities that they had to make decisions in the nonprofit sector in the public sector. However, several of the respondents believed public sector experience was helpful because it gave them insight into how government agencies function and how individuals who lead public organizations should conduct themselves.

Level of experience. The qualitative findings also suggested that the amount and breadth of experience that respondents had in a particular affected the impact their prior sector experience had upon their ability to lead nonprofit organizations. For instance, the private sector experience for respondent four, who rated her experience as having "some positive impact," consisted of only two summer internships. Respondent two, who rated his private sector 
experience as having "neither a positive nor negative impact" said that his experience in the private sector was also limited and that he didn't have any exposure to organization leadership whom he felt were closed off from him. Respondent three, who rated her public sector experience as having "neither a positive nor negative impact" spent only two years working for a government agency in a role in which she said she learned nothing about decision making. On the contrary, those leaders who had more experience and the opportunity to exercise leadership in a particular sector seemed to rate their experience has having a more positive impact than those who did not have the opportunity to exercise leadership. The findings that the ability to lead effectively is positively impacted by breadth of experience is not surprising in light of prior studies on leadership development that suggest that leadership skills are directly influenced by well-timed experiences in one's career (Mumford, Zaccaro, Hardking, Jacobs, \& Flesichman, 2000, Mumford, Marks, Connelly, Zaccaro, Reiter-Palmon, 2000).

Industry versus sector experience. The qualitative findings also point to the probability that experience in a particular industry may be more important than a particular sector, per se. For instance, respondent two, who leads a nonprofit charter school, felt that having positions of leadership in public schools had a "strong positive impact" upon her ability to lead a nonprofit organization. Moreover, respondent three actually said she forgot the for-profit therapy business she had worked at was private sector because it was run so much like a nonprofit. Conversely, another respondent said she actually classified her experience at a nonprofit trade association as "private sector" experience because she said it was run so much like a business. Interestingly, she rated this experience, which was actually at a nonprofit organization as having "neither a positive nor negative impact" upon her ability to lead her current organization. These findings are consistent with institutional theory, which suggests that organizations with similar functions 
share many of the same aspects of culture (Dimagio \& Powell, 1991, Scott \& Meyer, 1991, \& Trice \& Beyer, 1993).

\section{Research Question Four}

The fourth research question was: How much of the variation in measures of financial performance among California nonprofit organizations is associated with the prior sector experience of their leaders? The regression models I ran uncovered no relationship between the impact of a leader's years of experience in the private, public, and nonprofit sectors, on the one hand, and organizations' operating margins, debt to equity, total revenues, and revenue diversification. Thus, I did not find that leaders' years of experience in any sector accounts for the variation in these measures across organizations with different leaders who had different sector experience.

The results of the study suggest that career experiences in the nonprofit sector may be more helpful than career experiences in the private and public sector in building effective leadership skills for nonprofit organizations. However, experience in the nonprofit sector is not necessarily a prerequisite for leading nonprofit organizations. While there are some clear differences in how nonprofit organizations should be run compared to private and public sector organizations, at least some of the participants in the study suggested that the nuances required to effectively lead nonprofit organizations can be learned on the job.

Furthermore, this study suggests that prior experience in other sectors may actually be beneficial to some extent. For example, experience in the private sector may provide experience with business principles that may benefit sustainability and competitiveness and experience in the public sector may provide knowledge of public entities that is useful for organizations that 
receive their funding from the government. However, leaders from other sectors also need to understand those ways in which nonprofit leadership is different and be willing and able to adapt. It's also important to note that experience in a particular industry may provide even more knowledge of organizational context than experience in a nonprofit organization in a different industry.

\section{Practical Implications of the Study}

As I have previously discussed, the nonprofit sector faces a leadership deficit. As a result, nonprofit organizations may need to hire leaders who do not have prior experience in the nonprofit sector. The primary purpose of this study was to expand the research on sector experience of nonprofit executives and to determine what impact experience in each of the three primary sectors—nonprofit, private, and public — has on a leader's ability to lead nonprofit organizations.

Many nonprofit organizations are already hiring leaders who do not have prior experience in the nonprofit sector. Although the quantitative results suggested that nonprofit experience was more helpful than experience in the private and public sectors, experience in all three sectors had a positive impact on one's ability to lead nonprofit organizations. Importantly, the qualitative results suggest that experience in the same industry may be more helpful to leadership development than prior nonprofit sector experience in a different industry.

Although prior nonprofit sector experience is not necessarily a prerequisite to becoming a leader of a nonprofit organization, leaders who have prior nonprofit sector experience, particularly in the same industry, will generally be better equipped to run a nonprofit organization than a leader who does not have sector- or industry-specific experience. Because 
many nonprofit organizations may not be able to find seasoned leaders with such specific experience, they may need to hire leaders who do not have prior sector experience. Based upon the results of the study, leaders who did not have prior experience leading nonprofit organizations felt like they needed to learn new skills in order to effectively lead nonprofit organizations that they did not learn in the private and/or public sectors. As a result, boards of directors who hire leaders who do not have prior sector-experience and the leaders themselves need to understand that it may take several years for leaders to gain some of the skills to effectively lead nonprofit organizations.

Although leaders without prior sector experience can effectively lead nonprofit organizations, the results of the study suggest that prior nonprofit experience or experience in the same industry are preferable to experience in the other two sectors. However, studies that have examined the perceptions of emerging leaders, executive directors, and board members have found that the majority of nonprofits do not effectively develop leaders or plan for succession (Cornelius, Corvington, \& Ruesga, 2008 Froelich, McKee, \& Rathge, 2011; Nonprofit HR Solutions, 2013). Thus, nonprofit organizations and the nonprofit sector in general need to improve leadership development within the sector.

\section{Limitations}

As with any study, there are limitations to this research. While I sought to gain a representative sample of all nonprofit organizations in California, it is possible that similar factors may have precluded some respondents from not responding to the survey and have encouraged others to respond to the survey. Although I conducted tests for non-response bias

(e.g.), it is still possible that more significant bias existed in the sample. The study also did not 
seek responses from nonprofit leaders from other states. Thus, the study may not have been representative of all paid nonprofit leaders in the United States and beyond.

While cleaning the data I noticed that some respondents' total years of experience in all three sectors seemed to be greater than it should be based upon their age. When I followed up with these individuals I discovered that a limited number of respondents did not completely understand the meanings of the terms nonprofit, private, and public sectors. Although I did correct for those errors in the respondents whom I followed up with, it is possible some of the other responses may have been incorrect due to a lack of understanding of the questions. Thus, it is possible that sampling bias and lack of understanding may have skewed the responses to questions one and two.

Another limitation to the study is that assessments of the relationship between sector experience and effective leadership were based upon the perceptions of the leaders themselves. According to Herman and Renz (1997), organizational effectiveness of nonprofit organizations is evaluated differently by paid staff members, board members, funders, and executives. Thus, it is likely that effective leadership may be judged differently by other stakeholders than by the executives themselves. Moreover, the leaders' perceptions may have been biased toward a greater utility of prior nonprofit experience because they are currently in the nonprofit sector.

The study did move beyond a reliance on the perceptions of the survey respondents when the relationship between sector experience and organizations' financial health was explored. Even here, however, readers should be cautious when interpreting findings. For instance, the few independent variables that did appear to be associated with the financial outcomes were not significant across the models. Thus, there is a possibility that those results were caused by a 
Type I error, meaning that the results appear to be associated with financial results when they are not. Conversely, the regression models I used for the study used a limited amount of time for the change metric of the dependent variable. Bearing in mind that the leaders had been in their positions for varying amounts of time, a change metric that takes into account changes in financial results over the length of the respondents' time in their positions may have yielded different results.

Although a multiple regression analysis did not find that leaders' years of experience in any sector had a significant impact upon the financial results of the organizations they lead, it may be that there are other factors that have a more significant direct impact upon financial results than the leadership effectiveness of the organization's Chief Executive Officer or Executive Director. Moreover, financial outcomes are but one of many possible measures of a nonprofit organization's effectiveness (Sowa, Selden, \& Sandfort, 2004). Thus, additional triangulation is needed in order to evaluate the impact of prior sector experience upon the act of leading nonprofit organizations.

\section{Directions for Future Research}

There are a number of areas in which further research could be conducted to explore the relevance of prior sector experience. A few of these are discussed below.

\section{Interviews with Other Stakeholders}

As I mentioned in the limitations section, it is possible that the leaders' evaluations of effective leadership may be different than those of other organizational stakeholders. Thus, studies that examine not only the perceptions of the leaders, themselves, but also those of followers and board members may provide further insight about the effects that prior sector 
experience had upon the chief executive officers' and executive directors, ability to lead their organizations.

\section{Evaluating Types of Prior Sector Experience}

Although the perception data gathered as part of the quantitative portion of the study suggested that prior nonprofit experience may have a more positive impact than experience in other sectors upon one's ability to lead, qualitative interviews suggested that perception may be moderated by the type of experience respondents had in each sector. Thus, studies that measure the correlation of years of experience in a particular sector or whether that experience included management experience, on the one hand, and research subjects' perceptions of the impact of their experience on their ability to lead a nonprofit organization could yield potentially richer results.

The qualitative results also suggest that each sector provides different types of experience that can have a positive impact upon one's ability to lead nonprofit organizations. Thus, quantitative studies alone cannot capture all of the complexity regarding the impacts that experience in each sector has upon one's ability to lead nonprofit organizations. According to Patton (2002), a case study is a method the researcher uses to compile data into a coherent whole in a manner that pays particular attention to context. Additional case studies geared toward providing thick-description can help to evaluate the contextual factors in each sector that build specific leadership skills that are necessary to lead nonprofit organizations. Bearing in mind that nonprofit organizations are not all the same, case studies can provide additional insight into the factors specific to different nonprofit organizations that may also impact the usefulness of prior experience. 


\section{Other Quantitative Measures of Leadership Effectiveness}

This study sought to evaluate leader effectiveness based upon various financial measures of the organizations the leaders led. Although financial results provide an indicator of an organization's sustainability, in this study, at least, there was no established direct link between the effectiveness of the leader and the measures of the financial health of the organization. Thus, studies that explore the impact of prior sector experience with other dependent variables that may indicate leadership effectiveness, such as organizational turnover or leadership tenure, may provide more insight about the effects that prior sector experience has on one's ability to lead an organization.

\section{Conclusion}

The study supported prior studies on career development of nonprofit leaders that suggested that there is substantial variation in the sector experience of those who lead nonprofit organizations (Harrow \& Mole, 2005, Suarez, 2009). Thus, nonprofit experience is not necessarily a prerequisite for leading a nonprofit organization. The study, however, also suggested that leaders value prior nonprofit experience as being more helpful than experience in the private and/or public sectors in developing leadership skills that a leader can use in the nonprofit sector. Prior experience in a particular industry, regardless of sector, was also helpful in cultivating one's ability to lead a nonprofit organization of the same industry. The study did not find any evidence that leaders' experience in a particular sector had an impact on the financial results of their organizations. 


\section{References}

Argyris, C. \& Schön, D. A. (1974). Theory in Practice: Increasing Professional Effectiveness. San Francisco: Jossey-Bass.

Baker, R. P., Crawford, S., \& Swinehart (2004). Develoment and Testing of Web Questionnaires. In S. Presser, J. M. Rothgeb, M. P. Couper, J. T. Lessler, E. Martin, E. Singer (Eds.), Methods for testing and evaluating survey questionnaires (pp. 361-384). New York: John Wiley.

Bass, B. M. (1985). Leadership and performance beyond expectations. New York: Free Press.

Beck, J. B., and Wiersema, M. F. (2013). Executive Decision Making: Linking Dynamic Managerial Capabilities to the Resource Portfolio and Strategic Outcomes. Journal of Leadership \& Organizational Studies. 20 (4), 408-419. doi: 10.1177/1548051812471722

Blackwood, A. S., and Pollak, T. H. (2009). Washington-Area Nonprofit Operating Reserves. Retrieved from the Urban Institute website at http://www.urban.org/uploadpdf/ 411913_dc_nonprofit_reserves.pdf

Bowman, W. (2006). Should donors care about overhead costs? Do they care? Nonprofit and Voluntary Sector Quarterly, 35 (2), 288-310. doi: 10.1177/0899764006287219

Burns, J. M. (1978). Leadership. New York: Harper \& Row.

CalNonprofits. (2014). Causes Count: The Economic Power of California's Nonprofit Sector. Retrieved from CalNonprofits at http://calnonprofits.org/causes-count

Carroll, D. A., \& Stater, K. J. (2009). Revenue diversification in nonprofit organizations: Does it lead to financial stability? Journal of Public Administration Research and Theory, 19 (4), 947 - 966. doi:10.1093/jopart/mun025

Chabotar, K. J. (1989). Financial ratio analysis comes to nonprofits. The Journal of Higher Education, 60 (2), 188-208. Retrieved from http://jstor.org/stable/1982176

Chemers, M. M., Hays, R., Rhodewalt, F., \& Wysocki, J. (1985). A person-environment analysis of job stress: A contingency model explanation. Journal of Personality and Social Psychology, 49, 628-635

Cornelius, M., Corvington, P., \& Ruesga, A. (2008). Ready to Lead?: Next Generation Leaders Speak Out. Retrieved from the Meyer Foundation website at http://www.meyerfoundation.org/downloads/ready_to_lead/ReadytoLead2008.pdf

Creswell, J. W., \& Plano Clark, V. L. (2010). Designing and Conducting Mixed Methods Research. Thousand Oaks, CA: Sage. 
De Cooman, R. D., De Gieter, S., Pepermans, R., \& Jegers, M. (2009). A Cross-Sector Comparison of Motivation-Related Concepts in For-Profit and Not-For-Profit Service Organizations. Nonprofit and Voluntary Sector Quarterly OnlineFirst. doi: $10.1177 / 0899764009342897$

Dillman, D. A., Smyth, J. D., \& Christian, L. M. (2008). Internet, mail and mixed mode surveys: The tailored design method ( $3^{\text {rd }}$ ed.). New York: John Wiley.

Dimaggio, P. J., \& Powell, W. W. (1991). The Iron Cage Revisited: Institutional Isomorphism and Collective Rationality in Organizational Fields. In W. W. Powell, \& P. J. Dimaggio, The New Institutionalism in Organizational Analysis (pp. 63-82). Chicago: The University of Chicago Press.

Eikenberry, A. M. (2009). Refusing the Market: A Democratic Discourse for Voluntary and Nonprofit Organizations. Nonprofit and Voluntary Sector Quarterly, 38(4), 582-596. doi:10.1177/0899764009333686

Fiedler, F. E. (1967). A theory of leadership effectiveness. New York: McGraw-Hill.

Froelich, K. A., Knoeplfle, T. W. (1996). Internal revenue service 990 data: Fact or fiction? Nonprofit and Voluntary Sector Quarterly, 25 (1), 40-52.

Froelich, K. A., Knoeplfle, T. W., \& Pollack, T. H. (2000). Financial measures in nonprofit organization research: Comparing IRS 990 return and audited financial statement data. Nonprofit and Voluntary Sector Quarterly, 29 (6), 232-254.

Froelich, K., Mckee, G., \& Rathge, R. (2011). Succession Planning in Nonprofit Organizations. Nonprofit Management \& Leadership 22 (1). 3-20. doi: 10.1002/nml

Frumkin, P. \& Andre-Clark, A. (2000). When Missions, Markets, and Politics Collide: Values and Strategy in the Nonprofit Human Services. Nonprofit and Volunteer Sector Quarterly 29 (1). 141-163. doi: 10.1177/089976400773746373

Gronjberg, K. A. (1993). Understanding Nonprofit Funding: Managing Revenues in Social Services and Community Development Organizations. San Francisco: Jossey-Bass.

Gronjberg, K. A., \& Paarlberg, L. (2002). Extent and overlap between listings of IRS tax-exempt registration and nonprofit incorporation: The case of Indiana. Nonprofit and Voluntary Sector Quarterly, 31 (12), 565-594.

Harrow, J., \& Mole, V. (2005). I want to move once I have go things straight: Voluntary sector chief executives' career accounts. Nonprofit Management and Leadership, 16(1), 79-100.

Hansmann, H. (1980). The Role of Nonprofit Enterprise. Yale Law Journal, 89(5), 835-901, Retrieved from http://0-www.heinonline.org.sally.sandiego.edu/HOL/Index 
Henrikson, L. S., Smith, S. R., \& Zimmer, A. (2012). At the Eve of Convergence?

Transformations of Social Service Provision in Denmark, Germany, and the United States. Voluntas, (23), 458-501. doi: 10.1007/s11266-011-9221-5

Herman, R. D., \& Renz, D. O. (1997). Multiple constituencies and the social constructino of nonprofit organization effectiveness. Nonprofit and Voluntary Sector Quarterly, 26 (2), 185-206. doi: 10.1177/0899764097262006

House, R. J. and Mitchell, R. R. (1974) Path-Goal Theory of Leadership. Journal of Contemporary Business, 3 (4), 81-97. In Wren, J. T., Hicks, D. A., and Price. T. L. Modern Classics on Leadership

Houston, D. J. (2006). "Walking the walk" of public service motivation: Public employees and charitable gifts of time, blookd and money. Journal of Public Administration Research and Theory, 16 (1), 67-86.

Hwang, H., \& Powell, W. W. (2009). The rationalization of charity: The influences of professionalization in the nonprofit sector. Administrative Science Quarterly, 54, 268298.

Iddekinge, C. H., Ferris, G. R., \& Heffner, T. S. (2009) Test of a Multistage Model of Distal and Proximal Antecedents of Leader Performance. Personnel Psychology, 62. 463-495. Retrieved from http://0-www3.interscience.wiley.com.sally.sandiego.edu/cgibin/fulltext/122546714/HTMLSTART

James, E. (2004). Commericalism and the Mission of Nonprofits. P. Frumkin and J. B. Imber, In Search of the Nonprofit Sector (pp. 73-84). Nw Brunswick, NJ: Transaction Publishers.

Jaskyte, K. \& Dressler, W. W. (2004). Studying Culture as an Integral and Aggregate Variable: Organizational Culture and Innovation in a Group of Nonprofit Organizations. Field Methods, 16 (3), 265-284. doi: 10.1177/1525822X03262281

Jeavons, T. H. (2005). Ethical Nonprofit Management, The Jossey-Bass Handbook of Nonprofit Leadership and Management ( $2^{\text {nd }}$ ed.) (pp. 204-229). San Francisco: Jossey-Bass.

Johnson, J. L. (2009). The nonprofit leadership deficit: A case for more optimism. Nonprofit Management \& Leadership, 19 (3), 285-304.

Katz, D. \& Kahn, R. L. (1978). The Social Psychology of Organizations (2 ${ }^{\text {nd }}$ ed.). New York: Wiley

King. N. K. (2004). Social Capital and Nonprofit Leaders. Nonprofit Management \& Leadership, 14 (4), 471-486. 
Korack-Kakabadse, A., Korack-Kakabadse, N., \& Myers, A. (1998). Demographics and leadership philosophy: exploring gender differences. Journal of Management Development, 17 (5), 351-388.

Lee, Y-J. (2012). Behavioral implications of public service motivation. The American Review of Public Administration, 42 (1), 104-121.

Lee, Y-J., \& Wilkins, V. M. (2011). More similarities or more differences? Comparing public and nonprofit managers' job motivations. Public Administration Review, 71 (1), 45-56.

Lord, R. G. \& Hall, R. J. (2005). Identity, deep structure and the development of leadership skill. The Leadership Quarterly, 16, 591-615. doi: 10.1016/j.leaqua.2005.06.003.

Met Life Foundation \& Civic Ventures (2005). New Face of Work Survey. Retrieved from Civic Ventures at http://www.civicventures.org/publications/surveys/new_face_of_work/ new_face_of_work.pdf

Mitchell, G. E. (2013). The construct of organizational effectiveness: Perspectives from leaders of international nonprofits in the United States. Nonprofit and Voluntary Sector Quarterly, 42 (2), 324-?)

Mumford, M. D., Marks, M. A., Connelly, M. S., Zaccaro, S. J., \& Reiter-Palmon, R. (2000). Development of Leadership Skills: Experience and Timing. Leadership Quarterly, 11 (1), 87-114. doi: 10.1016/S1048-9843(99)00044-2

Mumford, M. D., Zaccaro, S. J., Harding, F. D., Jacobs, T. O., \& Fleishman, E. A. (2000). Leadership skills for changing world: Solving complex social problems. Leadership Quarterly, 11 (1), 11-35. doi: 10.116/S1048-9843(99)0004-7

Nanus, B. \& Dobbs, S. M. (1999). Leaders Who Make A Difference: Essential Strategies for Meeting the Nonprofit Challenge. Jossey-Bass: San Francisco

Nonprofit Finance Fund. (2013). 2013 State of the Nonprofit Sector Survey. Retrieved from http://nonprofitfinancefund.org/files/docs/2013/2013survey-results.pdf

Nonprofit HR Solutions (2013). Nonprofit Employment Trends Survey. Retrieved from http://www.nonprofithr.com/advocacy/nonprofit-employment-practices-survey/2013employment-trends-survey/

Patton, M. Q. (2002). Qualitative Research and Evaluation Methods. Thousand Oaks, CA: Sage.

Peters, L. H., Hartke, D. D., \& Pohlmann, J. F. (1985). Fiedler's contingency theory of leadership: An application of the meta-analysis procedures of Schmidt and Hunter. Psychological Bulletin, 97, 274-285. 
Pettijohn, S. L. (2013). The Nonprofit Sector in Brief: Public Charities, Giving, and Volunteering, 2013. Retrieved from the Urban Institute website at http://www.urban.org/ UploadedPDF/412923-The-Nonprofit-Sector-in-Brief.pdf

Piatek, J. S. (2014). Altruism by job sector: Can public sector employees lead the way in rebuilding social capital. Journal of Public Administration \& Theory, Advance Access, doi: 10.1093/jopart/muu013

Podsakoff, P. M., MacKenzie, S. B., \& Bommer, W. H. (1996). Transformational leader behaviors and substitutes for leadership as determinants of employee satisfaction, commitment, trust, and organizational citizenship behaviors. Journal of Management, 22 (2), 259-298. doi: 10.1177/014920639602200204

Salamon, L. M. (2012). The Resilient Sector: The Future of Nonprofit America. In L. M. Salamon (Ed.), The State of Nonprofit America (2 ${ }^{\text {nd }}$ ed.) (pp. 3-86). Washington D.C.: Brookings Institution Press

Sass, M. D., Liao-Troth, M. A., \& Wonder, B. D. (2011). Determining Person-Organization Fit for Healthcare CEOs: How Executive Equity Sensitivity Relates to Nonprofit and ForProfit Sector Selection. Nonprofit Management \& Leadership, 22 (2), 199-216. Doi: $10.1002 / \mathrm{mml} .20049$

Schein, E. (2004). Organizational culture and leadership. San Francisco: Jossey-Bass.

Schriesheim, C. A., Tepper, B. J., \& Tetrault, L. A., (1994). Least Preferred Co-worker score, situational control, and leadership effectiveness: A Meta-analysis of contingency model performance predictions. Journal of Applied Psychology, 79, 561-573.

Scott, W. R. \& Meyer, J. W. (1991). The Organization of Societal Sectors: Propositions and Early Evidence. In W. W. Powell, \& P. J. Dimaggio, The New Institutionalism in Organizational Analysis (pp. 108-140). Chicago: The University of Chicago Press.

Silverman, L. \& Taliento, L. (2006). What Business Execs Don't Know - but Should - About Nonprofits. Stanford Social Innovation Review; Summer, 2006: 37-43.

Sowa, J. E., Selden, S. C., \& Sandfort, J. R. (2004). No Longer Unmeasurable? A multidimensional integrated model of nonprofit organizational effectiveness. Nonprofit and Voluntary Sector Quarterly, 33(4), 711-728, doi: 10.1177/0899764004269146

Steinberg, R. (2006). Economic Theories of Nonprofit Organizations. In W. W. Powell, \& R. Steinberg (Eds.), The Nonprofit Sector: A Research Handbook (pp. 117-139). New Haven: Yale University Press.

Stogdill, R. M. (1974). Handbook of Leadership. New York: Free Press. 
Strube, M. J., \& Garcia, J. E. (1981). A meta-analytical investigation of Fiedler's contingency model of leadership effectiveness. Psychological Bulletin, 90, 307-321.

Suarez, D. F. (2009). Street Credentials and Management Backgrounds: Careers of Nonprofit Executives in an Evolving Sector. Nonprofit and Voluntary Sector Quarterly, OnlineFirst. doi: 10.1177/0899764009350370

Teegarden, P. H., Hinden, D. R., \& Sturm, P. (2011). Nonprofit Organizational Culture Guide: Revealing the Hidden Truths that Impact Performance. San Francisco: Jossey-Bass

Tierney, T. J. (2006). The Leadership Deficit. Stanford Social Innovation Review, 4(2), 26-35.

Trice, H. M. \& Beyer, J. M. (1993). The Cultures of Work Organizations. Englewood Cliffs, NJ: Prentice Hall.

Tschirhart, M., Reed, K. K., Freeman, S. J., \& Anker, A. L. (2008). Is the Grass Greener? Sector Shifting and Choice of Sector by MPA and MBA Graduates. Nonprofit and Voluntary Sector Quarterly, 37(4), 668-688. doi: 10.1177/0899764008314808

Tuckman, H. P., and Chang, C. F. (1991). A Methodology for Measuring the Financial Vulnerability of Charitable Nonprofit Organizations. Nonprofit and Voluntary Sector Quarterly. 20. 445-460.

Trussel, J., Greenlee, J. S., and Brady, T. (2002, June). Predicting financial vulnerability in charitable organizations. The CPA Journal. 66-69.

The Urban Institute. (2014). Number of Nonprofit Organizations in the United States, 20032013. Retrieved from http://nccsweb.urban.org/PubApps/profile1.php?state=US

Weisbrod, B. A. (1975). Toward a Theory of the Voluntary Sector in a Three-Sector Economy. In E. Phelps (Ed.), Altruism, Morality, and Economic Theory (pp. 171-195). New York: Russell Sage.

Weisbrod, B. (1998). Institutional form and organizational behavior. In W. Powell \& E. Clemens (Eds.), Private action and the public good (pp. 69-84). New Haven, CT: Yale University Press.

Word, J. \& Park, S. M. (2009). Working Across the Divide: Job Involvement in the Public and Nonprofit Sectors. Review of Public Personnel Administration, 29 (2), 103-133. doi: 10.1177/073437/X09331619

Young, D. (1983). If Not for Profit, for What?: Behavioural Theory of the Nonprofit Based on Entrepreneurship. Lexington, MA: Lexington Books. 
Zaccaro, S. J., Kemp, C., \& Bader, P. (2004). Leader Traits and Attributes. In J. Antonakis, A. T. Cianciolo, \& R. J. Sternberg, The Nature of Leadership (pp. 101-124). Thousand Oaks, CA: SAGE. 


\section{Appendix A - Recruitment Letter}

Hello Mr./Ms. ????

I am a PhD student at the University of San Diego. There is some evidence that there is a leadership deficit in the nonprofit sector that may become worse in the future. One way that nonprofit organizations may choose to deal with this problem is by hiring leaders with private and public sector experience for leadership positions.

I am currently gathering data for my dissertation that will examine the impact of sector experience - nonprofit, private, public - on leadership of California Nonprofit organizations. My study will seek to gather data on the actual sector experience of leaders of nonprofit organizations and leaders' perceptions regarding the importance of sector experience on leadership. I will also examine how much of the variance in financial measures is associated with the prior sector experience of leaders.

In order to assist in this study, I am hopeful that you could fill out a survey that will give me knowledge into your personal experience and your perceptions regarding the impact of sector experience on nonprofit leadership. The survey consists of 20 closed-ended questions and I anticipate it will take approximately 15 minutes to complete.

Please click on the link below in order to complete the survey. If you have any questions you may reach me at $915-238-8457$.

Thank you for considering my request.

Sincerely,

Darren Tune 


\section{Appendix B - Survey Questions}

1. What is your age? (Open ended)

2. What is your gender?

○ Female

- Male

3. Are you White, Black or African, American, American Indian or Alaskan native, Asian, Native Hawaiian or other Pacific islander, or some other race?

○ White

- Black or African-American

- American Indian or Alaskan Native

○ Asian

- Native Hawaiian or other Pacific Islander

○ From multiple races

- Some other race (please specifiy)

4. What is the highest level of education you have completed?
○ High School
- Some College
○ Bachelors
○ Masters
○ Doctoral

5. What was your major? (open ended)

6. About how long have you been in your current position?

- Years (open ended) 
○ Months (open ended)

7. What is your current title? (open ended)

8. About how long have you been at your current organization?

$\circ \quad$ Years (open ended)

○ Months (open ended)

9. Is your current position paid or voluntary?

○ Paid

- Voluntary

10. Prior to working at your current organization, did you work in the nonprofit sector?

$\circ$ Yes

$\circ$ No

11. [If answer to question 10 is "yes)] How many years did you work in the nonprofit sector before you began to work at your current organization? (open ended)

12. [If the answer to \#10 is "yes"] What impact did your prior experience in the nonprofit sector have upon your ability to lead a nonprofit organization?

○ Strong Positive Impact

○ Some Positive Impact

- Neither Negative nor Positive impact

○ Some Negative Impact

○ Strong Negative Impact

13. [If the answer to \#10 is "no"] What impact do you think that nonprofit sector experience has upon the ability to lead a nonprofit organization?

- Strong Positive Impact 
○ Some Positive Impact

- Neither Negative nor Positive impact

- Some Negative Impact

○ Strong Negative Impact

14. Have you ever worked in the private sector?

$\circ$ Yes

$\circ$ No

15. [If yes] How many years did you work in the private sector?

16. [If the answer to \#14 is "yes"] What impact did your prior experience in the private sector have upon your ability to lead a nonprofit organization?

- Strong Positive Impact

○ Some Positive Impact

- Neither Negative nor Positive impact

- Some Negative Impact

- Strong Negative Impact

17. [If the answer to \#14 is "no"] What impact do you think that private sector experience has upon the ability to lead a nonprofit organization?

- Strong Positive Impact

- Some Positive Impact

○ Neither Negative nor Positive impact

- Some Negative Impact

- Strong Negative Impact 
18. Have you ever worked in the public sector?

19. [If the answer to \#18 is "yes"] How many years did you work in the public sector?

20. [If the answer to \#18 is "yes"] What impact did your prior experience in the public sector have upon your ability to lead a nonprofit organization? [If the answer to \#18 is "no"] What impact do you think that public sector experience has upon the ability to lead a nonprofit organization?

○ Strong Positive Impact

○ Some Positive Impact

- Neither Negative nor Positive impact

○ Some Negative Impact

○ Strong Negative Impact

21. [If the answer to \#18 is "no"] What impact do you think that public sector experience has upon the ability to lead a nonprofit organization?

○ Strong Positive Impact

○ Some Positive Impact

- Neither Negative nor Positive impact

○ Some Negative Impact

○ Strong Negative Impact

22. Are you interested in being contacted for a 30 to 60 minute follow-up interview to further discuss the effects of sector experience on leading nonprofit organizations? 


\section{Appendix C \\ University of San Diego \\ Institutional Review Board \\ Research Participant Consent Form}

For the research study entitled:

Who Leads Nonprofit Organizations and What Does it Matter? A Mixed Methods Study of the Impact of Different Sector Experience on Nonprofit Leadership

\section{Purpose of the research study}

Darren Tune is a student in the (School of Leadership and Education Sciences) at the University of San Diego. You are invited to participate in a research study he is conducting. The purpose of this research study is: to expand the research on sector experience of nonprofit executives and begin to address what, if any, impact sector experience of leaders has upon the ability to lead nonprofit organizations.

\section{What you will be asked to do}

If you decide to be in this study, you will be asked to:

Participate in a private interview about your leadership experience and your perceptions regarding the effect that prior sector experience has upon the ability to lead nonprofit organizations.

You will be audiotaped during the interview.

Your participation in this study will take a total of 45 minutes.

\section{Foreseeable risks or discomforts}

This study involves no more risk than the risks you encounter in daily life.

\section{Benefits}

While there may be no direct benefit to you from participating in this study, the indirect benefit of participating will be knowing that you helped researchers better understand the sector experience of California nonprofit executives and what, if any, impact sector experience has upon the ability to lead nonprofit organizations.

\section{Confidentiality}

Any information provided and/or identifying records will remain confidential and kept in a locked file and/or password-protected computer file in the researcher's office for a minimum of five years. All data collected from you will be coded with a number or 
pseudonym (fake name). Your real name will not be used. The results of this research project may be made public and information quoted in professional journals and meetings, but information from this study will only be reported as a group, and not individually.

\section{Compensation}

You will receive no compensation for your participation in the study.

\section{Voluntary Nature of this Research}

Participation in this study is entirely voluntary. You do not have to do this, and you can refuse to answer any question or quit at any time. Deciding not to participate or not answering any of the questions will have no effect on any benefits you're entitled to, like your health care, or your employment or grades. You can withdraw from this study at any time without penalty.

VIII. Contact Information

If you have any questions about this research, you may contact either:

1) Darren Tune

Email: dtune@sandiego.edu

Phone: 915-238-8457

2) Dr. Robert Donmoyer

Email: donmoyer@sandiego.edu

Phone: 619-260-7445

I have read and understand this form, and consent to the research it describes to me. I have received a copy of this consent form for my records.

Name of Participant (Printed) 


\section{Appendix D - Interview Questions}

1. Please tell me about your career?

2. What lessons do you feel you've learned in your career that have helped you to lead (organization name)?

3. Please tell me about some of the leadership challenges you've encountered in your current position? How do you feel your prior experience has equipped you to face these challenges?

4. How has leading your current organization differed from other organizations you've led in your career?

5. (If the leader had prior experience in the nonprofit sector) In the internet survey, you said that you felt that your experience in the nonprofit sector has a (xx) impact upon the ability to lead a nonprofit organization. Can you please explain your answer?

6. (If the leader had prior experience in the private sector) In the internet survey, you said that you felt that your experience in the private sector has a $(\mathrm{xx})$ impact upon the ability to lead a nonprofit organization. Can you please explain your answer?

7. (If the leader had prior experience in the public sector) In the internet survey, you said that you felt that your experience in the public sector has a (xx) impact upon the ability to lead a nonprofit organization. Can you please explain your answer?

8. How would you explain the difference in scores you assigned for your experience in the different sectors (The question was asked differently to each respond asking specifically about the relationships among the scores they provided)? 


\title{
UNIVERSITY OF SAN DIEGO \\ Institutional Review Board (IRB) \\ SUMMARY OF RESEARCH PROJECT
}

Instructions to the researcher: When you conclude your research study, you MUST submit this form to the IRB. Complete this form and print out hard copy. Sign and send a hard copy to: Ms. Lori Ermac-Nash, Provost's Office, HC-214 Note: If you are CONTINUING your study, do NOT submit this form. Instead, download and submit a "Request for a Continuation" form from the IRB website.

FACULTY ADVISORS: IF THE STUDENT WHO COMPLETED THIS RESEARCH HAS GRADUATED AND IS NO LONGER AVAILABLE, IT IS YOUR RESPONSIBILITY TO COMPLETE THIS FORM, SIGN IT, AND SUBMIT IT.

\section{Name of PI: Darren Tune}

\section{Name of Faculty Advisor/Sponsor (if applicable): Dr. Robert Donmoyer}

\section{Project ID \# 2014-11-087}

(This number can be found on your original approval form. It begins with the year in which your project was originally approved. Example: 2010-05-001)

\section{Project Title: Who Leads Nonprofit Organizations and What Does It Matter?} A Mixed Methods Study of the Impact of Different Sector Experience on Nonprofit Leadership

\author{
Level of Initial Approval (check ONE): \\ $x$ Expedited \\ Exempt \\ Full
}

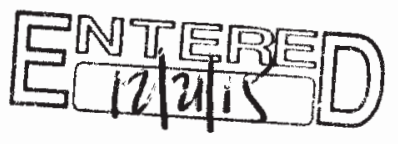

\section{A. Progress of Research:}

Data have been collected from a total of: 191 participants

B. Human Subjects: Informed Consent Forms on file:

$\mathrm{X}$ Yes

No If "No," please explain:

C. Have you made any changes to your study protocol necessitating a Request for Modification during the past year?

_ ${ }_{\text {Y Nes, }}^{\text {No }}$ and the Request for Modification was approved and is on file. 
D. Have any adverse events occurred during the past year?

(See http://www.hhs.gov/ohrp/policy/AdvEvntGuid.htm\#Q2 for a definition of adverse event.)

- X No

Yes, and the adverse event(s) consisted of:

If "Yes", describe your response to and reporting of the adverse event:

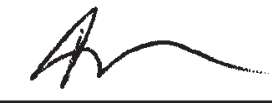

SIGNATURES

Researcher (signature)

Itune⿻sandieguredu

$9 / 5-238-8457$

FOR FACULTY ADVISORS: IF THE STUDENT IS NO LONGER AYAILABLE TO SIGN, PLEASE CHECK THIS BOX AND SIGN BELOW.

I have completed this form on behalf of the student.

Faculty Advisor/USD Sponsor (signature) Email

SUMMARY REPORT TO THE PROVOST'S OFFICE.

I have received this form and entered the appropriate information on the agenda for the next IRB meeting.

An Thomar R Alume

IRB Administrator

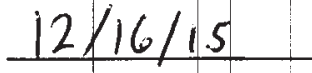

Date 